\title{
Multi-scale characterization of glaucophane from Chiavolino (Biella, Italy): implications for international regulations on elongate mineral particles
}

\author{
Ruggero Vigliaturo ${ }^{1}$, Sabrina M. Elkassas ${ }^{2,3}$, Giancarlo Della Ventura ${ }^{4,5}$, Günther J. Redhammer ${ }^{6}$, \\ Francisco Ruiz-Zepeda ${ }^{7,8}$, Michael J. O'Shea ${ }^{1}$, Goran Dražićc ${ }^{8}$, and Reto Gieré ${ }^{1,9}$ \\ ${ }^{1}$ Department of Earth and Environmental Science, University of Pennsylvania, 240 S. 33rd Street, \\ Hayden Hall, Philadelphia, PA, USA \\ ${ }^{2}$ Department of Earth, Atmospheric, and Planetary Sciences, Massachusetts Institute of Technology, \\ 77 Massachusetts Avenue, Cambridge, MA, USA \\ ${ }^{3}$ Department of Marine Chemistry and Geochemistry, Woods Hole Oceanographic Institution, \\ Woods Hole, MA, USA \\ ${ }^{4}$ Department of Geological Sciences, University of Roma Tre, Rome, Italy \\ ${ }^{5}$ INFN-Istituto Nazionale di Fisica Nucleare, Frascati, Rome, Italy \\ ${ }^{6}$ Department of Materials Science and Physics, University of Salzburg, Salzburg, Austria \\ ${ }^{7}$ Department of Physics and Chemistry of Materials, Institute of Metals and Technology, \\ Lepi pot 11, Ljubljana, Slovenia \\ ${ }^{8}$ Department of Materials Chemistry, National Institute of Chemistry, Hajdrihova 19, Ljubljana, Slovenia \\ ${ }^{9}$ Center of Excellence in Environmental Toxicology, University of Pennsylvania, Philadelphia, PA, USA
}

Correspondence: Ruggero Vigliaturo (ruggero.vigliaturo@gmail.com)

Received: 8 September 2020 - Revised: 1 January 2021 - Accepted: 16 January 2021 - Published: 9 February 2021

\begin{abstract}
In this paper, we present the results of a multi-analytical characterization of a glaucophane sample collected in the Piedmont region of northwestern Italy. Investigation methods included optical microscopy, powder X-ray diffraction, Fourier-transform infrared spectroscopy, $\mu$-Raman spectroscopy, Mössbauer spectroscopy, electron probe microanalysis, environmental scanning electron microscopy and energy-dispersive X-ray spectroscopy, and scanning/transmission electron microscopy combined with energy-dispersive X-ray spectroscopy and electron energy-loss spectroscopy. In addition to the crystal-chemical characterization of the sample from the mesoscale to the near-atomic scale, we have also conducted an extended study on the morphology and dimensions of the mineral particles. The main finding is that studying the same particle population at different magnifications yields different results for mineral habit, dimensions, and dimensional distributions. As glaucophane may occur as an elongate mineral particle (e.g., asbestiform glaucophane occurrences in California and Nevada), the observed discrepancies therefore need to be considered when assessing potential breathability of such particles, with implications for future regulations on elongate mineral particles. While the sample preparation and particle counting methods are not directly investigated in this work, our findings suggest that different magnifications should be used when characterizing an elongate mineral particle population, irrespective of whether or not it contains asbestiform material. These results further reveal the need for developing improved regulation for elongate mineral particles. We thus propose a simple methodology to merge the datasets collected at different magnifications to provide a more complete description and a better risk evaluation of the studied particle population.
\end{abstract}




\section{Introduction}

Glaucophane is a silicate mineral that belongs to the sodic amphibole group (Hawthorne et al., 2012). The root of the name "glaucophane" is the Greek glaukos, which means bluish green, and phainesthai, which means to appear. The type locality of glaucophane is on the island of Syros (Cyclades, Greece), where metamorphic rocks including blueschists, metapelites, and glaucophane-bearing marbles (Ridley, 1981) underwent two distinct Eocene eclogiteblueschist facies events: the first occurring at $470-520^{\circ} \mathrm{C}$ and $14-18 \mathrm{~kb}$, and the second at up to $460^{\circ} \mathrm{C}$ and $14 \mathrm{~kb}$ (Lister and Raouzaious, 1996). Historically, glaucophane was used as natural blue pigment during the Minoan period, especially in Santorini and Knossos, Crete. Its use was particularly widespread during the "Last Palace" period, beginning in the Middle Minoan III in 1700 BCE (Filippakis et al., 1976; Profi et al., 1976). Glaucophane represents one of the main amphiboles in blueschist-facies metamorphic rocks, where it plays a key role in defining conditions of mediumto high-pressure and low-temperature metamorphism (Jenkins et al., 2013). Glaucophane is associated with basaltic and gabbroic protoliths, in which it crystallizes as a result of subduction.

Glaucophane crystallizes in the monoclinic system and is classified in the sodium amphibole group, defined by ${ }^{\mathrm{B}}(\mathrm{Na}+\mathrm{Li}) / \Sigma \mathrm{B} \geq 0.75, \quad{ }^{\mathrm{B}} \mathrm{Na} / \Sigma \mathrm{B}>{ }^{\mathrm{B}} \mathrm{Li} / \Sigma \mathrm{B}$ (Hawthorne et al., 2012). Its end-member formula is $\mathrm{Na}_{2}\left[\mathrm{Mg}_{3} \mathrm{Al}_{2}\right] \mathrm{Si}_{8} \mathrm{O}_{22}(\mathrm{OH})_{2}$ but often forms a solid solution with riebeckite $\mathrm{Na}_{2}\left[\mathrm{Fe}_{3}^{2+} \mathrm{Fe}_{2}^{3+}\right] \mathrm{Si}_{8} \mathrm{O}_{22}(\mathrm{OH})_{2}$, which, in its asbestiform morphology, is known as crocidolite or blue asbestos. Glaucophane may occur as an elongate mineral particle, and specifically with an asbestiform habit, or it may host asbestiform riebeckite (crocidolite) particles (Erskine and Bailey, 2018; Bailey, 2020a, b). Furthermore, it is likely that the particulate matter released into the atmosphere from glaucophane- and/or riebeckite-bearing rocks during excavation and mining activities (Bailey, 2020a, b) is a mixture of particles. This mixture contains particles that range in morphology from fibrous to non-fibrous (Oberdörster and Graham, 2018) and might or might not be respirable. There is no general agreement yet whether or not nano-sized mineral particles (usually defined has having at least one dimension $<100 \mathrm{~nm}$ ) with certain dimensions and aspect ratios should be considered as elongate mineral particles (EMPs) (Oberdörster and Graham, 2018). The French ANSES (2015) report, however, already takes into account the nano-sized portion of EMPs by defining an EMP as any particle with length/width $(L / w)>3$. The nano-sized portion of EMPs is ubiquitous; it can be found in the environment (e.g., Petriglieri et al., 2020), where humans may be exposed to industrially processed particles (e.g., Vigliaturo et al., 2016), and in the lungs of rats that live in urban areas with a heavy presence of asbestos released from industrial facilities (e.g., Ardizzone et al., 2014). In this respect, multiple literature sources suggest that counting and recording the presence or absence of nano-sized EMPs could be the best choice in terms of regulation and public health protection (Le Bouffant et al., 1987; Morrow, 1988; Donaldson et al., 2010; Oberdörster and Graham, 2018).

The term "EMP", which should substitute the term "fiber" (NIOSH, 2011), refers to a mineral particle that exhibits an aspect ratio $(L / w)$ of $\geq 3: 1$, has an $L>5 \mu \mathrm{m}$, and may include either an asbestiform or a non-asbestiform habit (NIOSH, 2011). The replacement of the term "fiber" with the term "EMP" was made specifically to include both the asbestiform and the non-asbestiform habits, which meet the dimensional criteria specified by NIOSH (2011). For clarity, in this paper, we will use the term EMP as defined by NIOSH (2011), whereas the term "fiber" will be used as defined in Belluso et al. (2017), i.e., for elongated particles with uniform parallel sides and geometrical faces exhibiting $L / w \geq 3, L \geq 5 \mu \mathrm{m}$, and $w \leq 3 \mu \mathrm{m}$. If the term "fiber" will be used to mineralogically identify a habit (as described in Zoltai, 1981; Veblen and Wylie, 1993), this will be specified in the text.

In this paper, we characterize a non-asbestiform glaucophane sample collected in Chiavolino (province of Biella), located in the Italian Piedmont region. Following a brief geological description of the sample locality, we report on a systematic characterization of the collected sample. The analysis of the sample was conducted by applying optical microscopy (OM), powder X-ray diffraction (PXRD), electron probe micro-analysis (EPMA), Fourier-transform infrared spectroscopy (FTIR), $\mu$-Raman spectroscopy, field-emission gun environmental scanning electron microscopy (FEGESEM), transmission electron microscopy with selected area electron diffraction (TEM-SAED, JEOL 2010F), highresolution TEM (HR-TEM, JEOL F200), and aberrationcorrected scanning transmission electron microscopy (accorrected JEOL ARM 200CF STEM; acSTEM), combined with energy-dispersive X-ray spectrometry (EDXS) and dual-range electron energy-loss spectroscopy (Dual-EELS). The simulated STEM image was calculated based on the atomic model for glaucophane and the microscope parameters using the quantitative STEM (QSTEM) code with a multi-slice method and frozen phonon approximation. We also conducted an extended dimensional characterization of the glaucophane by using OM, FEG-ESEM, and acSTEM. This study concludes with an acSTEM tomographic threedimensional (3-D) reconstruction of a particle to show how the orientation of the observed material may change the size classification and the habit of the particle, and its measured dimension in a 2-D projection.

In short, we demonstrate how an extended dimensional study using multiple magnifications allows for a better and 
more complete description of the real size and dimensional distributions of a given particle population. The multimagnification characterization of a mineral particle population avoids underestimating the number of particles that are classified by different dimensional parameters and different shape or morphology, and that might be dangerous to public health and in industrial settings.

\section{Geological setting}

Glaucophane is found globally and is associated with mountain-building events and past subduction zones. The most notable localities include the California Coast Ranges, USA; Kodiak Island, Alaska, USA; and St. Marcel, Val d'Aosta, and Piollore (Biella), Piedmont, Italy (Evans and Brown, 1986). The geological setting of the Italian Piedmont region, where our sample was found, is the result of complex geodynamic processes. Starting in the Late Cretaceous, two continental margins (the paleo-European and the paleoAdriatic) gradually converged and caused subduction of the oceanic domains (Piedmont-Liguria and Valais), which were entrapped between the continental plates (Piana et al., 2017). In the middle to late Eocene, the margins began colliding to form the Alps-Apennines (see Fig. 1a-b and Zingg, 1990), and as a result, Piedmont contains an almost complete crosssection of the crust (Piana et al., 2017).

The Biella province is situated in an area of dynamic metamorphism within the Sesia-Lanzo and the Ivrea-Verbano zones (Fig. 1b and Compagnoni and Schmid, 2014). The Sesia-Lanzo zone (SLZ) is a wide, preserved portion of the continental crust. During the early Alpine subduction in the Western Alps, the section was exposed to eclogite-facies conditions and was exhumed before the collision of the paleoEuropean and the paleo-Adriatic continental margins (Spalla et al., 1996; Cantù et al., 2016). The Ivrea-Verbano zone, part of the Southern Alps, is an exposed section of the lower crust and upper mantle, which underwent extensive high-pressure and high-temperature metamorphism (from granulite grade in the NW to high-temperature amphibolite grade in the SE; Quick et al., 1992). The unit in which the studied sample was found is known as the Eclogitic Micaschist Complex (EMC). This complex contains glaucophane schists, which represent former eclogites that have undergone retrograde metamorphism (Reinsch, 1979). The main mineralogical components of this unit are omphacite, lawsonite or epidote, garnet, and glaucophane (Bezacier et al., 2010).

\section{Experimental}

\subsection{Sample}

The hand specimen analyzed here was collected from an outcrop near the trail to an abandoned quarry along Rio Oremo, upstream of Chiavolino hamlet, which is located in
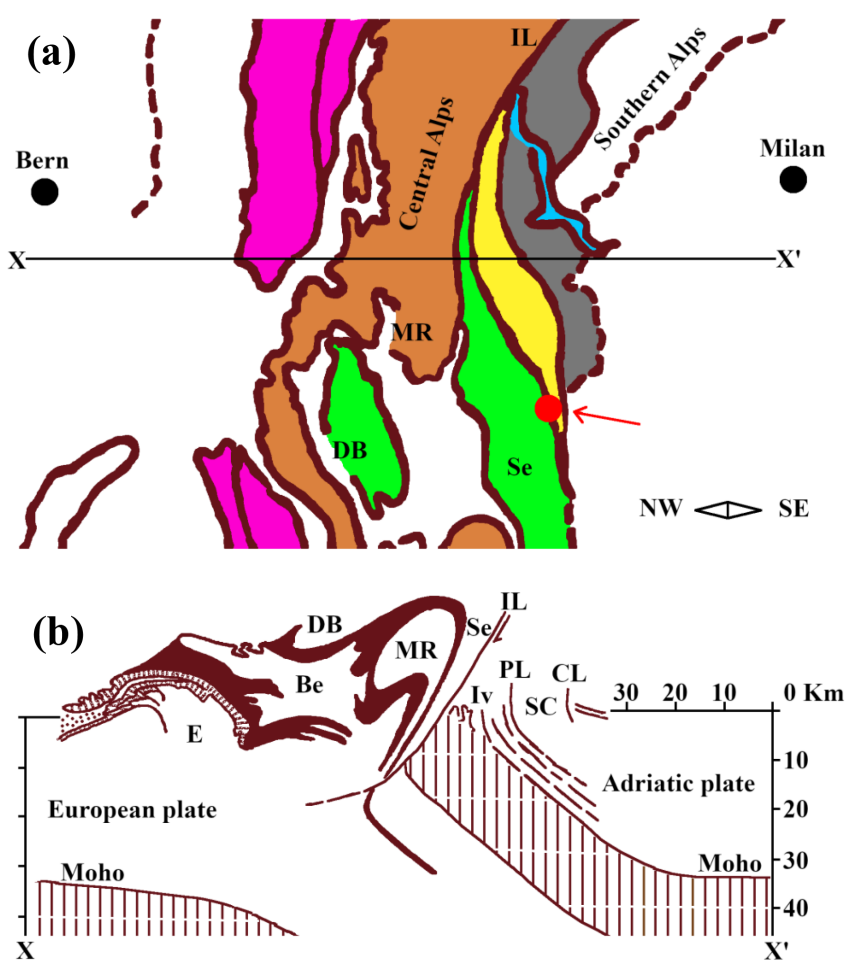

Figure 1. (a) Tectonic setting of the sample locality, digitally redrawn and modified after Zingg (1990). The $X-X^{\prime}$ line represents the profile section shown in panel (b). In panel (a), the purple area represents the external massifs, the light brown areas are the Penninic basement, the green area shows the Austroalpine basement, and the orange area is the South Alpine basement. The yellow area is the Ivrea zone, and the light blue area is Lake Maggiore. Sample locality is indicated by the red dot and red arrow. (b) Cross-section through the Western Alps, digitally re-drawn after Zingg (1990). E: external massifs, Be: Bernhard nappe, DB: Dent Blanche nappe, MR: Monte Rosa nappe, Se: Sesia zone, Iv: Ivrea zone, IL: Insubric line, PL: Pogallo line, SC: Strona-Ceneri zone; CL: Cremosina line.

the province of Biella, a part of the Italian Piedmont region. The area in which the sample was found is characterized by the presence of a grey, dark-blue-shaded amphibole-rich rock with carbonate veins. The hand sample $(\sim 5 \times 2 \mathrm{~cm})$, shown in the Appendix A (Fig. A1), contains mostly glaucophane (Fig. 2), which is accompanied by minor grey-greenish micas, carbonate veins, and some centimeter-sized pyrite cubes (Mottana et al., 1981; Boscardin and Orlandi, 1984).

\section{$3.2 \mathrm{OM}$}

The hand sample (Fig. A1) was examined as received and broken into small fragments ( $\sim 3 \mathrm{~mm}$ across) using tongs and/or finger pressure. These fragments (Figs. 2c, B1) were studied without further preparation using a Leica M165 C stereomicroscope equipped with a Leica IC80 D camera and an LED illumination system. 

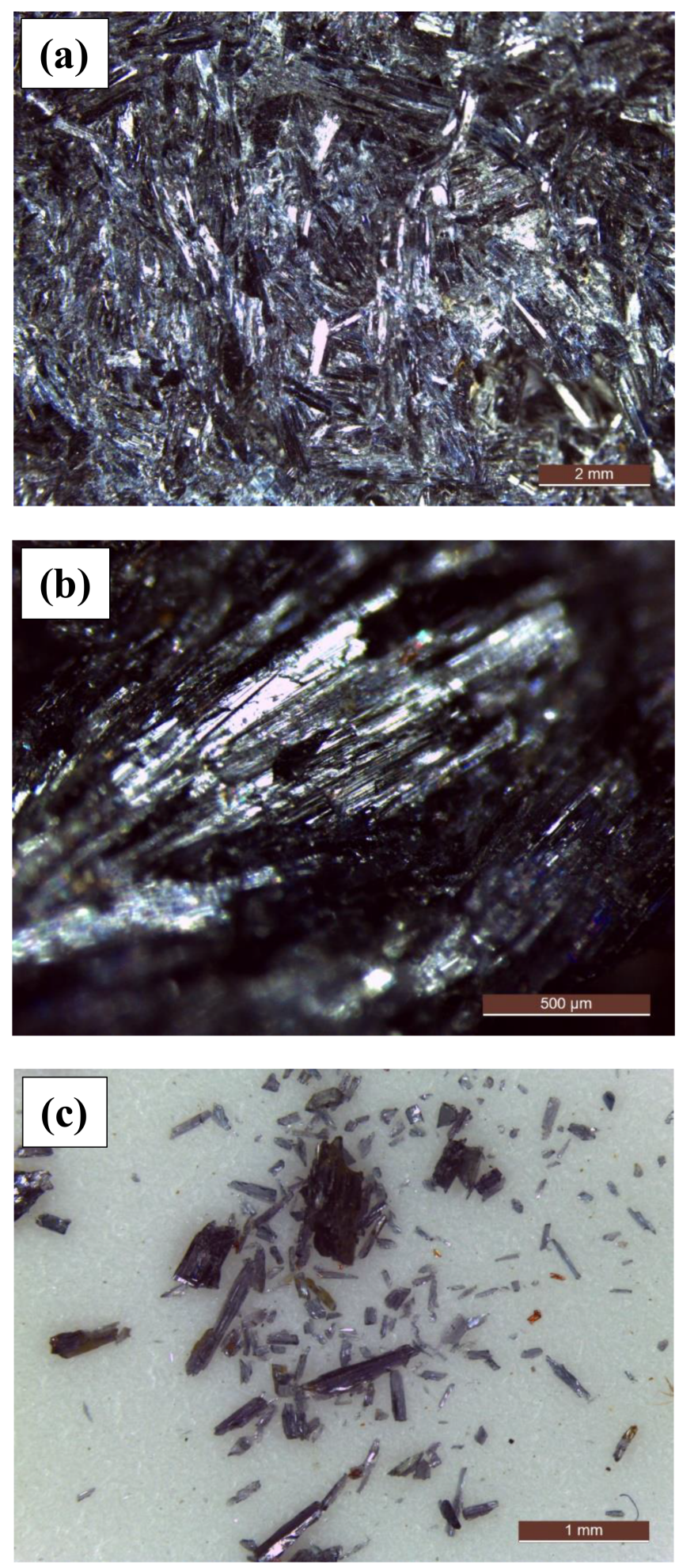

Figure 2. Optical microscopy pictures of the glaucophane sample. (a) A mix of columnar, acicular, and prismatic randomly oriented crystals; (b) parallel columnar crystals; and (c) crystals with various morphologies detached from the main rock by handling or scratching.

\subsection{PXRD}

The powder X-Ray diffraction data were collected on glaucophane powders using a Scintag X1 diffractometer (Thermo Fisher, Waltham, MA, USA) equipped with a $\mathrm{Cu}-K \alpha_{1}$ radiation source $(\lambda=1.54055 \AA, 40 \mathrm{~mA}, 45 \mathrm{kV})$, fixed divergence slits, and a Peltier-cooled $\mathrm{Si}(\mathrm{Li})$ detector with a resolution of $<200 \mathrm{eV}$. A divergent slit width of $2 \mathrm{~mm}$ and a scatter-slit width of $4 \mathrm{~mm}$ were used for the incoming beam, whereas a receiving slit width of $0.5 \mathrm{~mm}$ and scatter-slit width of $0.2 \mathrm{~mm}$ were used for the diffracted beam. Data were collected in step-scan mode in the $2-70^{\circ} 2 \theta$ range, with a step size of $0.05^{\circ} 2 \theta$, and a counting time of $3 \mathrm{~s}$ per step.

\subsection{FTIR spectroscopy}

The FTIR spectra of the glaucophane powders were collected at Roma Tre University using a Nicolet iS50 spectrometer, equipped with a Globar source, a potassium bromide $(\mathrm{KBr})$ beam splitter, and a deuterated triglycine sulfate (DTGS) detector. The powdered samples were prepared as $\mathrm{KBr}$ pellets, using $5: 150$ and $0.5: 150 \mathrm{mg}$ sample-to- $\mathrm{KBr}$ ratios for the 3000-4000 and $<1200 \mathrm{~cm}^{-1}$ regions, respectively. Single-crystal FTIR spectra in the $\mathrm{OH}$-stretching mediuminfrared (MIR) region were collected with unpolarized light, using a Bruker Hyperion 3000 microscope equipped with a mercury-cadmium-telluride (MCT) detector and a $\mathrm{KBr}$ beam splitter at Istituto Nazionale di Fisica Nucleare (INFN, Frascati, Rome).

\section{$3.5 \mu$-Raman spectroscopy}

Unpolarized $\mu$-Raman spectra of untreated samples were collected using a confocal Jasco NRS 5500 microscope at INFN (Frascati) equipped with a multi-channel charge-coupled device (CCD) detector and a fully automated stage. Raman spectra were excited with a $532 \mathrm{~nm}$ laser, an integration time of $5 \mathrm{~s}$ per scan, averaging $20 \mathrm{scans}$, with a $5 \times$ objective; the laser power was set to $20 \mathrm{~mW}$. The wavenumber accuracy was $\pm 0.5 \mathrm{~cm}^{-1}$, and the spectral resolution was $1 \mathrm{~cm}^{-1}$.

\subsection{Mössbauer spectroscopy}

Transmission ${ }^{57} \mathrm{Fe}$ Mössbauer data were acquired on glaucophane powders at room temperature using an apparatus in horizontal arrangement $\left({ }^{57} \mathrm{Fe} \mathrm{Co} / \mathrm{Rh}\right.$ single-line thin source, constant acceleration mode with symmetric triangular velocity shape, multi-channel analyzer with 1024 channels, regular velocity calibration against metallic $\mathrm{Fe}$ ). Data were evaluated using the RECOIL program suite. All spectra were corrected for thickness effects and then processed using the full static hyperfine interaction Hamiltonian analysis with Lorentzian-shaped doublets. Details of the sample preparation and data handling can be found in Redhammer and Roth (2002). 


\subsection{EPMA}

The electron probe micro-analysis data for untreated individual crystals (embedded in resin and polished) were collected by wavelength-dispersive X-ray spectroscopy (WDXS) techniques using a Cameca SX50 electron microprobe (Cameca, Gennevilliers, France) at Centro di Studi per il Quaternario e l'Evoluzione ambientale - CNR, Rome. Analytical conditions were $15 \mathrm{keV}$ accelerating voltage, $20 \mathrm{nA}$ beam current, $5 \mu \mathrm{m}$ beam size, and $100 \mathrm{~s}$ counting time. The data were processed by using the ZAF4/FLS software (standard version) by Link Analytical (Oxford, UK). Compositions were determined relative to the following natural and synthetic standards: diopside ( $\mathrm{Si}, \mathrm{Mg}, \mathrm{Ca})$, metal oxide ( $\mathrm{Ti}, \mathrm{Fe}, \mathrm{Mn})$, orthoclase $(\mathrm{Al}, \mathrm{K})$, albite $(\mathrm{Na})$, and fluorite $(\mathrm{F})$.

\subsection{FEG-ESEM EDXS}

A FEI Quanta 600 FEG Mark II field-emission SEM equipped with a Bruker Quantax Silicon Drift Detector was used at the Singh Center for Nanotechnology, University of Pennsylvania, to obtain detailed information on the studied glaucophane. To prepare the sample for electron microscopy (EM) and to obtain proper particle dimensions, it was subjected to gentle hand grinding by pestle and mortar in 2propanol. Hand grinding was done for $5 \mathrm{~min}$, in agreement with previous investigations of amphiboles (Ministerial Decree, 1994; Vigliaturo et al., 2018). This procedure yields a granulometry that is similar to the one of the Union for International Cancer Control (UICC) asbestos standards at a magnification of $1000 \times$ and $2000 \times$ but without compromising the crystal structure of the amphibole particles (Ministerial Decree, 1994). The ground material was then transferred into an Eppendorf tube and brought into 2-propanol suspension for $5 \mathrm{~min}$ of low-power sonication to promote dispersion of the suspended particles.

Part of the suspension was transferred onto a $12.7 \mathrm{~mm}$ SEM stub covered by conductive carbon tabs. The SEM was set to environmental mode, with a voltage of $15 \mathrm{kV}$ and a chamber pressure of 0.38 torr, and operated in secondary electron (SE) mode. Variable spot dimension was used to optimize imaging (sizes 3 and 6).

Additionally, in order to complement the morphological study, we have prepared a sample on a $70^{\circ}$ inclined SEM stub, which allows operators to observe morphologies that are not usually visible on a flat stub (e.g., the (002) plane). The size-distribution and morphological studies were conducted under the same conditions but on flat stubs and at a magnification of $200 \times$ and $2000 \times$.

\subsection{Aberration-corrected S/TEM EDXS and Dual-EELS study}

A droplet of the same suspension prepared for SEM was transferred to each of three TEM copper grids (one holey car- bon grid, two lacey carbon support films - SPI) after quick vortexing in a mixer (Corning ${ }^{\mathrm{TM}} \mathrm{LSE}^{\mathrm{TM}}$ vortex mixer) to enhance particle dispersion. The holey carbon grid sample was used for dimensional measurements and for high-resolution TEM, whereas one of the lacey carbon grid samples was used for EELS and HR-TEM. The second lacey carbon grid was cut halfway in order to perform acSTEM tomography.

An acSTEM, model ARM 200 CF equipped with a highbrightness cold-field emission gun (CFEG) operating at $80 \mathrm{kV}$, an energy-dispersive X-ray spectroscopy (EDXS) system (Centurio $100 \mathrm{~mm}^{2}$, JEOL), and an energy filter (QuantumGIF, Gatan, USA) were used at the National Institute of Chemistry, Slovenia. The Gatan cryotransfer holder was employed to perform HR-STEM at $\mathrm{LN}_{2}$ temperature in order to reduce the effects of radiation damage on the sample during image acquisition.

The dimensional measurements of particle width $(w)$ and length $(L)$ were performed in STEM bright-field (BF) mode. Morphological observations of the sample were made in TEM mode, in STEM BF mode, and in medium-angle annular dark-field (MAADF) mode. To further augment the morphological description of the specimen, electron tomography and 3-D reconstruction were performed on a selected particle. The specimen was rotated around the JEOL tomography holder $\alpha$ axis for a range of $120^{\circ}$ with a step of $1^{\circ}$. For each step, a STEM BF and a MAADF image were collected, and the 3-D reconstruction was performed using the JEOL software TEMography ${ }^{\mathrm{TM}}$.

Dual-EELS was performed at the grain boundary of the particles on 10 different square areas of $625 \mathrm{~nm}^{2}$ each (Vigliaturo et al., 2019). The core-loss region was registered over a $10 \mathrm{~s}$ exposure and the low-loss region with an exposure of $2 \times 10^{-4} \mathrm{~s}$, both with a sum of three frames to generate a spectrum (Vigliaturo et al., 2019). The Fe-valence state was determined using the $\Delta E$ method described in Tan et al. (2012), with the same standards and experimental conditions as in Rojac et al. (2017). The use of the $L_{2,3}$ white-line intensity-ratio method for determining the $\mathrm{Fe}$-valence state is not the best solution for our sample, because the presence of $\mathrm{Al}^{3+}$ modifies the energy loss near edge structure (ELNES) of the $\mathrm{Fe}-L_{2,3}$ edge, and thus the calculated $\mathrm{Fe}^{3+}$ content is overestimated (Frost and Langenhorst, 2002; Langenhorst et al., 2013).

\subsection{Morphometry by operator}

The dimensional and morphological studies were conducted by OM $(10 \times)$, FEG-ESEM $(200 \times)$, FEG-ESEM $(2000 \times)$, and STEM $(25000 \times)$ under the same conditions as those described above. The descriptive statistics are based on particle length $(L)$, width $(w)$, and aspect ratio $(L / w)$, as well as additional parameters, such as the aerodynamic equivalent diameter $\left(D_{\mathrm{ae}}\right)$, using the simplified formulation proposed by Gonda and El Khalik (1985). The frequency of a specific mineral habit was investigated according to Zoltai (1981), 
and Veblen and Wylie (1993). All visible particles were measured and assigned to specific categories, namely particles with $L / w \geq 3$ (Gunter, 2018), EMPs (according to NIOSH, 2011), and fibers with $L / w \geq 3, L \geq 5 \mu \mathrm{m}$, and $w \leq 3 \mu \mathrm{m}$ (according to Belluso et al., 2017). We further classify the studied particles with respect to their potential to enter various parts of the respiratory system, i.e., as inhalable ( $\left.D_{\mathrm{ae}}<100 \mu \mathrm{m}\right), \mathrm{PM}_{10}\left(D_{\mathrm{ae}}<10 \mu \mathrm{m}\right.$; equivalent to thoracic fraction), respirable $\left(D_{\mathrm{ae}}<4 \mu \mathrm{m}\right)$, or $\mathrm{PM}_{2.5}\left(D_{\mathrm{ae}}<2.5 \mu \mathrm{m}\right)$ (ISO, 1995; CEN, 1993; ICRP, 1994).

The $300 D_{\text {ae }}$ data points obtained by SEM at $200 \times$, SEM at $2000 \times$, and STEM at $25000 \times$ were organized in descending order and then merged together to obtain a complete dimensional distribution of particle sizes across 3 orders of magnitude. When merged, the datasets show overlaps (supplementary merged dataset); they contain particles in a size range that was measured at two different magnifications, i.e., at $200 \times$ as well as at $2000 \times$, or at $2000 \times$ as well as at $25000 \times$. In these two overlapping regions of the dataset, several particles occur with similar $D_{\mathrm{ae}}$ (particle "pairs"). The $D_{\text {ae }}$ values of these latter particles were used to calculate the arithmetic average $D_{\text {ae }}$ of each pair. The two original particles were then discarded and replaced by the "new" particle with the calculated average $D_{\text {ae }}$, which was used in the final merged dataset $(n=216)$. In regard to the data for $L$, $w$, and $L / w$ for these particle pairs in the overlapping region of the datasets, a precaution principle was applied: for each particle pair, the particle conforming to a higher number of dimensional constraints (i.e., $L / w \geq 3, L \geq 5$, and $w \leq 3$ ) was counted as valid when defining the total number of particles falling in a certain category $\mathrm{P} 1(L / w \geq 3), \mathrm{P} 2(L / w \geq 3$ and $L>5)$, and $\mathrm{P} 3(L / w \geq 3, L \geq 5 \mu \mathrm{m}$, and $w \leq 3 \mu \mathrm{m})$. The information for $L, w$, and $L / w$ corresponding to each particle with a certain $D_{\text {ae }}$ was preserved. In the case that both particles in the pair were conforming to the same number of dimensional constraints (or none), the particle measured with the most accurate instrument (and higher magnification) was used to determine the descriptive statistics reported in Table 4 .

\section{Results}

\subsection{OM}

The hand specimen contains aggregates of prismatic glaucophane crystals ranging in color from dark grey to very dark blue (Fig. 2a and b). The luster is vitreous to pearly (Fig. 2, Appendix Fig. B1). Individual glaucophane crystals are predominantly in a random orientation throughout the sample (Fig. 2a), but in some regions columnar crystals occur in parallel orientation (Fig. 2b). The crystals that were detached from the main rock piece are mostly acicular and approximately a millimeter in length but in some cases smaller and equant (Figs. 2c, B1).

\subsection{PXRD}

The powder X-ray pattern (Fig. C1) for this sample perfectly matches the COD (Crystallographic Open Database) card 96900-4136 (glaucophane). All observed Bragg peaks could be indexed in the monoclinic $C 2 / \mathrm{m}$ symmetry. The refinement of the cell parameters, achieved by using the FULLPROF Rietveld program (Rodríguez-Carvajal, 2001), yielded ( $)$ $a=9.5672(7), b=17.7654(16), c=5.3009(5)$, and $\beta\left(^{\circ}\right)=$ 103.717(6).

\subsection{FTIR spectroscopy}

The powder FTIR spectrum collected in the $\mathrm{OH}$-stretching region (Fig. 3) shows the typical four-band pattern due to the distribution of $\mathrm{Mg}$ and $\mathrm{Fe}^{2+}$ at $M(1,3)$. From the relative band areas of the fitted Gaussian components, and by using the method discussed in Iezzi et al. (2005), Della Ventura et al. (2016), and Della Ventura (2017), we calculated Mg at $M(1,3)=2.11$ atoms per formula unit (a.p.f.u.), in agreement with the values provided by both electron microprobe analyzer (EMPA) and Mössbauer spectroscopy.

The single-crystal NIR (near-infrared) spectrum (Fig. 4) shows, in addition to the quadruplet of peaks observed in the powder pattern (displayed as the inset in Fig. 4), two broad absorptions at 4327 and $4194 \mathrm{~cm}^{-1}$, which result from the combination of the stretching and libration vibrations of the O-H dipole (Della Ventura et al., 2021a).

The powder FTIR spectrum in the low-frequency lattice region, between 1200 and $400 \mathrm{~cm}^{-1}$ (middle-IR or MIR), is relatively complex and shows several overlapping and broad peaks (Fig. 5). According to the work of Ishida et al. (2008) and Della Ventura et al. (2018, 2021a, b), the lattice-mode range of amphiboles may be conveniently divided into three regions: (1) the $1200-800 \mathrm{~cm}^{-1}$ range, where seven to eight very intense to medium intense bands due to lattice $\mathrm{Si}-\mathrm{O}, \mathrm{Si}-$ $\mathrm{O}-\mathrm{Si}$, and $\mathrm{O}-\mathrm{Si}-\mathrm{O}$ antisymmetric stretching vibrations are observed; in particular, the highest wavenumber peaks in this range can be assigned to $T(1)-\mathrm{O}(1)$, which is a very short bond in the amphibole structure (Della Ventura et al., 2021b); (2) The $800-600 \mathrm{~cm}^{-1}$ range, where four to six medium weak to very weak peaks resulting from $\mathrm{Si}-\mathrm{O}-\mathrm{Si}$ symmetric stretching or chain deformation modes occur; in this range, two O-H librations at around 700 and $690-640 \mathrm{~cm}^{-1}$ have been identified in ${ }^{\mathrm{T}} \mathrm{Al}$-free and A-site empty amphiboles (Ishida et al., 2008), whereas the same modes are shifted to lower wavenumbers in A-site filled amphiboles (Della Ventura et al., 2021a); and (3) the $600-400 \mathrm{~cm}^{-1}$ range, where essentially $\mathrm{Si}-\mathrm{O}$ bending vibrations and $M-\mathrm{O}$ modes are observed. The MIR spectrum of the glaucophane sample studied here is similar to the pattern given by Ishida (1990) for sodium amphiboles along the glaucophane-riebeckite series, in particular in the $1200-800 \mathrm{~cm}^{-1}$ range, where the patterns are almost identical. Small differences in the relative peak intensities and widths are observed in the $800-400 \mathrm{~cm}^{-1}$ range, 

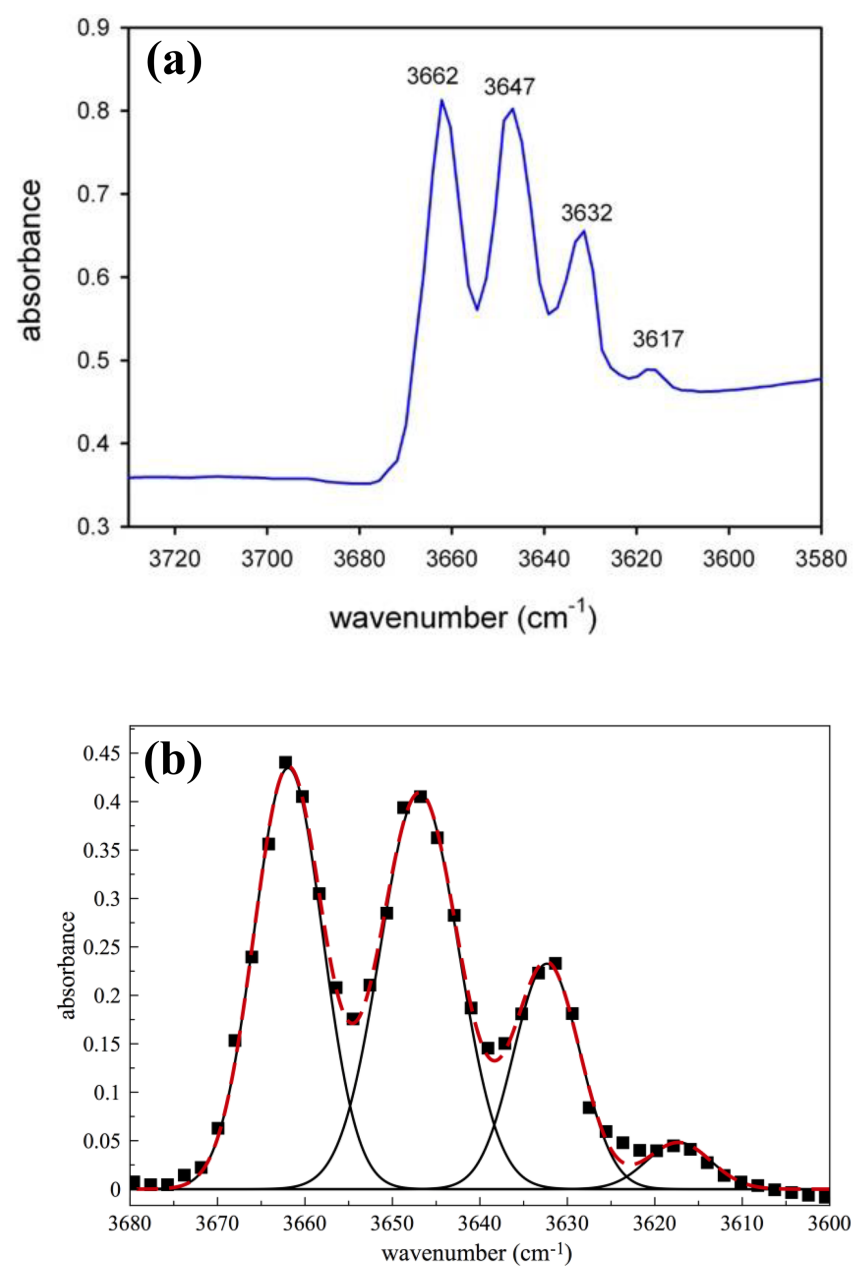

Figure 3. (a) Powder FTIR spectrum of the studied glaucophane in the $\mathrm{OH}$-stretching region; (b) fitted spectrum. Squares: experimental pattern; black lines: fitted components; dashed red line: calculated spectrum.

where the effect of cationic substitutions in these systems is significant (Ishida, 1990).

\section{$4.4 \quad \mu$-Raman spectroscopy}

As expected (e.g., Leissner et al., 2015; Della Ventura et al., 2021a, b), the OH-stretching region of the Raman spectrum obtained for the studied glaucophane (Fig. 6) is almost identical to the $\mathrm{OH}$-stretching FTIR pattern (Fig. 3) and shows the same quadruplet of peaks having the same relative intensities as those observed by fitting the IR curve. This important observation implies that both techniques provide the same crystal-chemical results.

The Raman spectrum in the lattice-mode region is displayed in Fig. 7. Similar to the FTIR spectra, the Raman spectra of amphiboles (e.g., Leissner et al., 2015; Waeselmann et al., 2019) can be conveniently divided into three main regions: (1) between 850 and $1200 \mathrm{~cm}^{-1}$, where

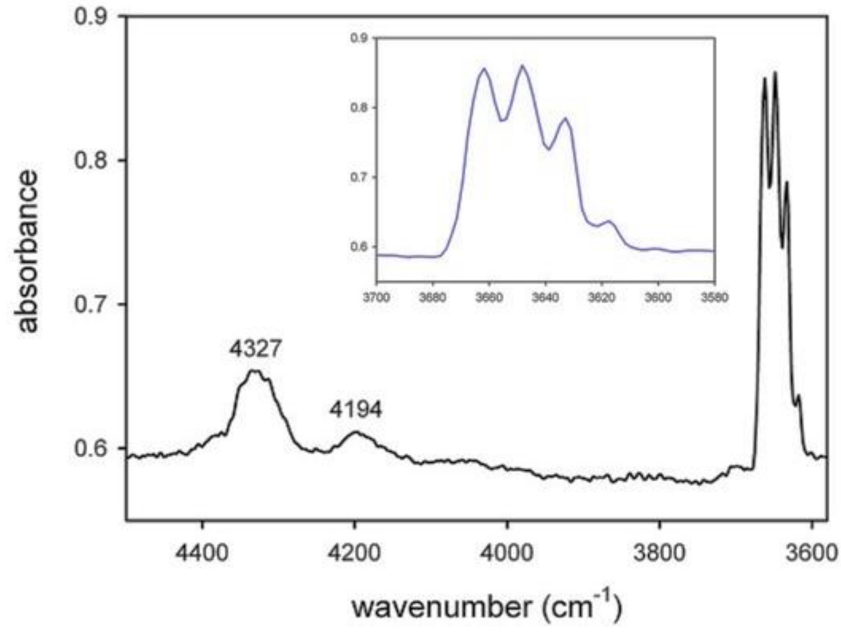

Figure 4. Single-crystal NIR spectrum of the studied glaucophane. The $\mathrm{OH}$-stretching region is magnified in the inset.

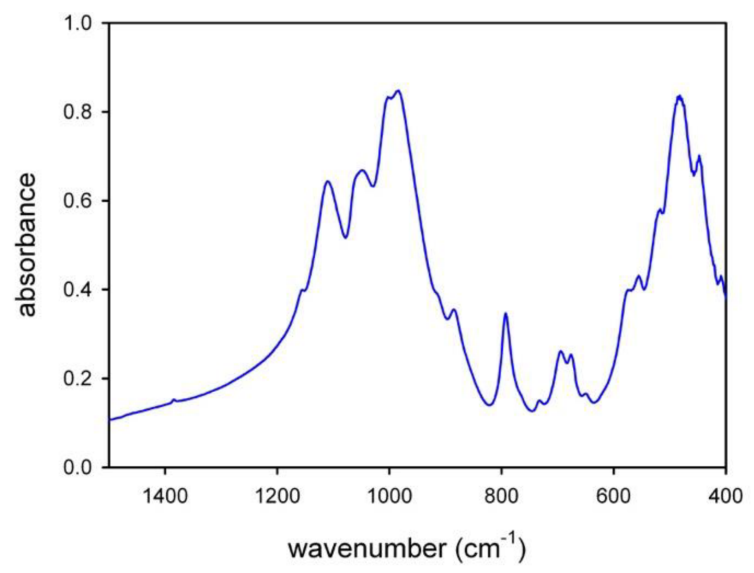

Figure 5. Powder FTIR spectrum of the studied glaucophane in the low-frequency lattice-mode region.

medium- to low-intensity peaks due to $T-\mathrm{O}$ stretching mode occur; (2) between 550 and $850 \mathrm{~cm}^{-1}$, where the strongest Raman peak occurs for the majority of amphiboles, with the notable exception of riebeckite (Susta et al., 2018). This peak, which occurs near $670 \pm 20 \mathrm{~cm}^{-1}$ (Waeselmann et al., 2019), is assigned to deformation of the tetrahedral double chain, and its position may provide a useful tool for amphibole identification (e.g., Della Ventura, 2017, and references therein). As recently shown by Bersani et al. (2019) and Della Ventura et al. (2021b), this peak linearly shifts in position as a function of the $\mathrm{Mg}-\mathrm{Me}^{2+}(\mathrm{Me}$ is the divalent metal cation) substitution at the octahedral sites; and (3) the range between 100 and $550 \mathrm{~cm}^{-1}$, which is complicated by the presence of many medium- to low-intensity peaks that are strongly polarized (Waeselmann et al., 2019). These peaks have been difficult to assign with confidence because of the overlapping of $M-\mathrm{O}$ modes, $T-\mathrm{O}$ bendings, and $\mathrm{O}-\mathrm{H}$ libra- 


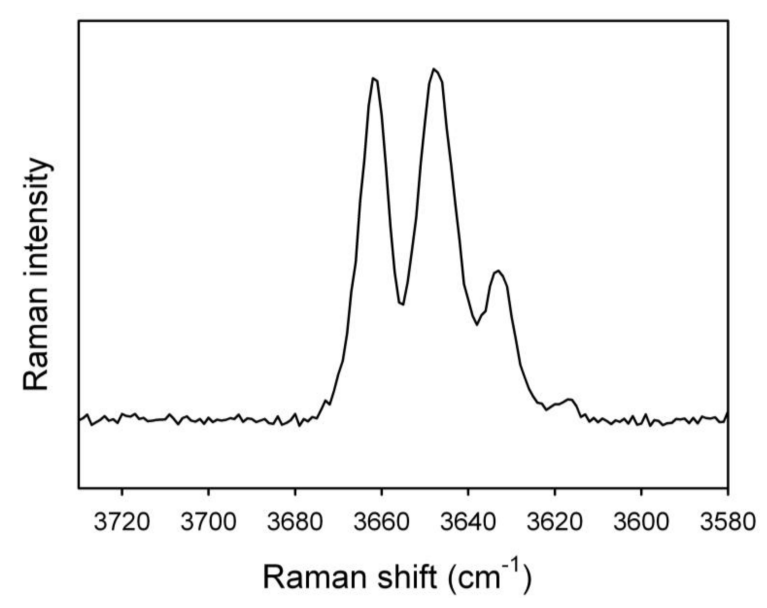

Figure 6. Raman spectrum of the studied glaucophane in the $\mathrm{OH}$ stretching region.

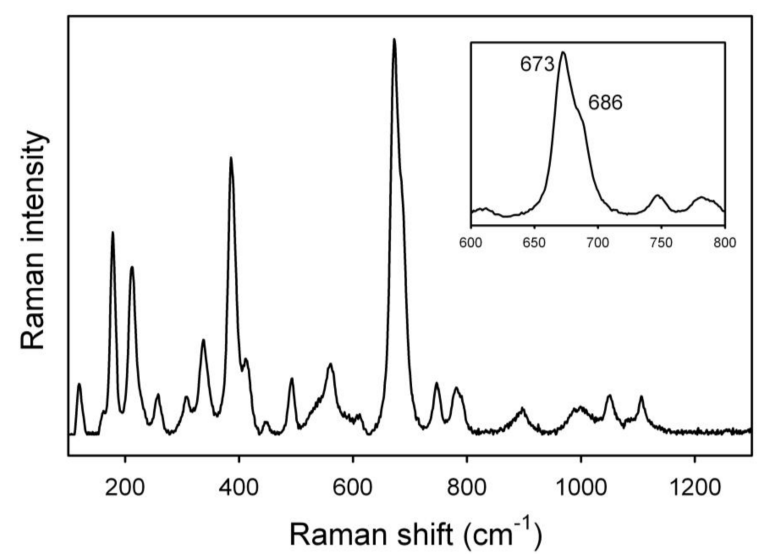

Figure 7. Raman spectrum of the studied glaucophane in the lattice-mode region. The inset displays a magnification of the ringbreathing mode range at $650-700 \mathrm{~cm}^{-1}$.

tions (Della Ventura et al., 2021a). According to Della Ventura et al. (2021b), most peaks in this range also shift linearly toward a lower wavenumber as a function of octahedral substitutions.

Overall, the pattern in Fig. 7 is almost identical to that given for glaucophane in Waeselmann et al. (2019, sample 22). In particular, a well-resolved component on the higherfrequency side of the ring-breathing mode at $673 \mathrm{~cm}^{-1}$ (see inset in Fig. 7) is consistent with the presence of ${ }^{\mathrm{C}} \mathrm{Al}$ in the amphibole, whereas the peak at $530-570 \mathrm{~cm}^{-1}$ can be assigned to octahedral $\mathrm{Fe}^{3+}$; the low intensity of these peaks is in agreement with the low amount of $\mathrm{Fe}^{3+}$ indicated by Mössbauer spectroscopy.

\subsection{Mössbauer spectroscopy}

The ${ }^{57} \mathrm{Fe}$ Mössbauer spectrum (Fig. 8) shows well-separated absorption lines with a distinct shoulder at $\sim+2.5 \mathrm{~mm} / \mathrm{s}$.

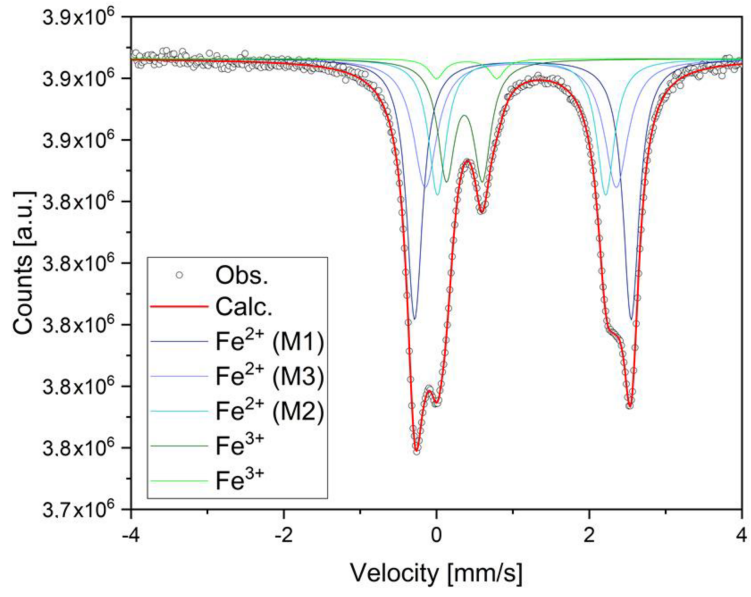

Figure 8. Fitted ${ }^{57} \mathrm{Fe}$ Mössbauer spectrum for glaucophane.

Satisfactory evaluation of the data is only possible when the three typical doublets due to $\mathrm{Fe}^{2+}$ at $M(1), M(2)$, and $M(3)$ and one $\mathrm{Fe}^{3+}$ component are used, all assigned to $\mathrm{Fe}$ in the octahedral strip, based on the ${ }^{57} \mathrm{Fe}$ hyperfine parameters. A slight asymmetry and small misfits around $+0.8 \mathrm{~mm} / \mathrm{s}$ in these four-component fits were accounted for by introducing a second, low-intensity $\mathrm{Fe}^{3+}$ doublet. This additional doublet significantly improved the refinement and led to stable fits. No clear evidence was found for $\mathrm{Fe}^{2+}$ at the M(4) site. The individual $\mathrm{Fe}^{2+}$ components were assigned in accordance with previous studies of amphiboles (e.g., Redhammer and Roth, 2002; Iezzi et al., 2005; Della Ventura et al., 2005,2016 ), and the result is given in Table 1 , together with the extracted relative area fractions. The refined $\mathrm{Fe}^{3+}$ content is $\sim 20 \%$ of the total $\mathrm{Fe}$, whereas $\sim 60 \%$ of the total $\mathrm{Fe}$ is allotted to the $\mathrm{OH}$-coordinated $M(1,3)$ sites, with the remainder being assigned to the $M(2)$ octahedron.

\subsection{EPMA}

The EPMA data shown in Table 2 represent the average of 35 analytical points on two crystals, with the $\mathrm{FeO}$ and $\mathrm{Fe}_{2} \mathrm{O}_{3}$ contents based on the Mössbauer results. The crystalchemical formula has been calculated on the basis of 23 oxygen atoms using the spreadsheet of Locock (2014). Ferrous and ferric iron were assigned to the various sites based on the Mössbauer data of Table 1, and the final site occupancies are given in Table 3.

\subsection{FEG-ESEM EDXS}

The habit of the studied particles is mostly prismatic and acicular. Surfaces parallel to the (002) plane occasionally show steps and irregularities (Fig. 9a and b). The characteristic angles between cleavage planes (56 and $124^{\circ}$ ) can be observed in some of the crystals (Fig. 9c). A large number of particles shows the presence of lamellar structures and possible 
Table 1. ${ }^{57} \mathrm{Fe}$ Mössbauer parameters for glaucophane. IS indicates isomer shift; QS indicates quadrupole splitting; HWHM indicates half width at half maximum. The standard deviations $\left(\sigma_{n-1}\right)$ are in parentheses.

\begin{tabular}{lrrrr}
\hline Site & IS $\delta(\mathrm{mm} / \mathrm{s})$ & QS $\Delta(\mathrm{mm} / \mathrm{s})$ & HWHM $\Gamma / 2(\mathrm{~mm} / \mathrm{s})$ & Area $(\%)$ \\
\hline $\mathrm{Fe}^{2+} M(1)$ & $1.131(5)$ & $2.835(9)$ & $0.127(6)$ & $35.3(9)$ \\
$\mathrm{Fe}^{2+} M(3)$ & $1.103(6)$ & $2.499(16)$ & $0.186(11)$ & $25.7(1.4)$ \\
$\mathrm{Fe}^{2+} M(2)$ & $1.114(12)$ & $2.200(14)$ & $0.139(8)$ & $19.9(1.2)$ \\
$\mathrm{Fe}^{3+}$ & $0.365(6)$ & $0.475(11)$ & $0.136(11)$ & $17.1(9)$ \\
$\mathrm{Fe}^{3+}$ & $0.397(8)$ & $0.81(2)$ & $0.101(8)$ & $2.0(1.3)$ \\
\hline
\end{tabular}

Table 2. Average EMPA data for the studied glaucophane. Chemical formula (in a.p.f.u.) calculated on the basis of 23 oxygen atoms.

\begin{tabular}{|c|c|c|}
\hline Oxide & wt $\%(n=35)$ & $\sigma_{(n-1)}$ \\
\hline $\mathrm{SiO}_{2}$ & 58.45 & 0.59 \\
\hline $\mathrm{TiO}_{2}$ & 0.03 & 0.02 \\
\hline $\mathrm{Al}_{2} \mathrm{O}_{3}$ & 10.54 & 0.35 \\
\hline $\mathrm{FeO}$ & 6.45 & 0.33 \\
\hline $\mathrm{Fe}_{2} \mathrm{O}_{3}$ & 1.79 & - \\
\hline $\mathrm{MnO}$ & 0.06 & 0.03 \\
\hline $\mathrm{MgO}$ & 11.91 & 0.28 \\
\hline $\mathrm{CaO}$ & 1.17 & 0.43 \\
\hline $\mathrm{Na}_{2} \mathrm{O}$ & 6.88 & 0.22 \\
\hline $\mathrm{K}_{2} \mathrm{O}$ & 0.02 & 0.02 \\
\hline $\mathrm{F}$ & 0.19 & 0.49 \\
\hline O_F_Cl & -0.08 & 0.01 \\
\hline Total & 97.49 & \\
\hline $\mathrm{Si}$ & 7.97 & \\
\hline $\mathrm{Al}$ & 0.03 & \\
\hline$\Sigma$ T site & 8.00 & \\
\hline $\mathrm{Al}$ & 1.66 & \\
\hline $\mathrm{Fe}^{3+}$ & 0.18 & \\
\hline $\mathrm{Ti}$ & 0.003 & \\
\hline $\mathrm{Mg}$ & 2.42 & \\
\hline $\mathrm{Fe}^{2+}$ & 0.74 & \\
\hline $\mathrm{Mn}$ & 0.007 & \\
\hline$\Sigma \mathrm{C}$ site & 5.00 & \\
\hline $\mathrm{Ca}$ & 0.17 & \\
\hline $\mathrm{Fe}^{2+}$ & 0.00 & \\
\hline $\mathrm{Na}$ & 1.83 & \\
\hline$\Sigma$ B site & 2.00 & \\
\hline $\mathrm{Na}$ & 0.00 & \\
\hline $\mathrm{K}$ & 0.003 & \\
\hline$\Sigma$ A site & 0.003 & \\
\hline $\mathrm{F}$ & 0.08 & \\
\hline $\mathrm{OH}$ & 1.92 & \\
\hline $\mathrm{Mg} / \mathrm{Mg}+\mathrm{Fe}$ & 0.77 & \\
\hline
\end{tabular}

evidence of dissolution at the edges (Fig. 9d). TEM grids investigated by FEG-ESEM show the presence of a diverse set of habits and particle morphologies (Fig. 9e and f). Some rare fibrous particles were visible (red arrows), having a habit that might be recognized as asbestiform or as fiber (Fig. 9e and f).

\subsection{HR-TEM-SAED and acSTEM Dual-EELS}

The investigated mineral particles show in some cases defects, as evidenced by the weak streaking visible along the [150] and the [131] directions, and cutting the [001] direction in the SAED patterns (Fig. 10). The stepped lamellar structures observed in the FEG-ESEM (Fig. 9D) are also visible at the TEM scale in regions where diffraction contrasts appear (Fig. 11). The misorientation of the laminae may generate the presence of diffraction contrast and possibly Moirée fringes (Fig. 11b).

In several areas of the studied particles, HR-TEM images reveal the presence of multiple orientations (Fig. 12). All the $d$ spacings of crystallographic planes and the associated direction angles were determined on the fast Fourier transform (FFT) image (not shown) that corresponded to the inverse fast Fourier transform (IFFT) image (Fig. 12) of a selected region $(\mathrm{B}, \mathrm{C}, \mathrm{D}$, and $\mathrm{E})$. In Region $\mathrm{B}$, the $d$ spacings of $4.03 \AA$ $\left(\sigma_{n-1}=0.23\right)$ and $4.85 \AA\left(\sigma_{n-1}=0.33\right)$, measured along the crystallographic directions (red arrows), may be assigned to the (111) and (-111) planes, respectively. The two directions are separated by an angle of $\sim 120.65^{\circ}$. In Region $\mathrm{C}, d$ spacings of $4.56 \AA\left(\sigma_{n-1}=0.08\right)$ and $4.26 \AA\left(\sigma_{n-1}=0.07\right)$ were measured along the crystallographic directions shown by red arrows and may be assigned to the (200) and (020) planes, respectively. The two crystallographic directions are separated by an angle of $\sim 82.83^{\circ}$. In Region $\mathrm{D}$, the two $d$ spacings measured along the crystallographic directions (red arrows) are $4.11 \AA\left(\sigma_{n-1}=0.08\right)$, which may be assigned to the $(-131)$ plane, and $5.24 \AA\left(\sigma_{n-1}=0.12\right)$, which may be assigned to the plane perpendicular to the $c$ direction (compatible with the unit-cell dimension). The angle between the two identified crystallographic directions is $\sim 93.70^{\circ}$. In Region E, two crystallographic directions (shown by red arrows) are seen, which correspond to planes with the $d$ spacings of $2.65 \AA\left(\sigma_{n-1}=0.07\right)$ and $6.95 \AA\left(\sigma_{n-1}=0.14\right)$, mea- 

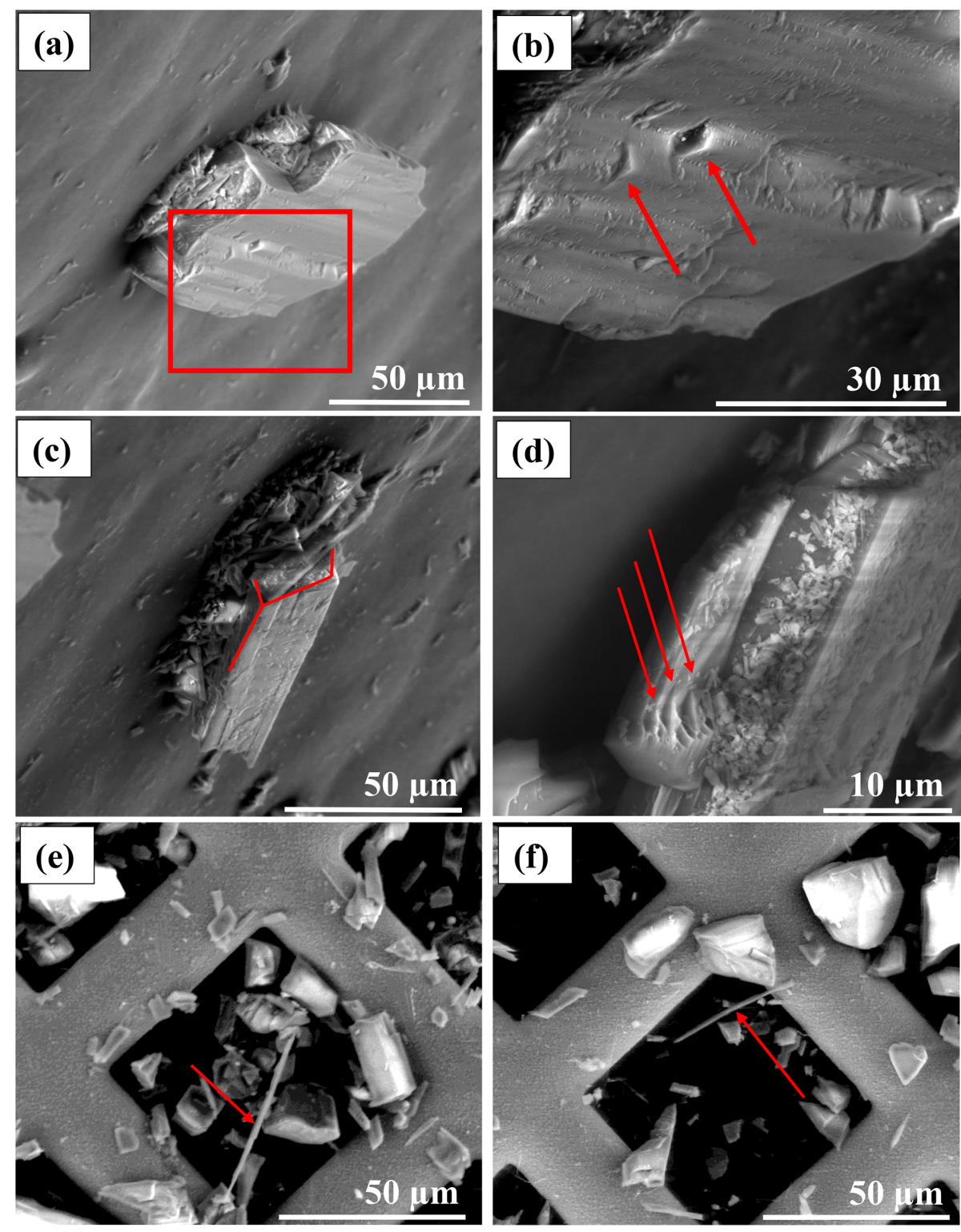

Figure 9. Glaucophane particle morphology observed on a $70^{\circ}$ inclined SEM stub. (a) Stepped glaucophane particle. The red square represents a region of interest (ROI) shown in greater detail in panel (b). (b) Stepped structure with slightly rounded edges. (c) An elongate prismatic particle in which the characteristic amphibole angles are visible $\left(56^{\circ}\right.$ and $\left.124^{\circ}\right)$. (d) Lamellar structures (red arrows) with rounded and sharp edges. (e, f) SEM picture of a TEM grid showing the presence of large fibrous particles (red arrows).

sured along these directions. The first spacing may be assigned to the (002) planes, whereas the second cannot be assigned to a specific direction. The two directions are separated by an angle of $\sim 89.55^{\circ}$. The unassigned $d$ spacing (6.95 $\AA$ ), shown in Fig. 12e, was further investigated by atomic resolution microscopy, which allowed us to simulate the chain-like structure visible at atomic resolution (Fig. 13a) by using a glaucophane model oriented with the $c$ and $b$ axes perpendicular to the electron beam (Fig. 13b).

The average $\mathrm{Fe}$-valence state at the particle grain boundary was estimated, using the $\Delta E$ method, at $2.55\left(\sigma_{n-1}=0.31\right.$; $n=10)$. Despite the well-known experimental limitation due to the $\mathrm{Fe}$-edge modification by the presence of $\mathrm{Al}^{3+}$, we also applied the $L_{2,3}$ white-line intensity-ratio method (Fig. 14), which returned a valence state of $2.78\left(\sigma_{n-1}=0.27 ; n=10\right)$, a value that is statistically identical to that determined by the $\Delta E$ method.

The particle displayed in Fig. 15 was used for investigating its dimensional properties using 3-D TEM tomography (see supplementary video): at the starting position of the tomographic sequence, $L$ was $1.86 \mu \mathrm{m}$ and $w$ was 0.81 , and thus $L / w=2.30$, whereas at the final position (after a ro- 

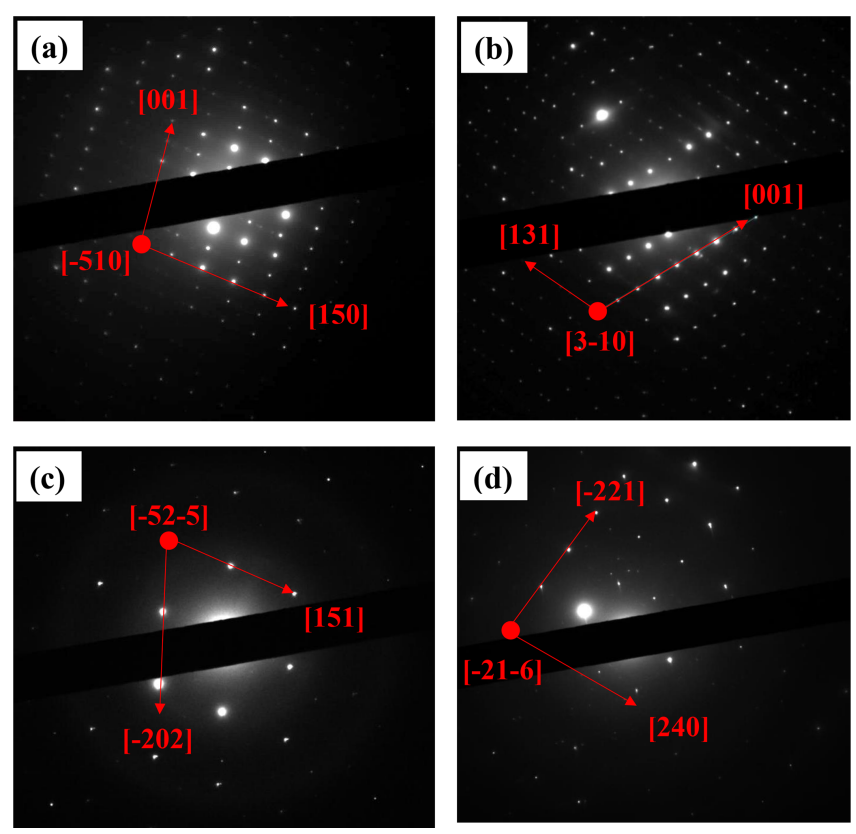

Figure 10. (a-d) SAED patterns collected using the JEOL 2010 TEM on different glaucophane crystals showing different orientations, crystallographic directions (red arrows), and lattice defects (streaking in panels $\mathbf{a}$ and $\mathbf{b}$ ). The zone axes are indicated by the red dots.

tation of $\left.120^{\circ}\right), L$ was $1.97 \mu \mathrm{m}, w$ was $0.31 \mu \mathrm{m}$, and $L / w$ was 6.36. Occasionally, nano-EMPs were observed in STEM mode (Fig. 15c and d).

\subsection{Morphometry by operator}

Figure 16 reveals that the habit as well as the dimension and assigned category by operational parameters $(\mathrm{P})$ of the investigated particles vary depending on the type of microscopy and the magnification used (Table 4). The nanosized portion of particles (i.e., $D_{\mathrm{ae}}<100 \mathrm{~nm}$ ) was detected by STEM but not by SEM (Table 4$)$. We have also plotted the morphological parameters $\left(L, w, L / w\right.$, and $\left.D_{\mathrm{ae}}\right)$ for all analyzed particles ( $n=100$ for each magnification) against progressive particle number, whereby the particle numbers have been arranged from the largest to the smallest dimensions (Fig. 17). The particle-size distribution, derived from the same datasets, and obtained by arbitrarily binning the dimensional parameters into 20 bins, is provided as histograms in Appendix D. The expected average $D_{\mathrm{ae}}$ for any selected magnification can be determined using the power-law relationship between the known average $D_{\text {ae }}$ for each studied particle population and the corresponding magnification. To confirm this relationship, we used the EM data from other amphiboles (tremolite-actinolite), which were dimensionally investigated with the same SEM instrument and the same sample-preparation method (Vigliaturo et al., 2018). The plot of all available average $D_{\text {ae }}$ values vs. magnification shows a
Table 3. Calculated site occupancies for glaucophane.

\begin{tabular}{llr}
\hline Site & Cation & a.p.f.u. \\
\hline$M(1,3)$ & $\mathrm{Fe}^{2+}$ & 0.56 \\
& $\mathrm{Mg}$ & 2.42 \\
& $\mathrm{Fe}^{3+}$ & 0.02 \\
\hline$M(2)$ & $\mathrm{Al}$ & 1.66 \\
& $\mathrm{Fe}^{3+}$ & 0.16 \\
& $\mathrm{Fe}^{2+}$ & 0.18 \\
\hline$M(4)$ & $\mathrm{Na}$ & 1.83 \\
& $\mathrm{Ca}$ & 0.17 \\
\hline
\end{tabular}

robust fit ( $R^{2}=0.95$ ) of the power law (Fig. 18). From these data, we can estimate the expected average $D_{\text {ae }}$ at any magnification.

\section{Discussion}

The amphibole in the studied sample was identified as glaucophane by the use of PXRD (Fig. C1). A combination of analytical techniques yielded a crystal chemical composition typical of glaucophane, with limited $\mathrm{Fe}^{2+}$ substituting for $\mathrm{Mg}$ in the $M(1,3)$ octahedra and limited $\mathrm{Fe}^{3+}$ and $\mathrm{Fe}^{2+}$ replacing $\mathrm{Al}$ at the $M(2)$ site.

The sample is highly crystalline and contains some defects, which appear as streaking that is occasionally visible along the [150] and the [131] crystallographic directions, and intersecting with the [001] crystallographic direction. The streaking might originate from Wadsley defects in the amphibole crystal structure (Chisholm, 1973). All measured $d$ spacings can be assigned to specific crystal planes (and corresponding crystallographic directions), except for one spac-

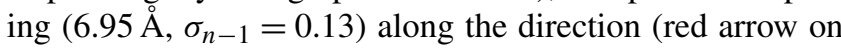
lower right) shown in Fig. 12e. The investigation at atomic resolution and the related simulated image, however, show that this unassigned spacing could be generated by the succession of double chains perpendicular to the [020] crystallographic direction (Fig. 13). Since we measured this unassigned $d$ spacing on different instruments, and the simulated image fits the real atomic-resolution image of the crystal structure, we do not think that this is an artifact but rather that it might be generated by a "stepped" superimposition of I beams and the occasional presence of Wadsley defects in the crystal structure.

The Fe-valence state determined by EELS in the grainboundary regions of the particles is higher when using the $L_{2,3}$ method $\left(2.78 ; \sigma_{n-1}=0.27 ; n=10\right)$ than when using the $\Delta E$ method $\left(2.55 ; \sigma_{n-1}=0.31 ; n=10\right)$. This difference in the Fe-valence state is a consequence of the presence of $\mathrm{Al}^{3+}$, which modifies the $L_{2}$ and $L_{3}$ peaks in the EELS spectrum and thus the shape of the $L_{2,3}-\mathrm{Fe}$ edge (Frost and Langenhorst, 2002; Langenhorst et al., 2013). Therefore, when 

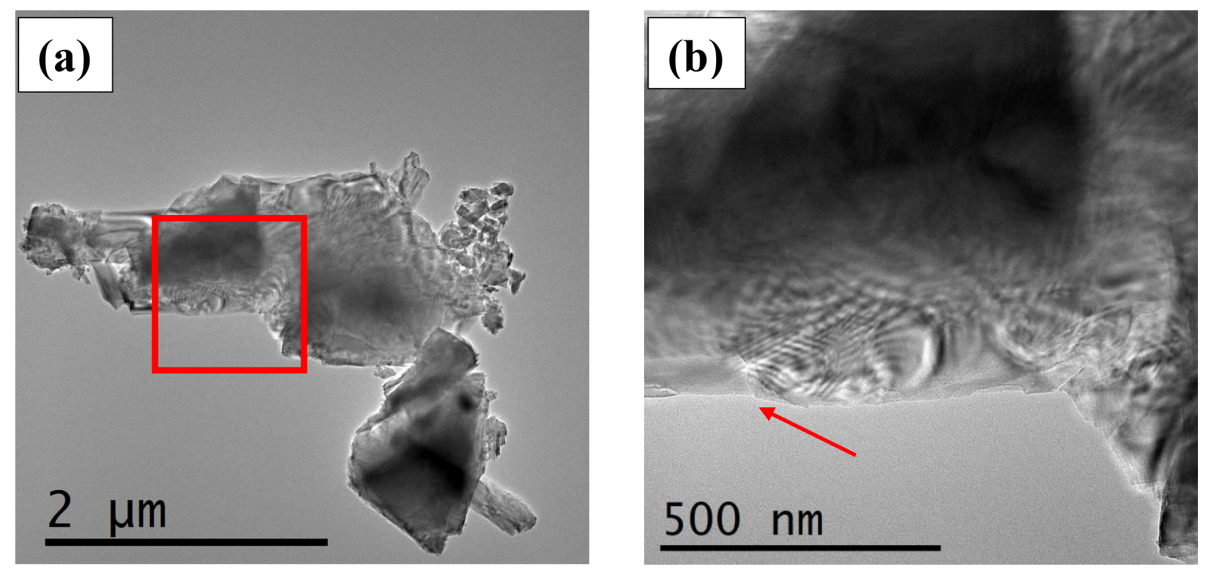

Figure 11. (a) Bright-field (BF) TEM image showing diffraction fringes on a glaucophane particle. The red square represents the area shown in panel (b). (b) Magnified image of the area with diffraction contrast that is generated by the presence by slightly misoriented lamellae. A step in the grain-boundary area is visible (red arrow).

evaluating the valence state of Al-containing amphiboles, the $\Delta E$ method is the better option. The value determined by the $\Delta E$ method for the grain-boundary region of the glaucophane (2.55) is higher than the bulk Fe-valence state obtained by Mössbauer spectroscopy $(\sim 2.20)$. This discrepancy is a consequence of (i) oxidation of the most external boundary of the glaucophane crystals, and (ii) the possible accumulation of Fe oxyhydroxides at the particle surfaces (Fantauzzi et al., 2010; Vigliaturo et al., 2019).

The studied sample shows a predominance of randomly oriented (Fig. 2a) crystals when observed at the mesoscale. The dark to very dark blue color (Fig. 2a and b) and the vitreous to pearly luster (Fig. 2 and Appendix B) are compatible with glaucophane. Some regions of the sample are texturally more ordered, with parallel crystals having a columnarlike habit (Fig. 2b). The millimetric crystals, which were easily detached from the main rock piece, mainly showed an acicular habit and less frequently smaller equant particles (Fig. 2c). At this level of investigation, we did not observe any asbestiform morphology, because we did not detect (a) small fiber thickness and large fiber length, (b) flexible and easily separable fibers, and (c) a parallel arrangement of the fiber in the unprocessed sample (Zoltai, 1981; Veblen and Wylie, 1993). The FEG-ESEM images of glaucophane particles confirmed the predominance of prismatic and acicular fragments (Fig. 9). Of note is that we observed a high abundance of lamellar structures (Fig. 9d), which were also detected with the TEM (e.g., Fig. 11). Interestingly, some particles with a fibrous habit that may be identified as asbestiform or simply as a cleavage fragment with a fiber-like habit were found in FEG-SEM micrographs (Fig. 9e and f). Analogously, nano-sized EMPs were found during dark-field STEM investigations (Fig. 15c and d). It is likely that these particles (fibrous particles and nano-sized EMPs) were produced by longitudinal splitting (Germine and Puffer, 2019), and they were not "native" asbestiform particles. We believe that these cleavage fragments must be taken into consideration when counting and measuring a given particle population since (1) the definition of EMPs includes both asbestiform and non-asbestiform morphologies (NIOSH, 2011); (2) the word "asbestos" does not have a definitive mineralogical significance (Case et al., 2011), being a commercial and regulatory definition (Williams et al., 2013), and there is a widespread "uncertainty and confusion about the specific nature of exposures described in many published studies" (NIOSH, 2011); and (3) the use of "trade names for mined asbestos minerals predated the development of rigorous scientific nomenclature" (NIOSH, 2011) and the non-scientific asbestos definition leads to a "taxonomic confusion and lack of standardized operating definitions of fibres" (Kane et al., 1996). Furthermore, most of the characteristics that define the asbestiform habit (and asbestos) identity might be considered controversial. As an example, a fibril is considered "an individual fiber of asbestos, generally a single crystal" (Veblen and Wylie, 1993 - glossary) or "the thinnest component (single crystal) of a fibre bundle" (Belluso et al., 2017); therefore, it would be impossible to apply the definition by Bailey et al. (2004), who described an asbestos fiber as "visible to the eye are bundles of individual crystal fibers known as fibrils [...]", because we would be unable to identify correctly a fibril (single crystal) by the naked eye or even by SEM, as a single crystal could be identified at this scale by TEM only. Along the same line, phase contrast microscopy (PCM), a method that is widely used for routine analysis, has been proven to have several limitations among which is the capability to distinguish and resolve very thin fibers and to differentiate different EMPs (NIOSH, 2011). One could even argue that defining a particle as flexible from an $\mathrm{OM}$ picture or an EM micrograph is impossible, since flexibility is a quantifiable mechanical property, whereas what is done operationally is a qualitative description of the presence of a "curved" particle. Probably, both the flexibility and the paral- 
Table 4. Summary of the descriptive statistics of glaucophane particles using different microscopy imaging techniques ( $n=100$ each, except for the merged dataset, where $n=216)$. The nano-sized $(<100 \mathrm{~nm})$ component is determined using $D_{\mathrm{ae}}$ as reference.

\begin{tabular}{|c|c|c|c|c|c|}
\hline & \multicolumn{4}{|c|}{ Optical $(10 \times)$} & \multirow[b]{2}{*}{ Nano-sized component } \\
\hline & $L(\mu \mathrm{m})$ & $w(\mu \mathrm{m})$ & $L / w$ & $D_{\mathrm{ae}}(\mu \mathrm{m})$ & \\
\hline \multirow{6}{*}{$\begin{array}{l}\text { Mean } \\
\sigma_{(n-1)} \\
\text { Max } \\
\text { Min }\end{array}$} & 155.55 & 62.32 & 2.66 & 131.67 & \multirow{4}{*}{$0.00 \%$} \\
\hline & 112.18 & 43.21 & 1.16 & 89.93 & \\
\hline & 654.87 & 249.25 & 7.33 & 485.24 & \\
\hline & 14.53 & 8.59 & 1.05 & 16.34 & \\
\hline & \multicolumn{4}{|c|}{$\operatorname{SEM}(200 \times)$} & \multirow[b]{2}{*}{ Nano-sized component } \\
\hline & $L(\mu \mathrm{m})$ & $w(\mu \mathrm{m})$ & $L / w$ & $D_{\mathrm{ae}}(\mu \mathrm{m})$ & \\
\hline Mean & 15.25 & 6.22 & 3.32 & 12.67 & \multirow{4}{*}{$0.00 \%$} \\
\hline$\sigma_{(n-1)}$ & 10.46 & 5.16 & 2.70 & 9.53 & \\
\hline Max & 59.56 & 28.49 & 16.14 & 58.91 & \\
\hline \multirow[t]{3}{*}{ Min } & 2.39 & 0.99 & 1.02 & 2.16 & \\
\hline & & SEM & $000 \times)$ & & \\
\hline & $L(\mu \mathrm{m})$ & $w(\mu \mathrm{m})$ & $L / w$ & $D_{\mathrm{ae}}(\mu \mathrm{m})$ & Nano-sized component \\
\hline Mean & 2.93 & 1.30 & 3.01 & 2.51 & \multirow{4}{*}{$0.00 \%$} \\
\hline$\sigma_{(n-1)}$ & 2.30 & 1.23 & 3.50 & 2.07 & \\
\hline Max & 11.71 & 8.79 & 33.13 & 13.26 & \\
\hline \multirow[t]{3}{*}{ Min } & 0.41 & 0.14 & 1.02 & 0.36 & \\
\hline & \multicolumn{4}{|c|}{ STEM $(25000 \times)$} & \multirow{6}{*}{$14.00 \%$} \\
\hline & $L(\mu \mathrm{m})$ & $w(\mu \mathrm{m})$ & $L / w$ & $D_{\mathrm{ae}}(\mu \mathrm{m})$ & \\
\hline Mean & 0.31 & 0.15 & 2.30 & 0.29 & \\
\hline$\sigma_{(n-1)}$ & 0.28 & 0.11 & 1.98 & 0.21 & \\
\hline Max & 1.93 & 0.54 & 17.23 & 1.15 & \\
\hline \multirow[t]{3}{*}{ Min } & 0.05 & 0.02 & 1.06 & 0.04 & \\
\hline & \multicolumn{4}{|c|}{ Merged } & \\
\hline & $L(\mu \mathrm{m})$ & $w(\mu \mathrm{m})$ & $L / w$ & $D_{\mathrm{ae}}(\mu \mathrm{m})$ & Nano-sized component \\
\hline Mean & 6.69 & 2.65 & 3.17 & 5.54 & \multirow{4}{*}{$6.48 \%$} \\
\hline$\sigma_{(n-1)}$ & 10.13 & 4.60 & 3.21 & 8.82 & \\
\hline Max & 59.56 & 28.49 & 33.13 & 58.91 & \\
\hline Min & 0.05 & 0.02 & 1.02 & 0.04 & \\
\hline
\end{tabular}

lel arrangement of fibers in a native (unprocessed) sample are concepts that can be used by a geologist/mineralogist studying an outcrop, but they cannot be applied when describing a particle that has been collected from air or water, or has been extracted from biological material. In these cases, we cannot know how the native fibers actually occurred, and mechanical tests are not performed routinely by laboratories. In addition, there is no clear explanation of the mechanism by which a fiber that splits ceases to be carcinogenic (Germine and Puffer, 2019), while the fragments still have dimensions and physicochemical properties that can induce carcinogenesis (e.g., EMPs with certain dimensions and chemical composition). In conclusion, our aim is not to discuss the controversial nomenclature and definition related to asbestos and asbestiform materials, but we want to stress that it is crucial that the investigated EMP populations are represented in their entirety and not just as a portion of the population determined by the selection of a single magnification and thus a specific dimensional range of particles within the sample. We believe that the future development of our merged dataset method together with an operational multi-scale approach could lead to that goal.

Consistent with previously published data (Vigliaturo et al., 2018; Vigliaturo et al., 2020), the particle-habit frequency, dimensions, dimensional distribution, and assigned category by operational parameters $(\mathrm{P})$ of the glaucophane studied here change when using different magnifications and instruments. Figure 16 demonstrates, for example, that the glaucophane samples investigated by SEM at a magnification of $200 \times$ exhibited proportions of crystal habits that were dif- 

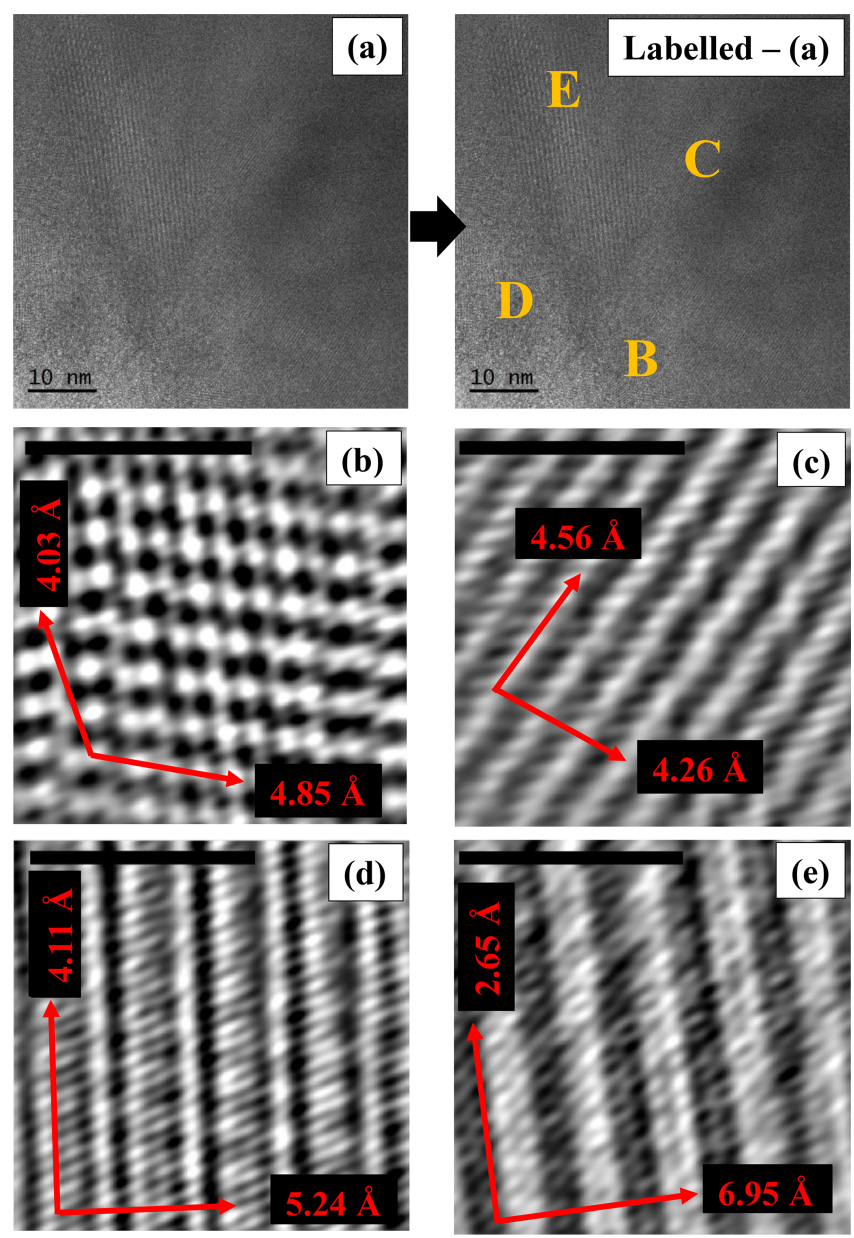

Figure 12. (a) High-resolution TEM micrograph of a region in which several orientations of the lattice are visible. The yellow labels (B, C, D, E) show the ROIs used to determine the main crystallographic directions and the $d$ spacings of the corresponding planes displayed at higher magnifications in the IFFT images shown in panels (b), (c), (d), and (e). Standard deviations $\left(\sigma_{n-1}\right)$ for the $d$ spacings of the planes that correspond to the crystallographic directions shown by red arrows are indicated in the text only. Scale bars in panels (b), (c), (d), and (e) are $2 \mathrm{~nm}$.

ferent from those observed when studied by SEM at a magnification of $2000 \times$ and from those studied by STEM (magnification $25000 \times$ ), even though the three samples were prepared identically. As expected, there is a difference in proportion of different habits between the particles studied by OM (sample not ground) and EM (sample ground for both SEM and TEM) (Fig. 16). The largest habit variations observed among all types of microscopy were found for bladed, platy, and fibrous particles, and to a lesser extent for acicular, lamellar, equant, and prismatic particles (Fig. 16). In addition, one should always consider that the definition of the habit might be biased by operator experience and background.
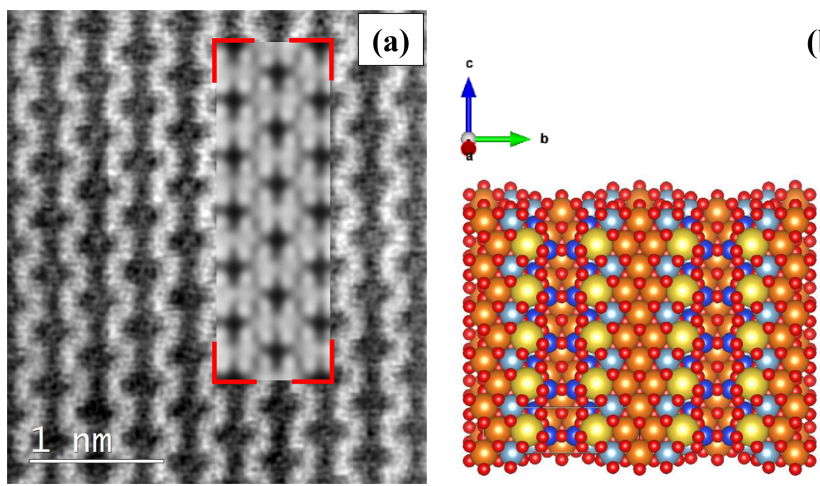

(b)

Figure 13. (a) Denoised atomic-resolution acSTEM picture of the chain-like structure of glaucophane. The simulated structure (delimited by red corners) is superimposed onto the real image. (b) Structural model, oriented to be consistent with the structure imaged in panel (a), was used to generate the simulated atomic-resolved crystal structure (delimited by red corners) in panel (a). Si atoms are blue, $\mathrm{Mg}$ - or $\mathrm{Fe}$-atom positions are orange, $\mathrm{O}$ atoms are red, $\mathrm{Al}$ atoms are light blue, and $\mathrm{Na}$ atoms are yellow.

Using $\mathrm{P} 1(L / w \geq 3), \mathrm{P} 2(L / w \geq 3$ and $L>5$, i.e., EMP according to the NIOSH, 2011 definition), and P3 (fiber with $L / w \geq 3, L \geq 5 \mu \mathrm{m}$, and $w \leq 3 \mu \mathrm{m}$, according to Belluso et al., 2017) as reference parameters, we observed that the STEM analyses at $25000 \times$ returned very different results not only compared to the OM data but also compared to the SEM analyses conducted at $200 \times$ and $2000 \times$, even though the latter two used the exact same ground material as the STEM analyses. Of all techniques, only the SEM data collected at $200 \times$ and $2000 \times$ revealed the presence of fibers with $L / w \geq$ $3, L \geq 5 \mu \mathrm{m}$, and $w \leq 3 \mu \mathrm{m}$ (P3). The tomographic investigation (Video Supplement - https://doi.org/10.5446/48657, Vigliaturo, 2020) showed that, in one orientation (Fig. 15a), the particle cannot be classified as a nano-sized EMP - according to the NIOSH (2011) and Oberdörster and Graham (2018) definitions - whereas in another orientation (Fig. 15b), the same particle has the dimensional characteristics of a nano-sized EMP.

To provide a visual representation of the change in particle size resulting from the use of different types of microscopy, the dimensional parameters $\left(L, w, L / w\right.$, and $\left.D_{\mathrm{ae}}\right)$ of every individual particle ( $n=100$ for each magnification) were plotted in Fig. 17 against progressive particle number, whereby the particle numbers have been arranged from the largest to the smallest dimensions. This plot shows a similar trend for all considered dimensions except for $L / w$. We observed that changing the magnification from $200 \times($ SEM) to $25000 \times$ (STEM) led to an apparent decrease in particle dimensions. This decrease is not due to mechanical comminution since the sample preparation was identical for both the SEM and the STEM samples. Furthermore, the nano-sized portion $(14 \%)$ of the mineral particle population was detected only by the STEM (Table 4). The variation of the aver- 

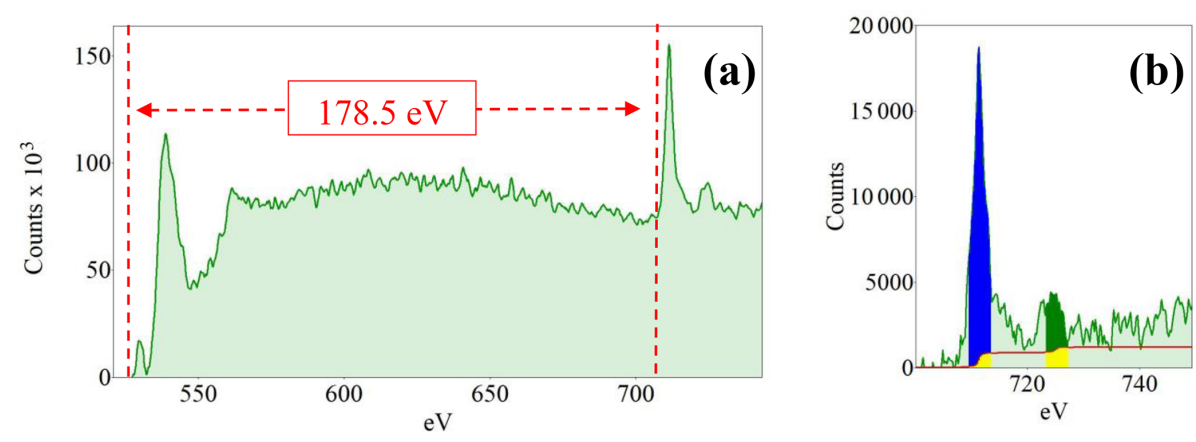

Figure 14. (a) Example of a core-loss spectrum showing both the $\mathrm{O}-K$ edge and $\mathrm{Fe}-L_{2,3}$ edges. (b) Zoom on the $\mathrm{Fe}-L_{2,3}$ edges used for the determination of the white-line intensity ratios. It displays the pre-edge background-subtracted core-loss region of a characteristic EELS spectrum with a focus on the Fe edges. The green area represents the collected original spectrum; the red line represents the double arctangent step function used to subtract the underlying background. The $4 \mathrm{eV}$ wide integration windows are shown in blue on the $L_{3}$ edge and in dark green for the $L_{2}$ edge. The yellow region represents the area of the window that is subtracted by the double arctangent step function.
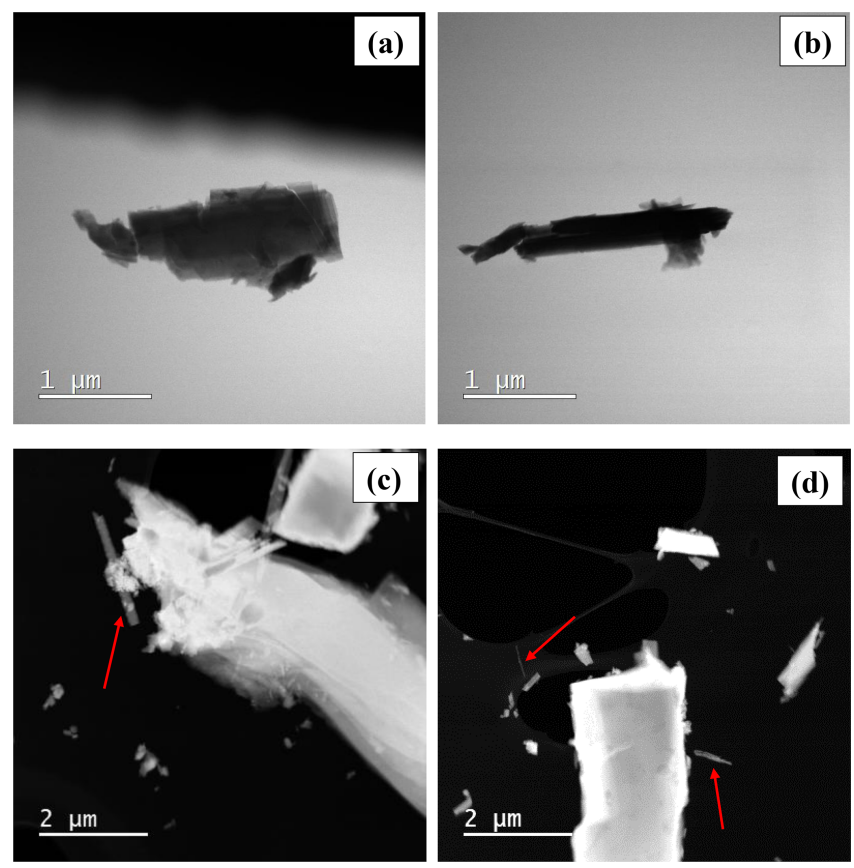

Figure 15. (a) STEM picture of the starting $\left(0^{\circ}\right)$ and (b) final position $\left(120^{\circ}\right)$ of the particle used for the three-dimensional tomographic reconstruction. (c, d) Dark-field STEM pictures showing the presence of nano-sized EMPs (red arrows).

age particle dimensions $\left(w, L, D_{\mathrm{ae}}\right)$ is about 1 order of magnitude per each order of magnitude change in magnification (Table 4 and Fig. 17).

These results have important implications for regulations in the area of environmental medicine, specifically in regard to which parts of the respiratory tract might be accessible to the particles. The location, where the particles might end up in the human respiratory tract, was determined by using the $D_{\text {ae }}$ of each particle. As shown in Table 5, the number of particles in the inhalable, thoracic $\left(\mathrm{PM}_{10}\right)$, respirable, and $\mathrm{PM}_{2.5}$ fractions is different for different microscopes and magnifications used. Specifically, the data obtained from the ground samples show that the SEM investigation performed at $200 \times$ underestimates the number of particles in the thoracic, respirable, and $\mathrm{PM}_{2.5}$ categories compared to that performed at $2000 \times$. The same trend can be observed between the SEM investigation conducted at $2000 \times$ and the STEM investigation conducted at $25000 \times$. Overall, the current regulations for asbestos and EMPs may fail to completely describe the studied particle population, which would lead to an underestimation or overestimation of the percentage of certain habits and regulated particles, and thus distort the exposure-risk evaluation. This aspect does not dispute the validity of the current regulation itself, the sample-preparation methods, or measuring procedure of the particles but highlights the fact that using a single magnification is not sufficient to fully characterize a given particle population and detect all the EMPs that are present.

To overcome this problem, we have proposed a simple method of merging datasets collected at different magnifications, which provides a better and more representative picture of the overall characteristics of the studied particle populations. Usually, legislation and protocols to count, measure, and quantify asbestos and/or EMPs either suggest that the operator should work at a fixed magnification or an operational magnification is not specified (NIOSH, 1994a, b; European Commission Directive, 1999; WHO, 2000; ASTM, 2006; Council of the European Union, 2009; ASTM, 2015). In the following, we will compare the results obtained by our data-merging method with the dataset collected on the SEM at $2000 \times$, which is a magnification that is typically suggested by different legislations (e.g., Italian legislation, Ministerial Decree, 1994) when measuring asbestos dimensions and quantifying the amount of asbestos present in bulk materials (Militello et al., 2019).

The first major difference is that the merged dataset contains information on all the operational parameters (P1, P2, 


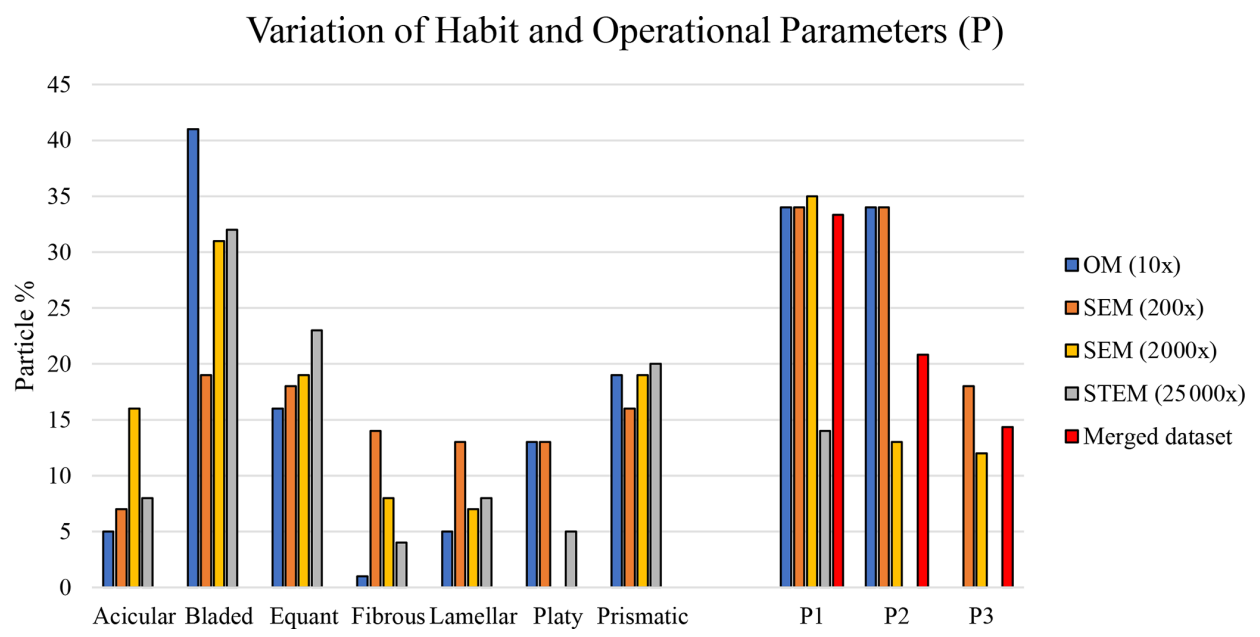

Figure 16. Habit variation using different types of microscopy and magnification. Habit nomenclature after Zoltai (1981), and Veblen and Wylie (1993). The variation of the different operational parameters is shown as $\mathrm{P} 1, \mathrm{P} 2$, and $\mathrm{P} 3$, where $\mathrm{P} 1$ represents $L / w \geq 3$ only (Gunter, 2018; including the nano-sized portion of the mineral particle population), $\mathrm{P} 2$ shows $L / w \geq 3$ and $L>5$ (i.e., EMP according to the National Institute for Occupational Safety and Health (NIOSH) definition), and P3 displays $L / w \geq 3, L \geq 5$ and $w \leq 3$ (i.e., Belluso et al., 2017).

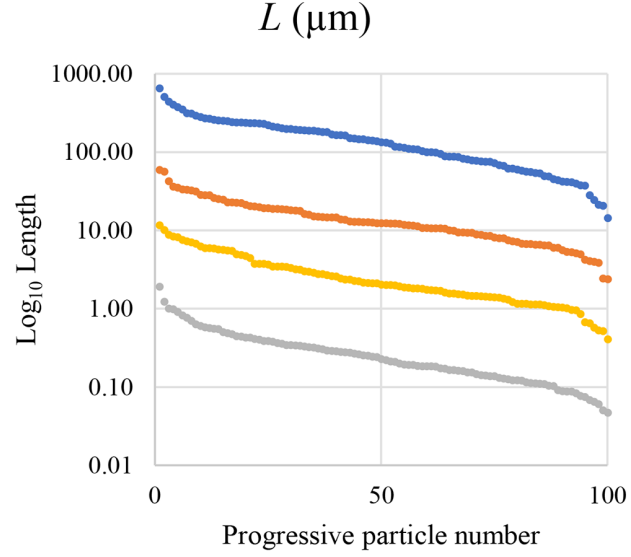

$L / w$

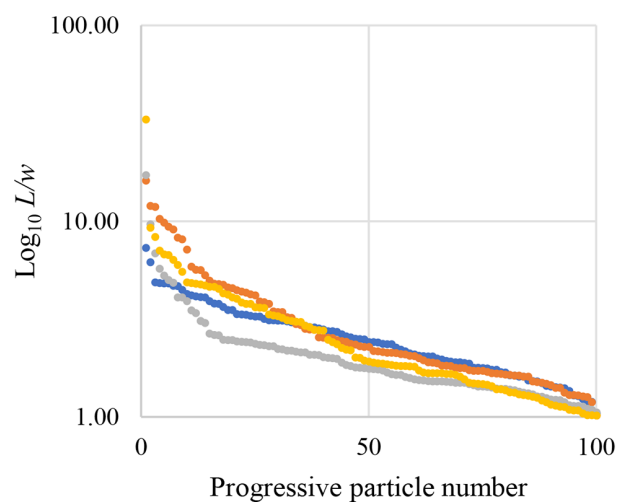

$w(\mu \mathrm{m})$

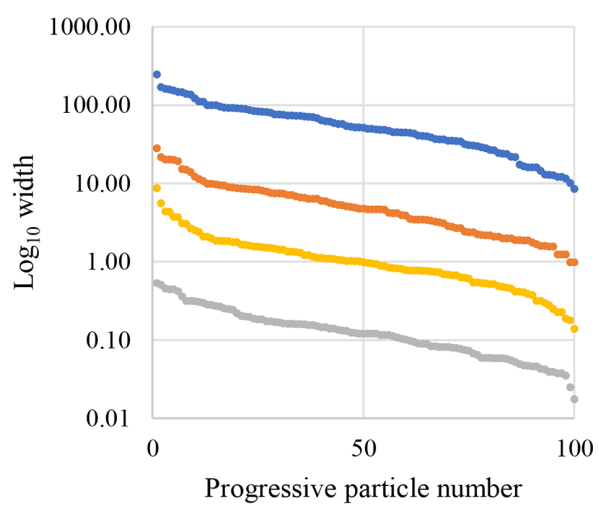

$D_{\text {ae }}(\mu \mathrm{m})$

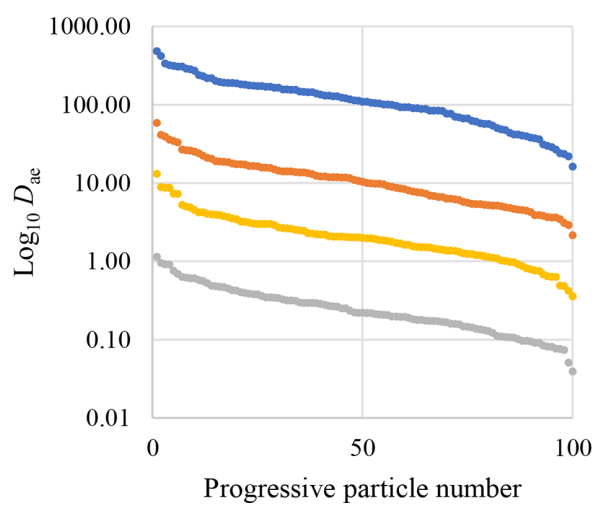

Figure 17. Plot of the dimensional data in descending order. Blue dots are particles measured by optical microscopy $(10 \times)$, orange dots are particles measured with SEM $(200 \times)$, yellow dots are particles measured with SEM $(2000 \times)$, and grey dots represent particles measured by $\operatorname{STEM}(25000 \times)$. 
Table 5. Percentage of particles that belong to a specific particle-size category based on their $D_{\mathrm{ae}}$, which was determined by using different microscopy imaging techniques.

\begin{tabular}{lrrrrr}
\hline & $\begin{array}{r}\text { Optical 10× } \\
\text { (not ground) }\end{array}$ & $\begin{array}{r}\text { SEM 200× } \\
\text { (ground) }\end{array}$ & $\begin{array}{r}\text { SEM 2000× } \\
\text { (ground) }\end{array}$ & $\begin{array}{r}\text { TEM 25 000× } \\
\text { (ground) }\end{array}$ & Merged \\
\hline Inhalable $(<100 \mu \mathrm{m})$ & $43.00 \%$ & $100.00 \%$ & $100.00 \%$ & $100.00 \%$ & $100.00 \%$ \\
$\mathrm{PM}_{10}($ equivalent to thoracic) & $0.00 \%$ & $49.00 \%$ & $99.00 \%$ & $100.00 \%$ & $81.02 \%$ \\
Respirable $(<4 \mu \mathrm{m})_{\mathrm{PM}_{2.5}}^{0.00 \%}$ & $10.00 \%$ & $86.00 \%$ & $100.00 \%$ & $65.74 \%$ \\
\hline
\end{tabular}

and P3), thus documenting that SEM analyses conducted only at one magnification underestimate the percentages of particles for the operational parameters $\mathrm{P} 2$ and $\mathrm{P} 3$, which correspond to EMPs and fibers (as in Belluso et al., 2017), respectively (Fig. 16). The P2 particles amount to $13.00 \%$ of the SEM $(2000 \times)$ data, whereas they represent $20.83 \%$ of the merged dataset. Similarly, the P3 particles represent $12.00 \%$ of the SEM $(2000 \times)$ data but $14.35 \%$ of the merged dataset. On the other hand, the percentages of particles with $L / w \geq 3$ are very similar for both datasets: $35.00 \%$ (SEM $2000 \times$ ) and $33.33 \%$ (merged dataset).

A second difference is represented by the fact that the dimensional distributions obtained from the SEM $(2000 \times)$ dataset exhibit a right-skewed normal distribution, whereas those obtained from our merged dataset can be described with a power law and cover a larger size range (Appendix D). The power-law distribution is mathematically equivalent to a fractal distribution (Carpinteri and Chiaia, 1997), identifying the fragmentation of our sample as a scale-invariant process, analogous to many processes observed in nature (Wylie, 1993). The dimensional distributions in the histogram charts obtained at $2000 \times$ for $L, w$, and $D_{\text {ae }}$ always had their maximum in the second-smallest size category rather than in the smallest one (Appendix D). The lower relative frequency in the smallest size bin might be a consequence of (1) an arbitrary exclusion of particles with certain dimensional parameters, (2) a real decrease of the number of particles in the considered range, or (3) a portion of the particle population not being visible at the selected magnification (Wylie, 1993). This lower relative frequency in the smallest size bin of the $2000 \times$ dataset was not observed in any of the merged datasets (Appendix D), which suggests that, when performing single-magnification characterizations, it is likely a consequence of the use of a fixed magnification that does not allow for correct visualization of the smaller portion of the observed population. In our specific case, we think that the drop in the number of particles in the smallest bin of the OM and SEM data is due to two possible problems: (1) small particles occurring as clusters might not be recognized as individual objects but are grouped into larger particles because of spatial resolution limits and superimposition of particles, and/or (2) the presence of small crystallites hidden from the observer by larger particles (e.g., when lying below).

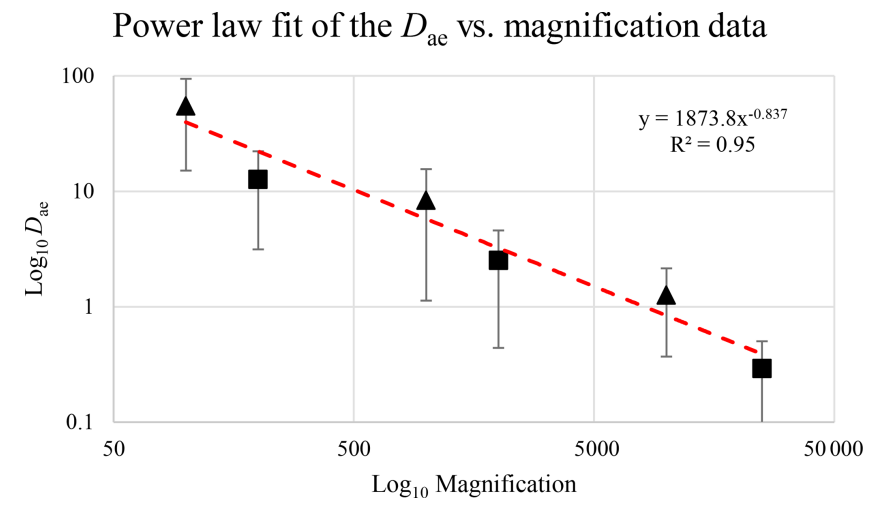

Figure 18. Average $D_{\mathrm{ae}}$ at different magnifications for actinolitetremolite (triangles; from Vigliaturo et al., 2018) and glaucophane (squares; this paper). The dashed red line shows the power-law fit.

On the other hand, a drop in the number of particles in the smallest bin is not always observed by TEM since it virtually has an infinite resolution power, but it can occur because of the deposition of smaller crystallites on or along the copper grid (thus not visible) or because there is a real decrease of particles in the given dimensionality, since the material has reached its "minimum" possible dimension.

Our results document that the total percentage of EMPs and fibers (as in NIOSH, 2011; Belluso et al., 2017) is always underestimated when using a single magnification compared to the percentage obtained from the merged dataset, as proposed here. Furthermore, the information on the nano-sized fraction of the particle population is not present in the SEM dataset, whereas the merged dataset shows that this fraction represents $6.48 \%$ of the overall particle population (Table 4). This difference might be important in terms of potential health impacts, because the smaller particles are more likely taken up by non-phagocytic cells, i.e., alveolar epithelial cells and mesothelial cells (Le Bouffant et al., 1987; Gelzleichter et al., 1996; Nagai and Toyokuni, 2012).

In summary, the merged dataset is a "weighted" distribution of all the percentages determined by SEM $(200 \times)$, SEM $(2000 \times)$, and STEM $(25000 \times)$. Therefore, when taking the $D_{\mathrm{ae}}$ as the parameter that determines the eventual distribution of the particles within the lungs, the values obtained from the merged dataset return more realistic results (Table 5). 


\section{Conclusions}

A detailed characterization of a glaucophane sample from northwestern Italy was conducted using different analytical techniques over different scales. A difference between the bulk and the grain-boundary Fe-valence state of individual amphibole particles was found, and the $\Delta E$ method to evaluate the valence state from EELS spectra in $\mathrm{Al}^{3+}$-containing amphiboles seems to be a more reliable approach than using the $L_{2,3}$ white-line intensity-ratio method. The habit and dimensional distributions are different at different scales, and thus it is important that EMP regulations consider multiple magnifications when assessing potentially dangerous mineral particle populations and developing an operational method to count and measure particles. Our results indicate that when describing a population of potentially dangerous EMPs (both asbestiform and non-asbestiform), the use of a merged dataset, as proposed in this paper, is superior compared to the use of a fixed magnification, which is suggested by current legislations and protocols for asbestos (usually at $400 \times, 600 \times, 1000 \times$, or $2000 \times$ ). We conclude that the use of a merged dataset obtained from at least two datasets is fundamental in determining the real presence of, and thus potential exposure to, EMPs in a given sample. 


\section{Appendix A: Hand sample}

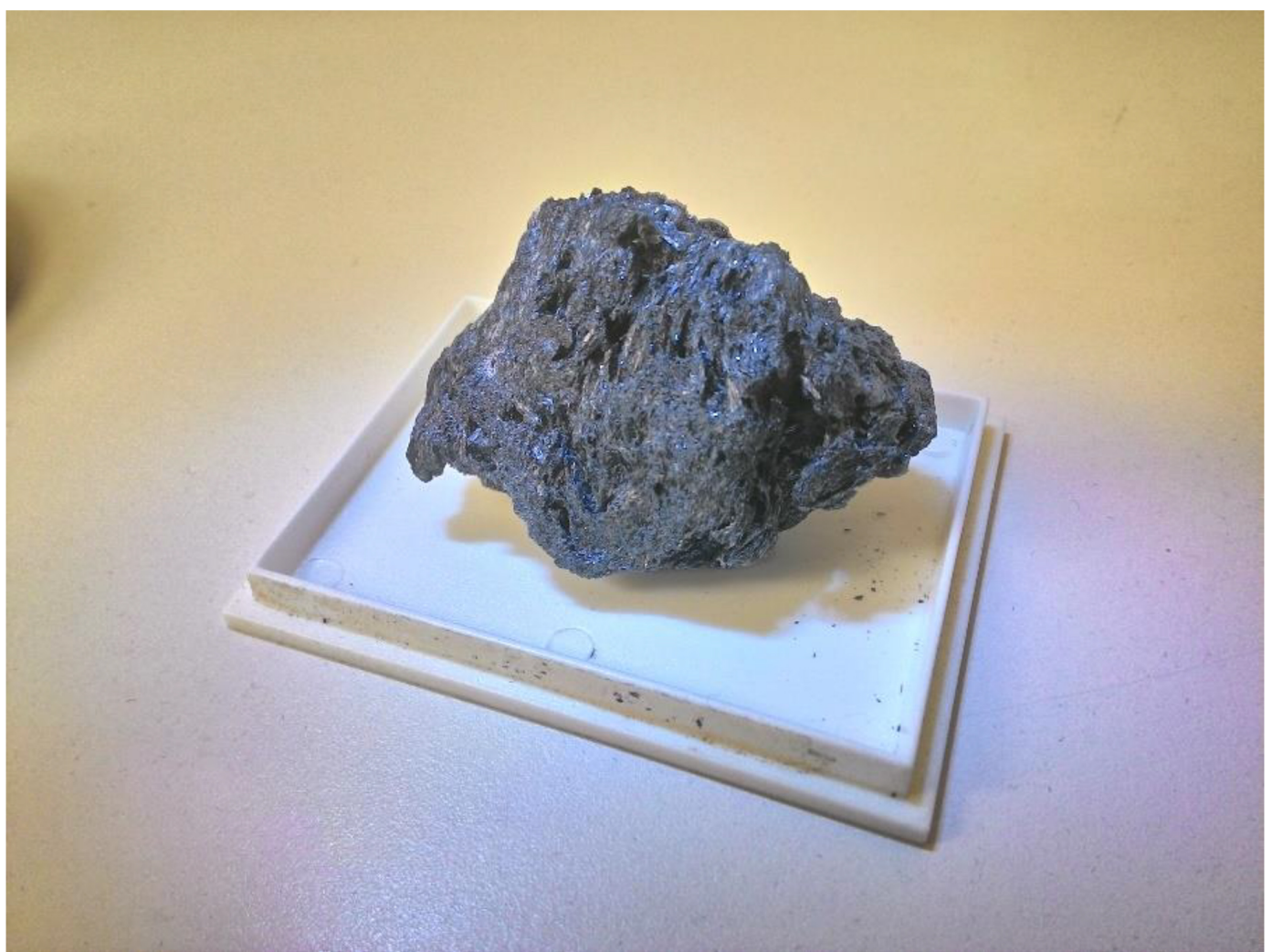

Figure A1. Hand sample as collected in the Chiavolino hamlet (Italy) before any manipulation. The size of the sample is about $5 \times 2 \mathrm{~cm}$. 
Appendix B: Fragmented sample observed by optical microscopy before grinding
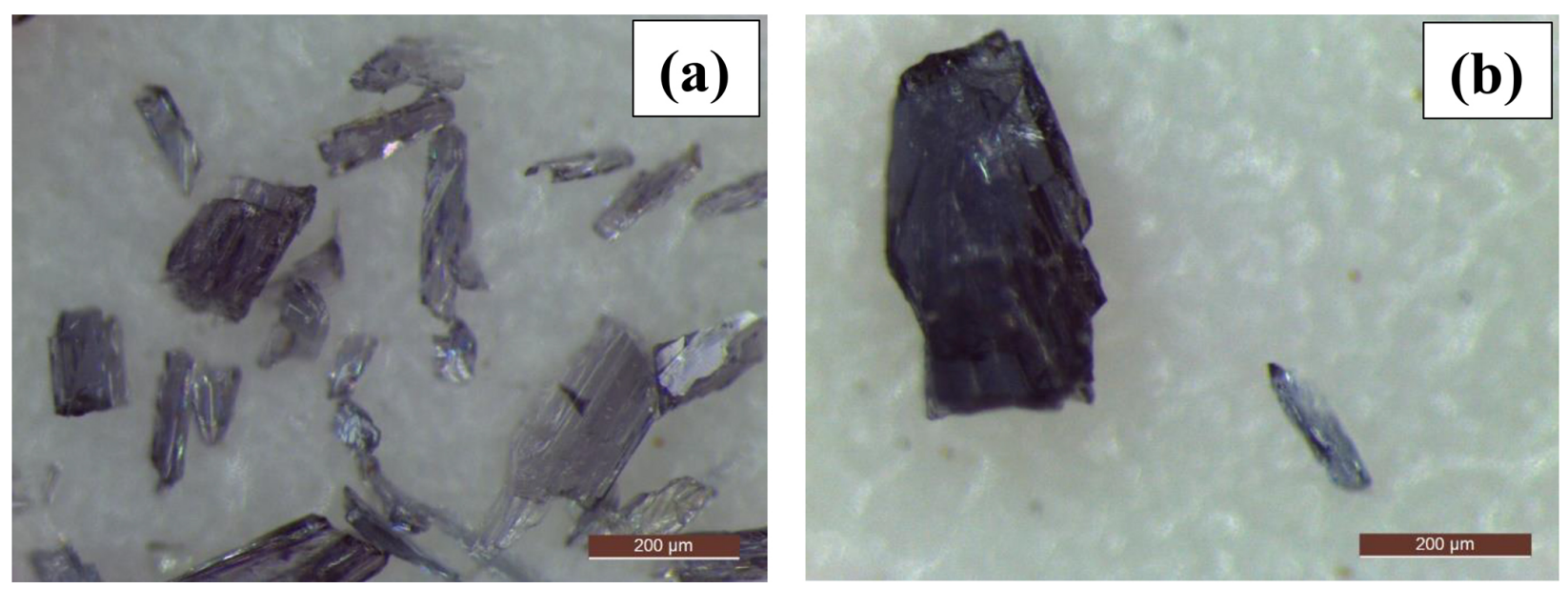

Figure B1. (a, b) Fragments detached from the hand sample by applying finger pressure and by scraping with tongs. The images were recorded at $10 \times$ in $\mathrm{OM}$. 
Appendix C: Powder X-ray diffraction pattern

\section{Glaucophane}

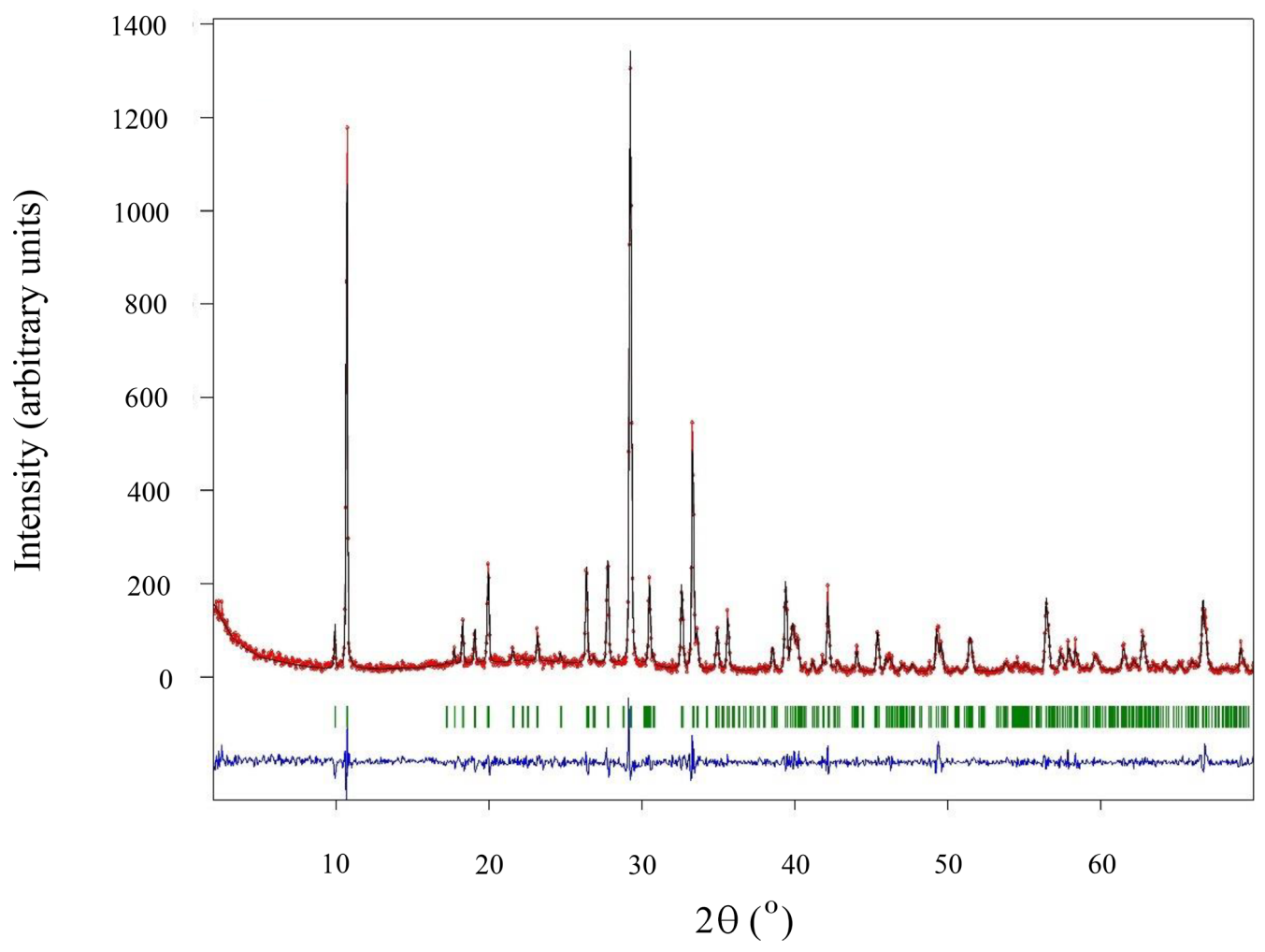

Figure C1. Observed (red points), calculated (black line), and difference (bottom blue line) X-ray powder diffraction pattern for the studied glaucophane sample. Bragg peak positions are given as vertical green bars. 


\section{Appendix D: Additional dimensional information}

These sections display the histograms obtained from our dataset by imposing 20 bins arbitrarily. The data are the same as those shown in the main text (Fig. 17). All data are listed in units of $\mu \mathrm{m}$, except for $L / w$, which is dimensionless.

The blue charts correspond to OM data $(10 \times)$, the orange to SEM data $(200 \times)$, the yellow to SEM data $(2000 \times)$, and the grey to TEM data $(25000 \times)$. Furthermore, the histograms obtained from the merged datasets (SEM 200×; SEM 2000×; STEM $25000 \times$ ) are shown in red. 
Data for length $(L)$

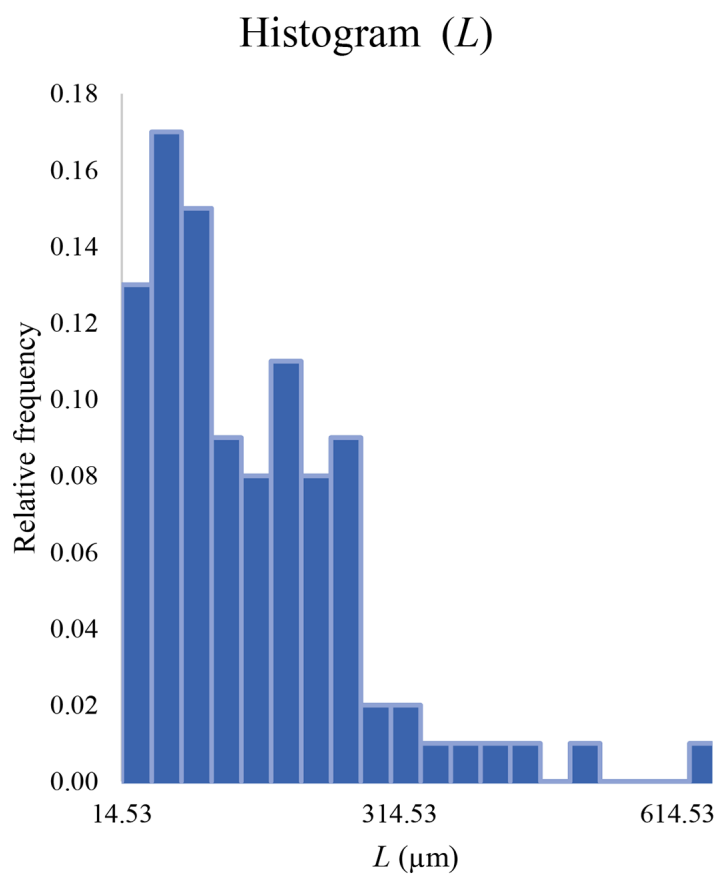

\begin{tabular}{cccc}
$\begin{array}{c}\text { Lower } \\
\text { limit }\end{array}$ & $\begin{array}{c}\text { Upper } \\
\text { limit }\end{array}$ & Frequency & $\begin{array}{c}\text { Relative } \\
\text { frequency }\end{array}$ \\
14.53 & 46.80 & 13.00 & 0.13 \\
46.80 & 79.08 & 17.00 & 0.17 \\
79.08 & 111.35 & 15.00 & 0.15 \\
111.35 & 143.62 & 9.00 & 0.09 \\
143.62 & 175.90 & 8.00 & 0.08 \\
175.90 & 208.17 & 11.00 & 0.11 \\
208.17 & 240.44 & 8.00 & 0.08 \\
240.44 & 272.72 & 9.00 & 0.09 \\
272.72 & 304.99 & 2.00 & 0.02 \\
304.99 & 337.27 & 2.00 & 0.02 \\
337.27 & 369.54 & 1.00 & 0.01 \\
369.54 & 401.81 & 1.00 & 0.01 \\
401.81 & 434.09 & 1.00 & 0.01 \\
434.09 & 466.36 & 1.00 & 0.01 \\
466.36 & 498.63 & 0.00 & 0.00 \\
498.63 & 530.91 & 1.00 & 0.01 \\
530.91 & 563.18 & 0.00 & 0.00 \\
563.18 & 595.45 & 0.00 & 0.00 \\
595.45 & 627.73 & 0.00 & 0.00 \\
627.73 & 660.00 & 1.00 & 0.01 \\
& & & \\
\hline
\end{tabular}

Figure D1.

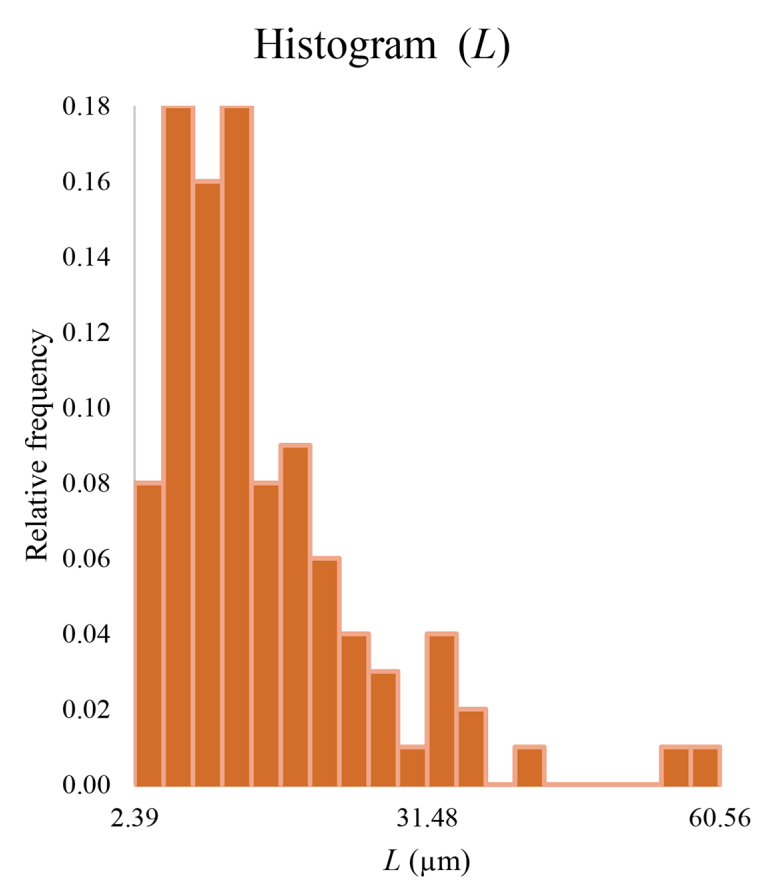

\begin{tabular}{|c|c|c|c|}
\hline $\begin{array}{c}\text { Lower } \\
\text { limit }\end{array}$ & $\begin{array}{c}\text { Upper } \\
\text { limit }\end{array}$ & Frequency & $\begin{array}{l}\text { Relative } \\
\text { frequency }\end{array}$ \\
\hline 2.39 & 5.30 & 8.00 & 0.08 \\
\hline 5.30 & 8.21 & 18.00 & 0.18 \\
\hline 8.21 & 11.12 & 16.00 & 0.16 \\
\hline 11.12 & 14.02 & 18.00 & 0.18 \\
\hline 14.02 & 16.93 & 8.00 & 0.08 \\
\hline 16.93 & 19.84 & 9.00 & 0.09 \\
\hline 19.84 & 22.75 & 6.00 & 0.06 \\
\hline 22.75 & 25.66 & 4.00 & 0.04 \\
\hline 25.66 & 28.57 & 3.00 & 0.03 \\
\hline 28.57 & 31.48 & 1.00 & 0.01 \\
\hline 31.48 & 34.38 & 4.00 & 0.04 \\
\hline 34.38 & 37.29 & 2.00 & 0.02 \\
\hline 37.29 & 40.20 & 0.00 & 0.00 \\
\hline 40.20 & 43.11 & 1.00 & 0.01 \\
\hline 43.11 & 46.02 & 0.00 & 0.00 \\
\hline 46.02 & 48.93 & 0.00 & 0.00 \\
\hline 48.93 & 51.83 & 0.00 & 0.00 \\
\hline 51.83 & 54.74 & 0.00 & 0.00 \\
\hline 54.74 & 57.65 & 1.00 & 0.01 \\
\hline 57.65 & 60.56 & 1.00 & 0.01 \\
\hline
\end{tabular}

Figure D2. 


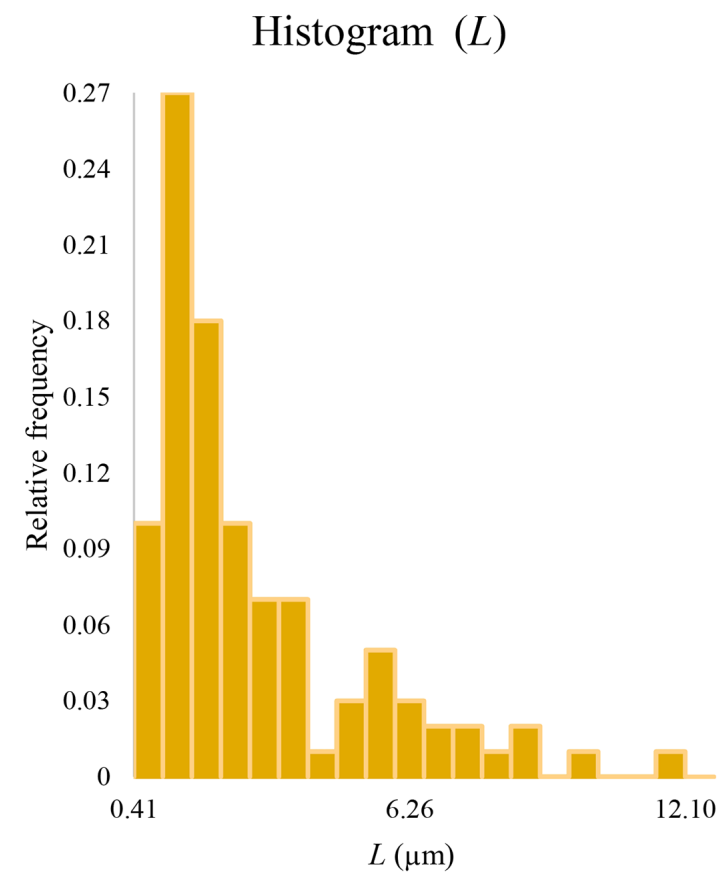

$\begin{array}{cccc}\begin{array}{c}\text { Lower } \\ \text { bound }\end{array} & \begin{array}{c}\text { Upper } \\ \text { bound }\end{array} & \text { Frequency } & \begin{array}{c}\text { Relative } \\ \text { frequency }\end{array} \\ 0.41 & 1.03 & 10.00 & 0.10 \\ 1.03 & 1.64 & 27.00 & 0.27 \\ 1.64 & 2.26 & 18.00 & 0.18 \\ 2.26 & 2.87 & 10.00 & 0.10 \\ 2.87 & 3.49 & 7.00 & 0.07 \\ 3.49 & 4.10 & 7.00 & 0.07 \\ 4.10 & 4.72 & 1.00 & 0.01 \\ 4.72 & 5.33 & 3.00 & 0.03 \\ 5.33 & 5.95 & 5.00 & 0.05 \\ 5.95 & 6.56 & 3.00 & 0.03 \\ 6.56 & 7.18 & 2.00 & 0.02 \\ 7.18 & 7.79 & 2.00 & 0.02 \\ 7.79 & 8.41 & 1.00 & 0.01 \\ 8.41 & 9.02 & 2.00 & 0.02 \\ 9.02 & 9.64 & 0.00 & 0.00 \\ 9.64 & 10.25 & 1.00 & 0.01 \\ 10.25 & 10.87 & 0.00 & 0.00 \\ 10.87 & 11.48 & 0.00 & 0.00 \\ 11.48 & 12.10 & 1.00 & 0.01 \\ 12.10 & 12.71 & 0.00 & 0.00\end{array}$

Figure D3.

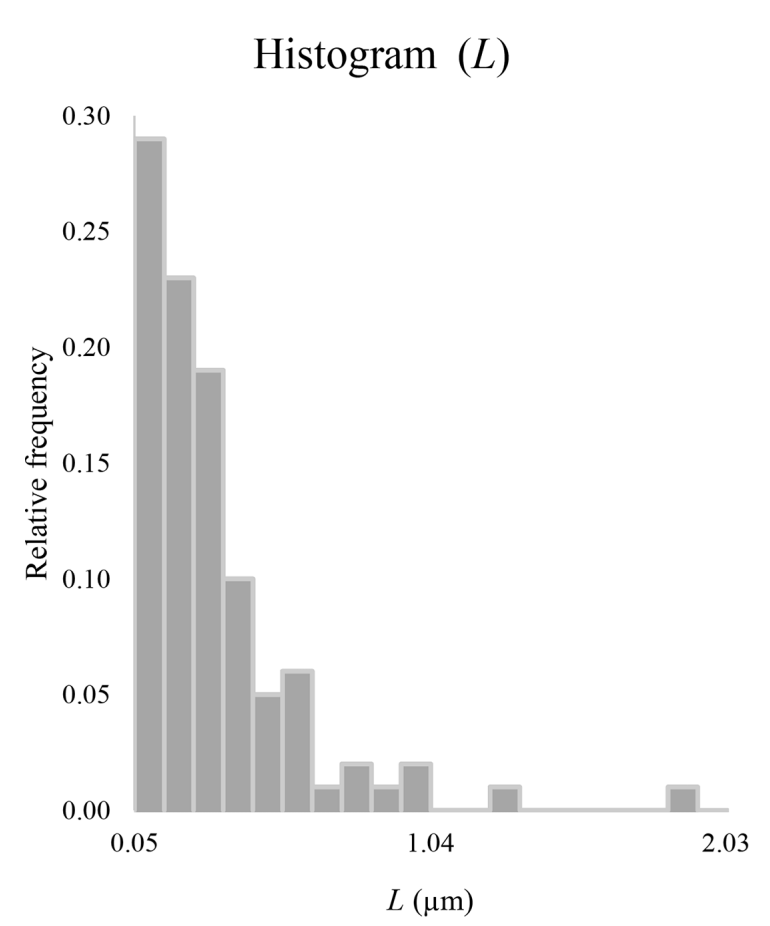

$\begin{array}{cccc}\begin{array}{c}\text { Lower } \\ \text { limit }\end{array} & \begin{array}{c}\text { Upper } \\ \text { limit }\end{array} & \text { Frequency } & \begin{array}{c}\text { Relative } \\ \text { frequency }\end{array} \\ 0.05 & 0.15 & 29.00 & 0.29 \\ 0.15 & 0.25 & 23.00 & 0.23 \\ 0.25 & 0.35 & 19.00 & 0.19 \\ 0.35 & 0.44 & 10.00 & 0.10 \\ 0.44 & 0.54 & 5.00 & 0.05 \\ 0.54 & 0.64 & 6.00 & 0.06 \\ 0.64 & 0.74 & 1.00 & 0.01 \\ 0.74 & 0.84 & 2.00 & 0.02 \\ 0.84 & 0.94 & 1.00 & 0.01 \\ 0.94 & 1.04 & 2.00 & 0.02 \\ 1.04 & 1.14 & 0.00 & 0.00 \\ 1.14 & 1.24 & 0.00 & 0.00 \\ 1.24 & 1.34 & 1.00 & 0.01 \\ 1.34 & 1.44 & 0.00 & 0.00 \\ 1.44 & 1.54 & 0.00 & 0.00 \\ 1.54 & 1.64 & 0.00 & 0.00 \\ 1.64 & 1.73 & 0.00 & 0.00 \\ 1.73 & 1.83 & 0.00 & 0.00 \\ 1.83 & 1.93 & 1.00 & 0.01 \\ 1.93 & 2.03 & 0.00 & 0.00\end{array}$

Figure D4. 
Data for width $(w)$

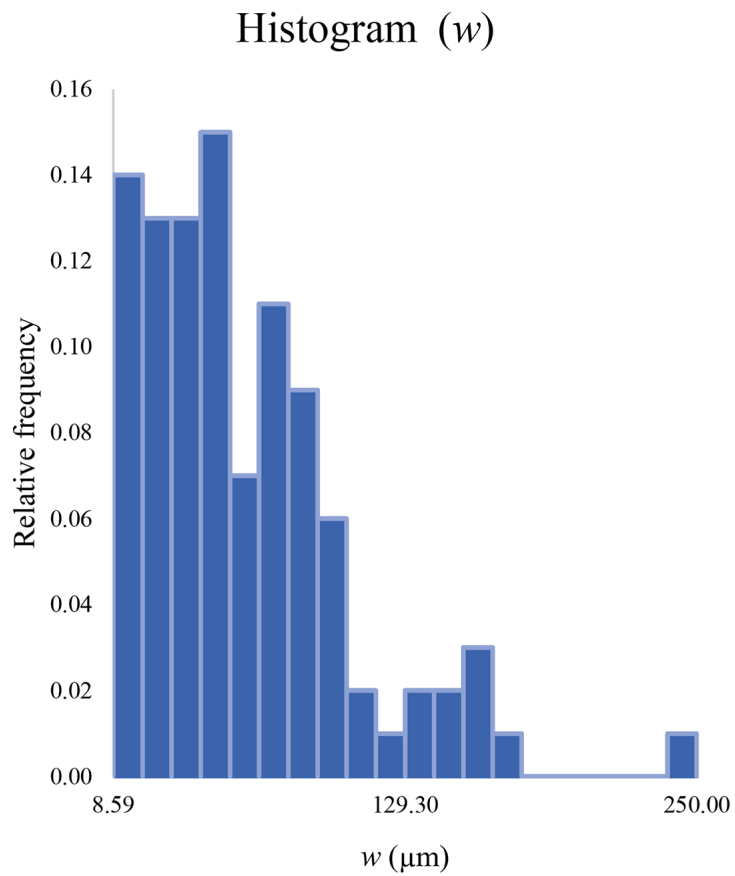

$\begin{array}{cccc}\begin{array}{c}\text { Lower } \\ \text { limit }\end{array} & \begin{array}{c}\text { Upper } \\ \text { limit }\end{array} & \text { Frequency } & \begin{array}{c}\text { Relative } \\ \text { frequency }\end{array} \\ 8.59 & 20.66 & 14.00 & 0.14 \\ 20.66 & 32.73 & 13.00 & 0.13 \\ 32.73 & 44.80 & 13.00 & 0.13 \\ 44.80 & 56.87 & 15.00 & 0.15 \\ 56.87 & 68.94 & 7.00 & 0.07 \\ 68.94 & 81.01 & 11.00 & 0.11 \\ 81.01 & 93.08 & 9.00 & 0.09 \\ 93.08 & 105.15 & 6.00 & 0.06 \\ 105.15 & 117.22 & 2.00 & 0.02 \\ 117.22 & 129.30 & 1.00 & 0.01 \\ 129.30 & 141.37 & 2.00 & 0.02 \\ 141.37 & 153.44 & 2.00 & 0.02 \\ 153.44 & 165.51 & 3.00 & 0.03 \\ 165.51 & 177.58 & 1.00 & 0.01 \\ 177.58 & 189.65 & 0.00 & 0.00 \\ 189.65 & 201.72 & 0.00 & 0.00 \\ 201.72 & 213.79 & 0.00 & 0.00 \\ 213.79 & 225.86 & 0.00 & 0.00 \\ 225.86 & 237.93 & 0.00 & 0.00 \\ 237.93 & 250.00 & 1.00 & 0.01 \\ & & & \end{array}$

Figure D5.

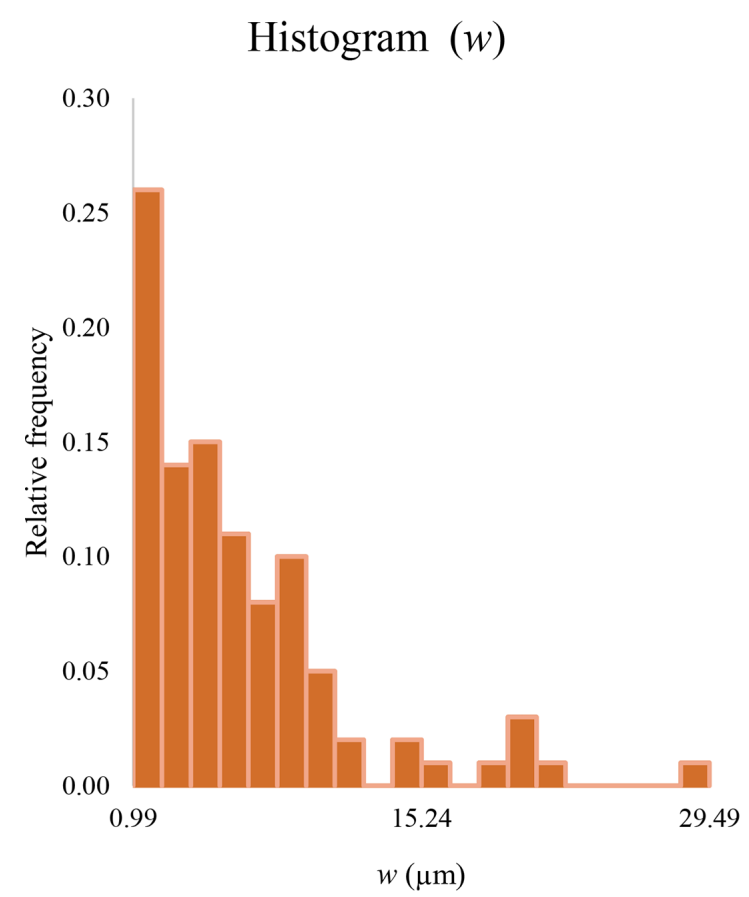

\begin{tabular}{|cccc}
\hline $\begin{array}{c}\text { Lower } \\
\text { limit }\end{array}$ & $\begin{array}{c}\text { Upper } \\
\text { limit }\end{array}$ & Frequency & $\begin{array}{c}\text { Relative } \\
\text { frequency }\end{array}$ \\
0.99 & 2.42 & 26.00 & 0.26 \\
2.42 & 3.84 & 14.00 & 0.14 \\
3.84 & 5.27 & 15.00 & 0.15 \\
5.27 & 6.69 & 11.00 & 0.11 \\
6.69 & 8.12 & 8.00 & 0.08 \\
8.12 & 9.54 & 10.00 & 0.10 \\
9.54 & 10.97 & 5.00 & 0.05 \\
10.97 & 12.39 & 2.00 & 0.02 \\
12.39 & 13.82 & 0.00 & 0.00 \\
13.82 & 15.24 & 2.00 & 0.02 \\
15.24 & 16.67 & 1.00 & 0.01 \\
16.67 & 18.09 & 0.00 & 0.00 \\
18.09 & 19.52 & 1.00 & 0.01 \\
19.52 & 20.94 & 3.00 & 0.03 \\
20.94 & 22.37 & 1.00 & 0.01 \\
22.37 & 23.79 & 0.00 & 0.00 \\
23.79 & 25.22 & 0.00 & 0.00 \\
25.22 & 26.64 & 0.00 & 0.00 \\
26.64 & 28.07 & 0.00 & 0.00 \\
28.07 & 29.49 & 1.00 & 0.01 \\
& & & \\
\hline
\end{tabular}

Figure D6. 


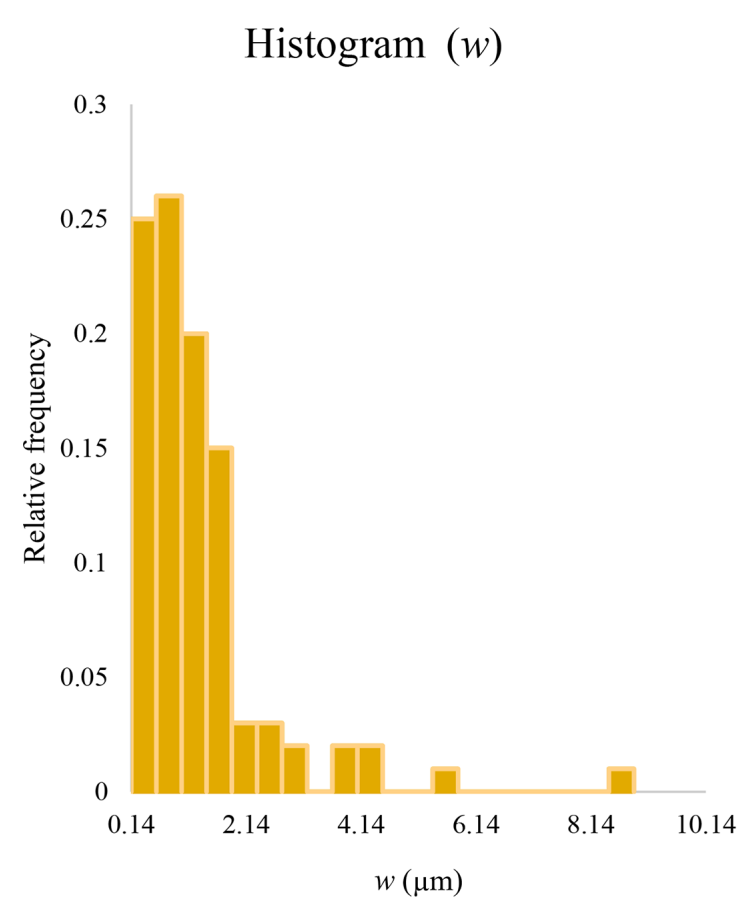

\begin{tabular}{cccc}
$\begin{array}{c}\text { Lower } \\
\text { bound }\end{array}$ & $\begin{array}{c}\text { Upper } \\
\text { bound }\end{array}$ & Frequency & $\begin{array}{c}\text { Relative } \\
\text { frequency }\end{array}$ \\
0.14 & 0.58 & 25.00 & 0.25 \\
0.58 & 1.02 & 26.00 & 0.26 \\
1.02 & 1.45 & 20.00 & 0.20 \\
1.45 & 1.89 & 15.00 & 0.15 \\
1.89 & 2.33 & 3.00 & 0.03 \\
2.33 & 2.77 & 3.00 & 0.03 \\
2.77 & 3.20 & 2.00 & 0.02 \\
3.20 & 3.64 & 0.00 & 0.00 \\
3.64 & 4.08 & 2.00 & 0.02 \\
4.08 & 4.52 & 2.00 & 0.02 \\
4.52 & 4.95 & 0.00 & 0.00 \\
4.95 & 5.39 & 0.00 & 0.00 \\
5.39 & 5.83 & 1.00 & 0.01 \\
5.83 & 6.27 & 0.00 & 0.00 \\
6.27 & 6.70 & 0.00 & 0.00 \\
6.70 & 7.14 & 0.00 & 0.00 \\
7.14 & 7.58 & 0.00 & 0.00 \\
7.58 & 8.02 & 0.00 & 0.00 \\
8.02 & 8.45 & 0.00 & 0.00 \\
8.45 & 8.89 & 1.00 & 0.01 \\
\hline & & & \\
\hline
\end{tabular}

Figure D7.

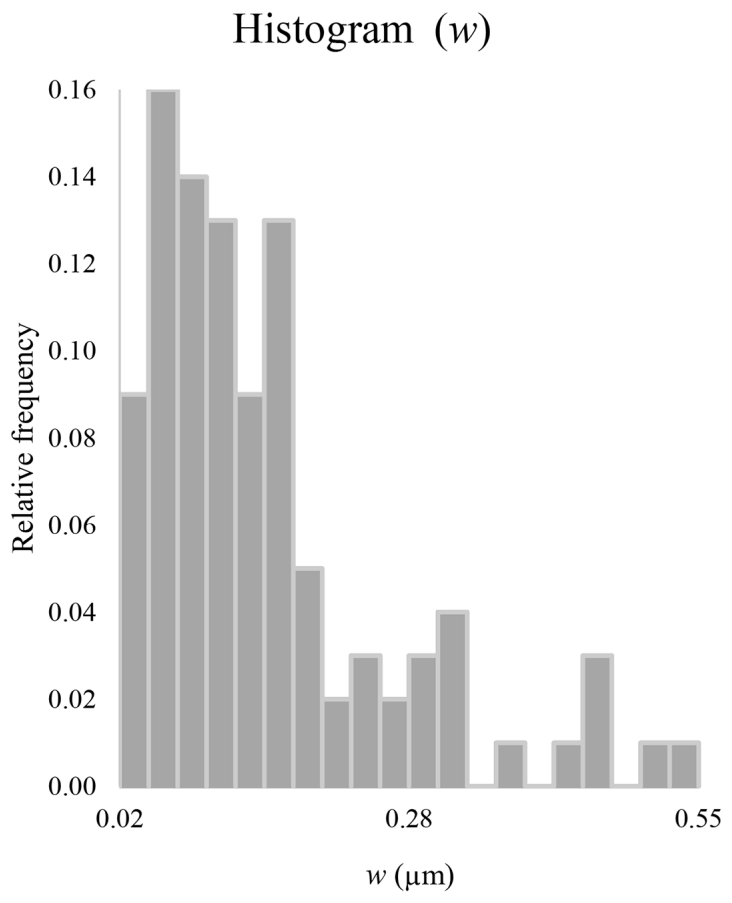

\begin{tabular}{cccc}
$\begin{array}{c}\text { Lower } \\
\text { limit }\end{array}$ & $\begin{array}{c}\text { Upper } \\
\text { limit }\end{array}$ & Frequency & $\begin{array}{c}\text { Relative } \\
\text { frequency }\end{array}$ \\
0.02 & 0.04 & 9.00 & 0.09 \\
0.04 & 0.07 & 16.00 & 0.16 \\
0.07 & 0.10 & 14.00 & 0.14 \\
0.10 & 0.12 & 13.00 & 0.13 \\
0.12 & 0.15 & 9.00 & 0.09 \\
0.15 & 0.18 & 13.00 & 0.13 \\
0.18 & 0.20 & 5.00 & 0.05 \\
0.20 & 0.23 & 2.00 & 0.02 \\
0.23 & 0.26 & 3.00 & 0.03 \\
0.26 & 0.28 & 2.00 & 0.02 \\
0.28 & 0.31 & 3.00 & 0.03 \\
0.31 & 0.34 & 4.00 & 0.04 \\
0.34 & 0.36 & 0.00 & 0.00 \\
0.36 & 0.39 & 1.00 & 0.01 \\
0.39 & 0.42 & 0.00 & 0.00 \\
0.42 & 0.44 & 1.00 & 0.01 \\
0.44 & 0.47 & 3.00 & 0.03 \\
0.47 & 0.49 & 0.00 & 0.00 \\
0.49 & 0.52 & 1.00 & 0.01 \\
0.52 & 0.55 & 1.00 & 0.01 \\
\hline & & &
\end{tabular}

Figure D8. 
Data for aspect ratio $(L / w)$

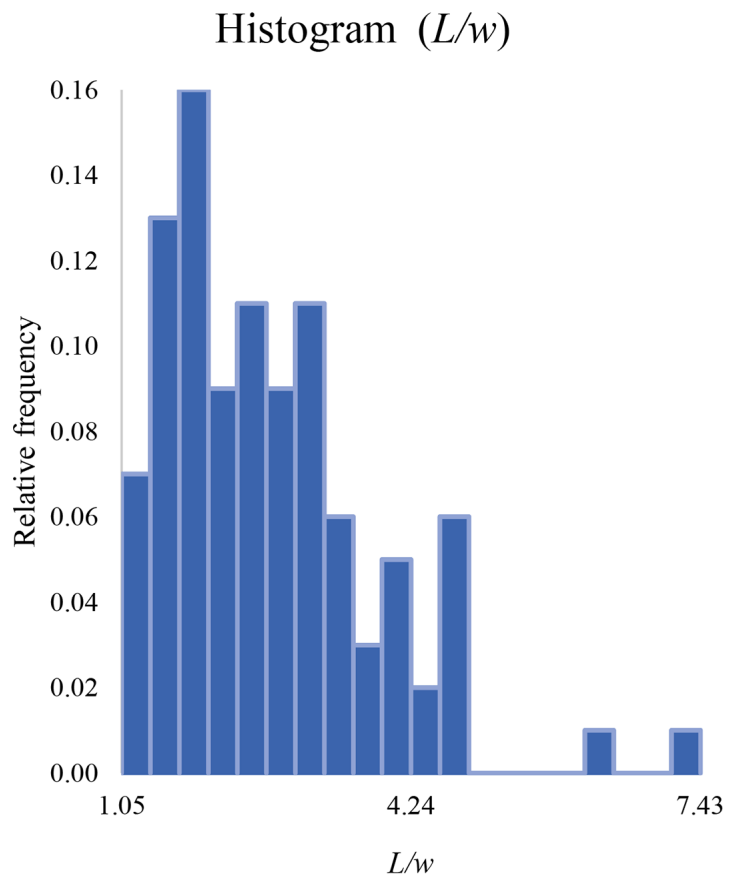

\begin{tabular}{cccc}
$\begin{array}{c}\text { Lower } \\
\text { limit }\end{array}$ & $\begin{array}{c}\text { Upper } \\
\text { limit }\end{array}$ & Frequency & $\begin{array}{c}\text { Relative } \\
\text { frequency }\end{array}$ \\
1.05 & 1.36 & 7.00 & 0.07 \\
1.36 & 1.68 & 13.00 & 0.13 \\
1.68 & 2.00 & 16.00 & 0.16 \\
2.00 & 2.32 & 9.00 & 0.09 \\
2.32 & 2.64 & 11.00 & 0.11 \\
2.64 & 2.96 & 9.00 & 0.09 \\
2.96 & 3.28 & 11.00 & 0.11 \\
3.28 & 3.60 & 6.00 & 0.06 \\
3.60 & 3.92 & 3.00 & 0.03 \\
3.92 & 4.24 & 5.00 & 0.05 \\
4.24 & 4.56 & 2.00 & 0.02 \\
4.56 & 4.88 & 6.00 & 0.06 \\
4.88 & 5.19 & 0.00 & 0.00 \\
5.19 & 5.51 & 0.00 & 0.00 \\
5.51 & 5.83 & 0.00 & 0.00 \\
5.83 & 6.15 & 0.00 & 0.00 \\
6.15 & 6.47 & 1.00 & 0.01 \\
6.47 & 6.79 & 0.00 & 0.00 \\
6.79 & 7.11 & 0.00 & 0.00 \\
7.11 & 7.43 & 1.00 & 0.01 \\
\hline
\end{tabular}

Figure D9.

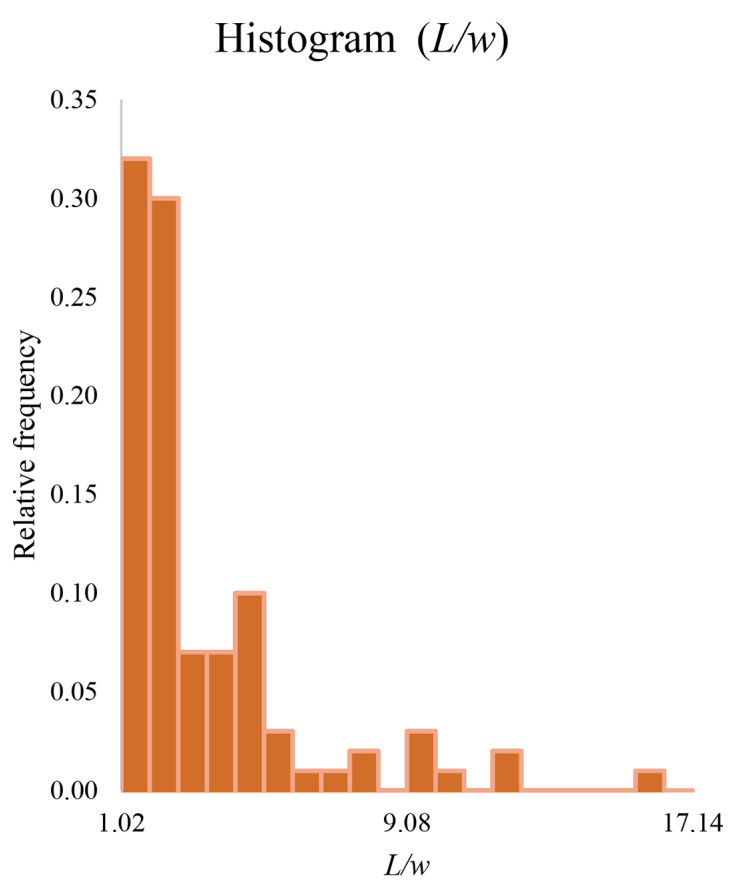

$\begin{array}{cccc}\begin{array}{c}\text { Lower } \\ \text { limit }\end{array} & \begin{array}{c}\text { Upper } \\ \text { limit }\end{array} & \text { Frequency } & \begin{array}{c}\text { Relative } \\ \text { frequency }\end{array} \\ 1.02 & 1.83 & 32.00 & 0.32 \\ 1.83 & 2.63 & 30.00 & 0.30 \\ 2.63 & 3.44 & 7.00 & 0.07 \\ 3.44 & 4.24 & 7.00 & 0.07 \\ 4.24 & 5.05 & 10.00 & 0.10 \\ 5.05 & 5.86 & 3.00 & 0.03 \\ 5.86 & 6.66 & 1.00 & 0.01 \\ 6.66 & 7.47 & 1.00 & 0.01 \\ 7.47 & 8.27 & 2.00 & 0.02 \\ 8.27 & 9.08 & 0.00 & 0.00 \\ 9.08 & 9.89 & 3.00 & 0.03 \\ 9.89 & 10.69 & 1.00 & 0.01 \\ 10.69 & 11.50 & 0.00 & 0.00 \\ 11.50 & 12.30 & 2.00 & 0.02 \\ 12.30 & 13.11 & 0.00 & 0.00 \\ 13.11 & 13.92 & 0.00 & 0.00 \\ 13.92 & 14.72 & 0.00 & 0.00 \\ 14.72 & 15.53 & 0.00 & 0.00 \\ 15.53 & 16.34 & 1.00 & 0.01 \\ 16.34 & 17.14 & 0.00 & 0.00 \\ & & & \end{array}$

Figure D10. 


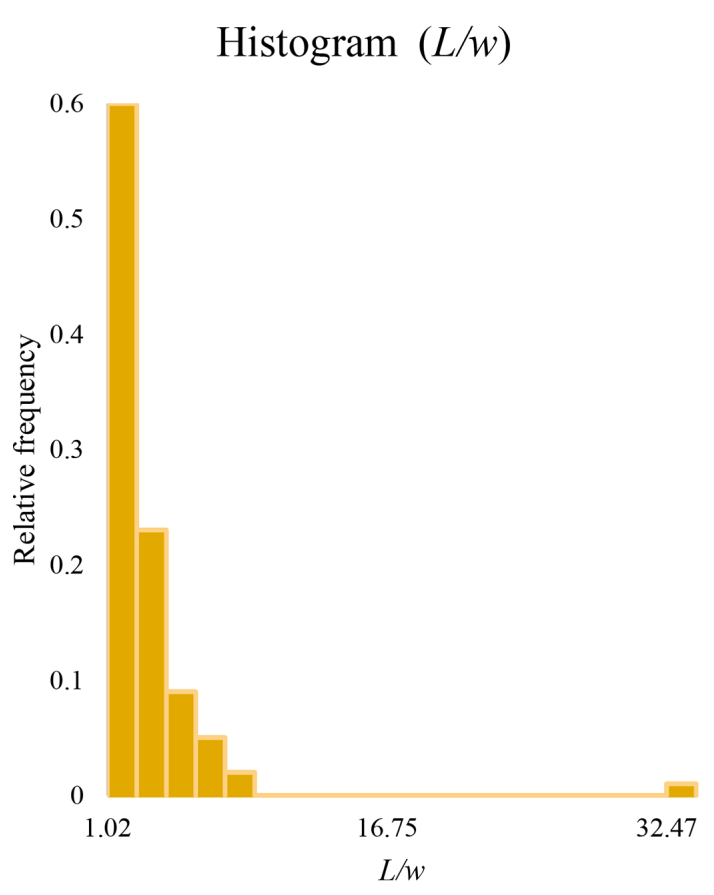

\begin{tabular}{cccc}
$\begin{array}{c}\text { Lower } \\
\text { bound }\end{array}$ & $\begin{array}{c}\text { Upper } \\
\text { bound }\end{array}$ & Frequency & $\begin{array}{c}\text { Relative } \\
\text { frequency }\end{array}$ \\
1.02 & 2.67 & 60.00 & 0.60 \\
2.67 & 4.33 & 23.00 & 0.23 \\
4.33 & 5.99 & 9.00 & 0.09 \\
5.99 & 7.64 & 5.00 & 0.05 \\
7.64 & 9.30 & 2.00 & 0.02 \\
9.30 & 10.95 & 0.00 & 0.00 \\
10.95 & 12.61 & 0.00 & 0.00 \\
12.61 & 14.26 & 0.00 & 0.00 \\
14.26 & 15.92 & 0.00 & 0.00 \\
15.92 & 17.57 & 0.00 & 0.00 \\
17.57 & 19.23 & 0.00 & 0.00 \\
19.23 & 20.89 & 0.00 & 0.00 \\
20.89 & 22.54 & 0.00 & 0.00 \\
22.54 & 24.20 & 0.00 & 0.00 \\
24.20 & 25.85 & 0.00 & 0.00 \\
25.85 & 27.51 & 0.00 & 0.00 \\
27.51 & 29.16 & 0.00 & 0.00 \\
29.16 & 30.82 & 0.00 & 0.00 \\
30.82 & 32.47 & 0.00 & 0.00 \\
32.47 & 34.13 & 1.00 & 0.01 \\
\hline
\end{tabular}

Figure D11.

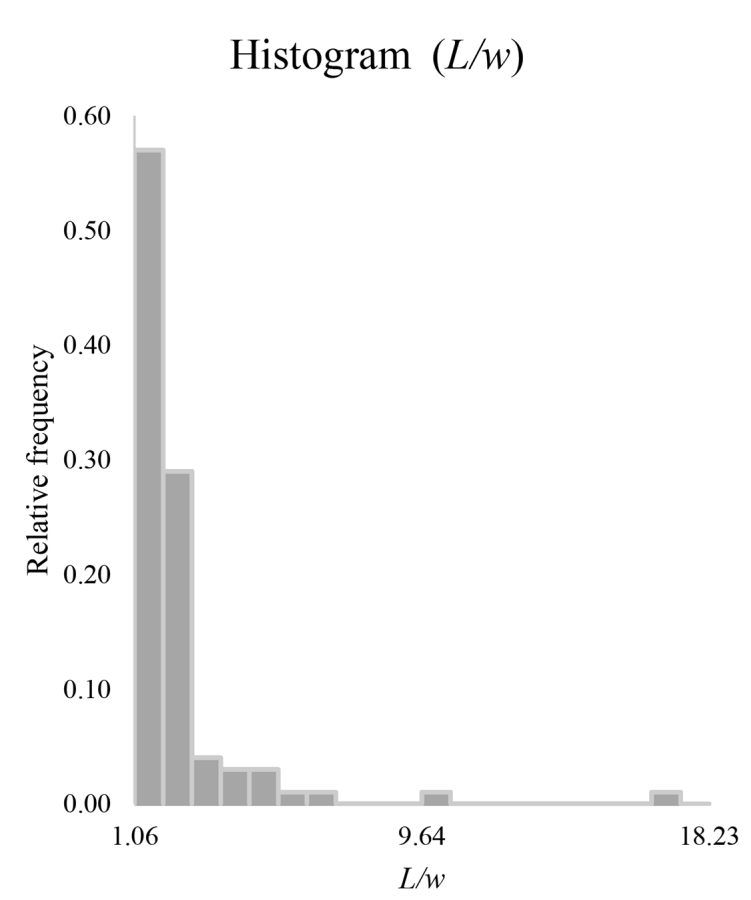

\begin{tabular}{|c|c|c|c|}
\hline $\begin{array}{l}\text { Lower } \\
\text { limit }\end{array}$ & $\begin{array}{l}\text { Upper } \\
\text { limit }\end{array}$ & Frequency & $\begin{array}{l}\text { Relative } \\
\text { frequency }\end{array}$ \\
\hline 1.06 & 1.92 & 57.00 & 0.57 \\
\hline 1.92 & 2.78 & 29.00 & 0.29 \\
\hline 2.78 & 3.63 & 4.00 & 0.04 \\
\hline 3.63 & 4.49 & 3.00 & 0.03 \\
\hline 4.49 & 5.35 & 3.00 & 0.03 \\
\hline 5.35 & 6.21 & 1.00 & 0.01 \\
\hline 6.21 & 7.07 & 1.00 & 0.01 \\
\hline 7.07 & 7.93 & 0.00 & 0.00 \\
\hline 7.93 & 8.78 & 0.00 & 0.00 \\
\hline 8.78 & 9.64 & 0.00 & 0.00 \\
\hline 9.64 & 10.50 & 1.00 & 0.01 \\
\hline 10.50 & 11.36 & 0.00 & 0.00 \\
\hline 11.36 & 12.22 & 0.00 & 0.00 \\
\hline 12.22 & 13.08 & 0.00 & 0.00 \\
\hline 13.08 & 13.93 & 0.00 & 0.00 \\
\hline 13.93 & 14.79 & 0.00 & 0.00 \\
\hline 14.79 & 15.65 & 0.00 & 0.00 \\
\hline 15.65 & 16.51 & 0.00 & 0.00 \\
\hline 16.51 & 17.37 & 1.00 & 0.01 \\
\hline 17.37 & 18.23 & 0.00 & 0.00 \\
\hline
\end{tabular}

Figure D12. 
Data for aerodynamic equivalent diameter $\left(D_{\mathrm{ae}}\right)$

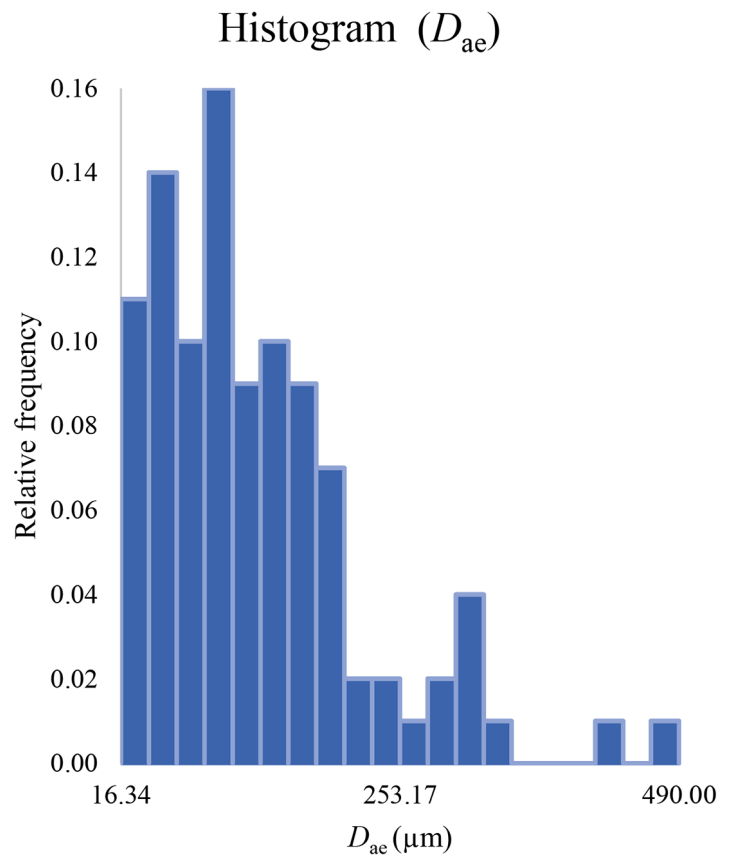

\begin{tabular}{cccc}
$\begin{array}{c}\text { Lower } \\
\text { limit }\end{array}$ & $\begin{array}{c}\text { Upper } \\
\text { limit }\end{array}$ & Frequency & $\begin{array}{c}\text { Relative } \\
\text { frequency }\end{array}$ \\
16.34 & 40.02 & 11.00 & 0.11 \\
40.02 & 63.71 & 14.00 & 0.14 \\
63.71 & 87.39 & 10.00 & 0.10 \\
87.39 & 111.07 & 16.00 & 0.16 \\
111.07 & 134.75 & 9.00 & 0.09 \\
134.75 & 158.44 & 10.00 & 0.10 \\
158.44 & 182.12 & 9.00 & 0.09 \\
182.12 & 205.80 & 7.00 & 0.07 \\
205.80 & 229.49 & 2.00 & 0.02 \\
229.49 & 253.17 & 2.00 & 0.02 \\
253.17 & 276.85 & 1.00 & 0.01 \\
276.85 & 300.54 & 2.00 & 0.02 \\
300.54 & 324.22 & 4.00 & 0.04 \\
324.22 & 347.90 & 1.00 & 0.01 \\
347.90 & 371.58 & 0.00 & 0.00 \\
371.58 & 395.27 & 0.00 & 0.00 \\
395.27 & 418.95 & 0.00 & 0.00 \\
418.95 & 442.63 & 1.00 & 0.01 \\
442.63 & 466.32 & 0.00 & 0.00 \\
466.32 & 490.00 & 1.00 & 0.01 \\
& & & \\
\hline
\end{tabular}

Figure D13.

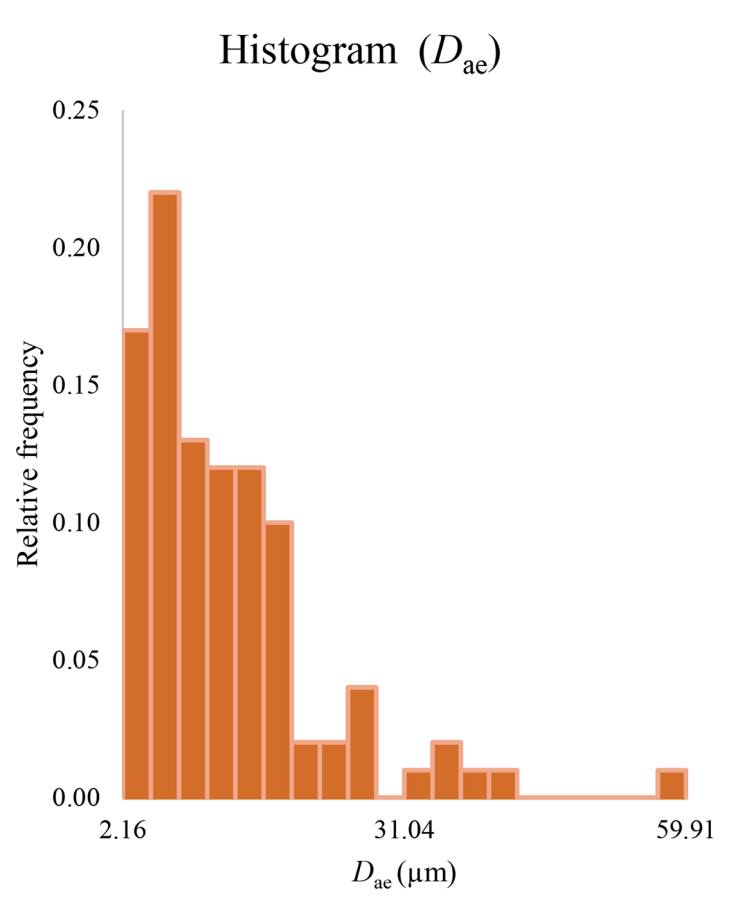

\begin{tabular}{|c|c|c|c|}
\hline $\begin{array}{l}\text { Lower } \\
\text { limit }\end{array}$ & $\begin{array}{l}\text { Upper } \\
\text { limit }\end{array}$ & Frequency & $\begin{array}{l}\text { Relative } \\
\text { frequency }\end{array}$ \\
\hline 2.16 & 5.05 & 17.00 & 0.17 \\
\hline 5.05 & 7.94 & 22.00 & 0.22 \\
\hline 7.94 & 10.83 & 13.00 & 0.13 \\
\hline 10.83 & 13.71 & 12.00 & 0.12 \\
\hline 13.71 & 16.60 & 12.00 & 0.12 \\
\hline 16.60 & 19.49 & 10.00 & 0.10 \\
\hline 19.49 & 22.38 & 2.00 & 0.02 \\
\hline 22.38 & 25.26 & 2.00 & 0.02 \\
\hline 25.26 & 28.15 & 4.00 & 0.04 \\
\hline 28.15 & 31.04 & 0.00 & 0.00 \\
\hline 31.04 & 33.93 & 1.00 & 0.01 \\
\hline 33.93 & 36.81 & 2.00 & 0.02 \\
\hline 36.81 & 39.70 & 1.00 & 0.01 \\
\hline 39.70 & 42.59 & 1.00 & 0.01 \\
\hline 42.59 & 45.48 & 0.00 & 0.00 \\
\hline 45.48 & 48.36 & 0.00 & 0.00 \\
\hline 48.36 & 51.25 & 0.00 & 0.00 \\
\hline 51.25 & 54.14 & 0.00 & 0.00 \\
\hline 54.14 & 57.03 & 0.00 & 0.00 \\
\hline 57.03 & 59.91 & 1.00 & 0.01 \\
\hline
\end{tabular}

Figure D14. 


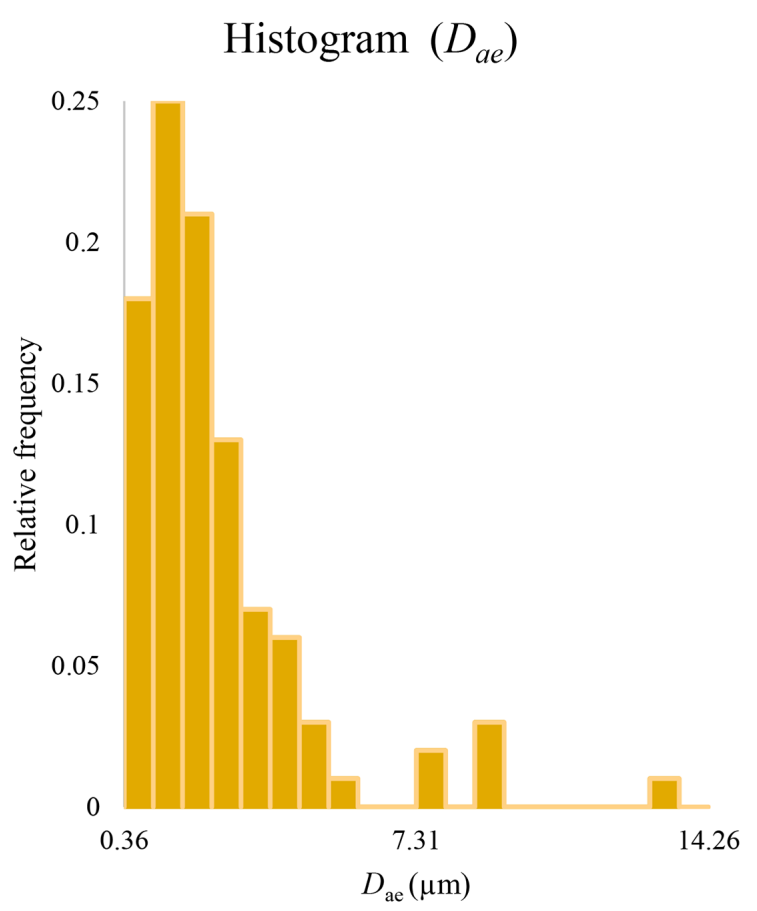

\begin{tabular}{cccc}
$\begin{array}{c}\text { Lower } \\
\text { bound }\end{array}$ & $\begin{array}{c}\text { Upper } \\
\text { bound }\end{array}$ & Frequency & $\begin{array}{c}\text { Relative } \\
\text { frequency }\end{array}$ \\
0.36 & 1.06 & 18.00 & 0.18 \\
1.06 & 1.75 & 25.00 & 0.25 \\
1.75 & 2.44 & 21.00 & 0.21 \\
2.44 & 3.14 & 13.00 & 0.13 \\
3.14 & 3.83 & 7.00 & 0.07 \\
3.83 & 4.53 & 6.00 & 0.06 \\
4.53 & 5.22 & 3.00 & 0.03 \\
5.22 & 5.92 & 1.00 & 0.01 \\
5.92 & 6.61 & 0.00 & 0.00 \\
6.61 & 7.31 & 0.00 & 0.00 \\
7.31 & 8.00 & 2.00 & 0.02 \\
8.00 & 8.70 & 0.00 & 0.00 \\
8.70 & 9.39 & 3.00 & 0.03 \\
9.39 & 10.09 & 0.00 & 0.00 \\
10.09 & 10.78 & 0.00 & 0.00 \\
10.78 & 11.48 & 0.00 & 0.00 \\
11.48 & 12.17 & 0.00 & 0.00 \\
12.17 & 12.87 & 0.00 & 0.00 \\
12.87 & 13.56 & 1.00 & 0.01 \\
13.56 & 14.26 & 0.00 & 0.00 \\
\hline
\end{tabular}

Figure D15.

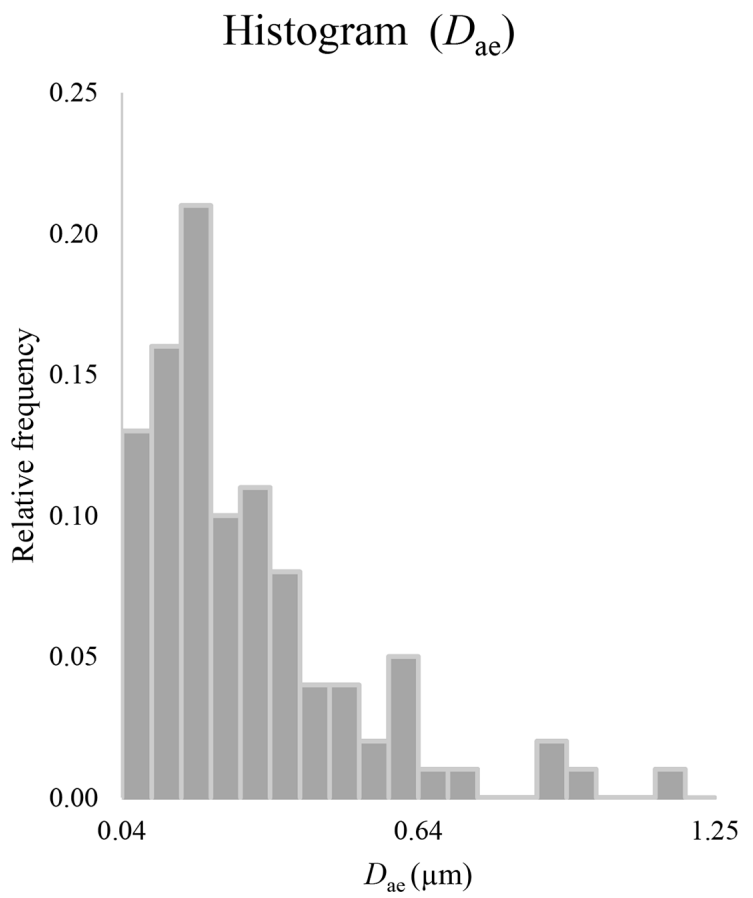

\begin{tabular}{cccc}
$\begin{array}{c}\text { Lower } \\
\text { limit }\end{array}$ & $\begin{array}{c}\text { Upper } \\
\text { limit }\end{array}$ & Frequency & $\begin{array}{c}\text { Relative } \\
\text { frequency }\end{array}$ \\
0.04 & 0.10 & 13.00 & 0.13 \\
0.10 & 0.16 & 16.00 & 0.16 \\
0.16 & 0.22 & 21.00 & 0.21 \\
0.22 & 0.28 & 10.00 & 0.10 \\
0.28 & 0.34 & 11.00 & 0.11 \\
0.34 & 0.40 & 8.00 & 0.08 \\
0.40 & 0.46 & 4.00 & 0.04 \\
0.46 & 0.52 & 4.00 & 0.04 \\
0.52 & 0.58 & 2.00 & 0.02 \\
0.58 & 0.65 & 5.00 & 0.05 \\
0.65 & 0.71 & 1.00 & 0.01 \\
0.71 & 0.77 & 1.00 & 0.01 \\
0.77 & 0.83 & 0.00 & 0.00 \\
0.83 & 0.89 & 0.00 & 0.00 \\
0.89 & 0.95 & 2.00 & 0.02 \\
0.95 & 1.01 & 1.00 & 0.01 \\
1.01 & 1.07 & 0.00 & 0.00 \\
1.07 & 1.13 & 0.00 & 0.00 \\
1.13 & 1.19 & 1.00 & 0.01 \\
1.19 & 1.25 & 0.00 & 0.00 \\
\hline & & &
\end{tabular}

Figure D16. 
Data for the merged datasets

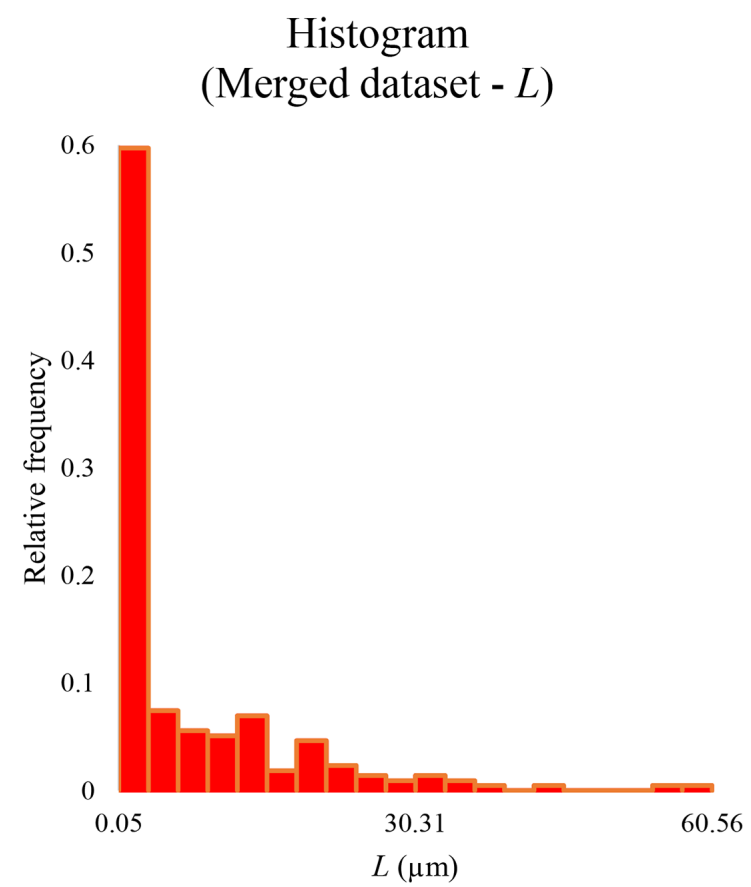

\begin{tabular}{cccc}
$\begin{array}{c}\text { Lower } \\
\text { bound }\end{array}$ & $\begin{array}{c}\text { Upper } \\
\text { bound }\end{array}$ & Frequency & $\begin{array}{c}\text { Relative } \\
\text { frequency }\end{array}$ \\
0.05 & 3.07 & 129.00 & 0.60 \\
3.07 & 6.10 & 16.00 & 0.07 \\
6.10 & 9.12 & 12.00 & 0.06 \\
9.12 & 12.15 & 11.00 & 0.05 \\
12.15 & 15.18 & 15.00 & 0.07 \\
15.18 & 18.20 & 4.00 & 0.02 \\
18.20 & 21.23 & 10.00 & 0.05 \\
21.23 & 24.25 & 5.00 & 0.02 \\
24.25 & 27.28 & 3.00 & 0.01 \\
27.28 & 30.30 & 2.00 & 0.01 \\
30.30 & 33.33 & 3.00 & 0.01 \\
33.33 & 36.35 & 2.00 & 0.01 \\
36.35 & 39.38 & 1.00 & 0.00 \\
39.38 & 42.41 & 0.00 & 0.00 \\
42.41 & 45.43 & 1.00 & 0.00 \\
45.43 & 48.46 & 0.00 & 0.00 \\
48.46 & 51.48 & 0.00 & 0.00 \\
51.48 & 54.51 & 0.00 & 0.00 \\
54.51 & 57.53 & 1.00 & 0.00 \\
57.53 & 60.56 & 1.00 & 0.00 \\
& & & \\
\hline
\end{tabular}

Figure D17.

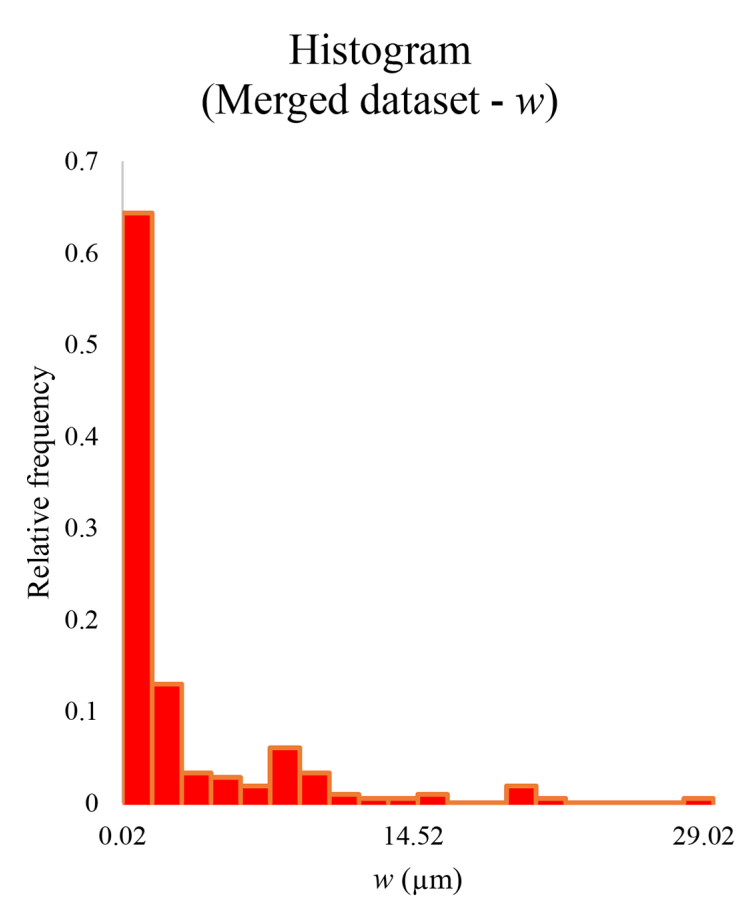

\begin{tabular}{cccc|}
$\begin{array}{c}\text { Lower } \\
\text { bound }\end{array}$ & $\begin{array}{c}\text { Upper } \\
\text { bound }\end{array}$ & Frequency & $\begin{array}{c}\text { Relative } \\
\text { frequency }\end{array}$ \\
0.02 & 1.49 & 139.00 & 0.64 \\
1.49 & 2.96 & 28.00 & 0.13 \\
2.96 & 4.44 & 7.00 & 0.03 \\
4.44 & 5.91 & 6.00 & 0.03 \\
5.91 & 7.39 & 4.00 & 0.02 \\
7.39 & 8.86 & 13.00 & 0.06 \\
8.86 & 10.33 & 7.00 & 0.03 \\
10.33 & 11.81 & 2.00 & 0.01 \\
11.81 & 13.28 & 1.00 & 0.00 \\
13.28 & 14.75 & 1.00 & 0.00 \\
14.75 & 16.23 & 2.00 & 0.01 \\
16.23 & 17.70 & 0.00 & 0.00 \\
17.70 & 19.17 & 0.00 & 0.00 \\
19.17 & 20.65 & 4.00 & 0.02 \\
20.65 & 22.12 & 1.00 & 0.00 \\
22.12 & 23.60 & 0.00 & 0.00 \\
23.60 & 25.07 & 0.00 & 0.00 \\
25.07 & 26.54 & 0.00 & 0.00 \\
26.54 & 28.02 & 0.00 & 0.00 \\
28.02 & 29.49 & 1.00 & 0.00 \\
& & & \\
\hline
\end{tabular}

Figure D18. 


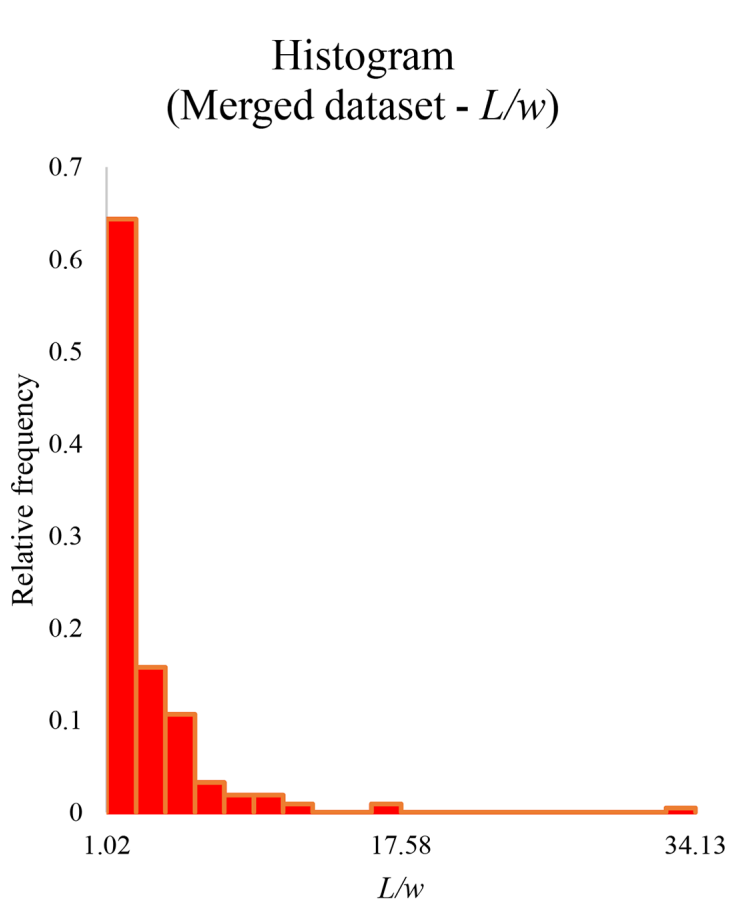

\begin{tabular}{cccc}
$\begin{array}{c}\text { Lower } \\
\text { bound }\end{array}$ & $\begin{array}{c}\text { Upper } \\
\text { bound }\end{array}$ & Frequency & $\begin{array}{c}\text { Relative } \\
\text { frequency }\end{array}$ \\
1.02 & 2.67 & 139.00 & 0.64 \\
2.67 & 4.33 & 34.00 & 0.16 \\
4.33 & 5.99 & 23.00 & 0.11 \\
5.99 & 7.64 & 7.00 & 0.03 \\
7.64 & 9.30 & 4.00 & 0.02 \\
9.30 & 10.95 & 4.00 & 0.02 \\
10.95 & 12.61 & 2.00 & 0.01 \\
12.61 & 14.26 & 0.00 & 0.00 \\
14.26 & 15.92 & 0.00 & 0.00 \\
15.92 & 17.57 & 2.00 & 0.01 \\
17.57 & 19.23 & 0.00 & 0.00 \\
19.23 & 20.89 & 0.00 & 0.00 \\
20.89 & 22.54 & 0.00 & 0.00 \\
22.54 & 24.20 & 0.00 & 0.00 \\
24.20 & 25.85 & 0.00 & 0.00 \\
25.85 & 27.51 & 0.00 & 0.00 \\
27.51 & 29.16 & 0.00 & 0.00 \\
29.16 & 30.82 & 0.00 & 0.00 \\
30.82 & 32.47 & 0.00 & 0.00 \\
32.47 & 34.13 & 1.00 & 0.00 \\
\hline
\end{tabular}

Figure D19.

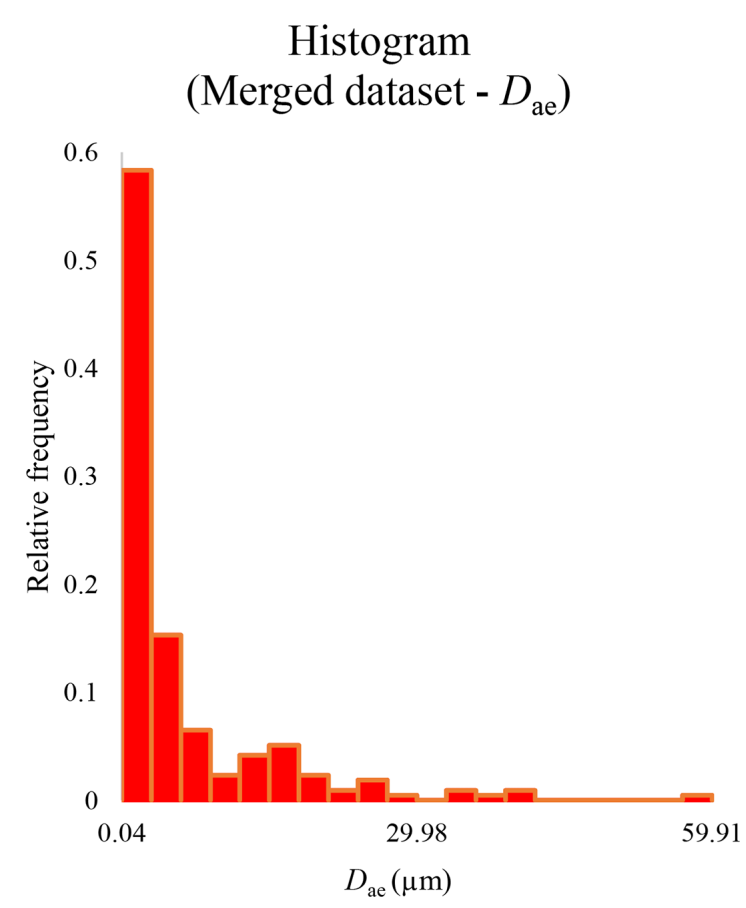

\begin{tabular}{cccc}
$\begin{array}{c}\text { Lower } \\
\text { bound }\end{array}$ & $\begin{array}{c}\text { Upper } \\
\text { bound }\end{array}$ & Frequency & $\begin{array}{c}\text { Relative } \\
\text { frequency }\end{array}$ \\
0.04 & 3.03 & 126.00 & 0.58 \\
3.03 & 6.03 & 33.00 & 0.15 \\
6.03 & 9.02 & 14.00 & 0.06 \\
9.02 & 12.01 & 5.00 & 0.02 \\
12.01 & 15.01 & 9.00 & 0.04 \\
15.01 & 18.00 & 11.00 & 0.05 \\
18.00 & 21.00 & 5.00 & 0.02 \\
21.00 & 23.99 & 2.00 & 0.01 \\
23.99 & 26.98 & 4.00 & 0.02 \\
26.98 & 29.98 & 1.00 & 0.00 \\
29.98 & 32.97 & 0.00 & 0.00 \\
32.97 & 35.96 & 2.00 & 0.01 \\
35.96 & 38.96 & 1.00 & 0.00 \\
38.96 & 41.95 & 2.00 & 0.01 \\
41.95 & 44.95 & 0.00 & 0.00 \\
44.95 & 47.94 & 0.00 & 0.00 \\
47.94 & 50.93 & 0.00 & 0.00 \\
50.93 & 53.93 & 0.00 & 0.00 \\
53.93 & 56.92 & 0.00 & 0.00 \\
56.92 & 59.91 & 1.00 & 0.00 \\
\hline & & &
\end{tabular}

Figure D20. 
Data availability. All the data of this research are presented in the manuscript and additional material is uploaded as a Supplement.

Video supplement. The supplementary video can be found at https://doi.org/10.5446/48657 (Vigliaturo, 2020). Brief description: Three-dimensional tomographic reconstruction of a glaucophane particle observed in STEM mode.

Supplement. The supplement related to this article is available online at: https://doi.org/10.5194/ejm-33-77-2021-supplement.

Author contributions. RV, GD, GDV, FRZ, MJO, and RG designed the experiments. RV, FRZ, GDV, MJO, and GJR carried out the experiments, and GD performed the simulations and modeling. RV, SME, MJO, and RG prepared the manuscript with contributions from all co-authors.

Competing interests. The authors declare that they have no conflict of interest.

Acknowledgements. This research was supported by a Rotary Global Grant (no. GG1640842) awarded to Ruggero Vigliaturo and grant no. P2-0393 from the Slovenian Research Agency. Financial support to Giancarlo Della Ventura was provided by the grant to the Department of Science, Roma Tre University (MIURItaly Dipartimenti di Eccellenza, ARTICOLO 1, COMMI 314-337 LEGGE 232/2016). The study was further supported in part by grant nos. P30-ES013508 and P42-ES023720 awarded by the National Institute of Environmental Health Sciences (NIEHS). The findings are not the official opinions of NIEHS or NIH.

Financial support. This research has been supported by the Rotary Foundation (grant no. GG1640842), Javna Agencija za Raziskovalno Dejavnost RS (grant no. P2-0393), Ministry of Education, University and Research, Italy Dipartimenti di Eccellenza (ARTICOLO 1, COMMI 314-337 20 LEGGE 232/2016), and the National Institute of Environmental Health Sciences (grant nos. P30ES013508 and P42-ES023720).

Review statement. This paper was edited by Elena Belluso and reviewed by John Puffer and one anonymous referee.

\section{References}

ANSES: Opinion of the French Agency for Food, Environmental and Occupational Health and Safety on "Health Effects and the identification of cleavage fragments of amphiboles from quarried minerals", Request No. 2014_SA_0196, available at: https://www.anses.fr/en/system/files/AIR2014sa0196RaEN. pdf (last access: 16 January 2021), 2015.
Ardizzone, M., Vizio C., Bozzetta, E., Pezzolato, M., Meistro, S., Dondo, A., Giorgi, I., Seghesio, A., Mirabelli, D., Capella, S., Vigliaturo, R., and Belluso, E.: The wild rat as sentinel animal in the environmental risk assessment of asbestos pollution: A pilot study, Sci. Total. Environ., 479-480, 31-38, https://doi.org/10.1016/j.scitotenv.2014.01.108, 2014.

ASTM D6281-15: Standard Test Method for Airborne Asbestos Concentration in Ambient and Indoor Atmospheres as Determined by Transmission Electron Microscopy Direct Transfer (TEM), ASTM International, West Conshohocken, PA, USA, https://doi.org/10.1520/D6281-15, available at: http://www.astm.org/cgi-bin/resolver.cgi?D6281-15 (last access: 16 January 2021), 2015.

ASTM D7200-06: Standard Practice for Sampling and Counting Airborne Fibers, Including Asbestos Fibers, in: Mines and Quarries, by Phase Contrast Microscopy and Transmission Electron Microscopy, ASTM International, West Conshohocken, PA, USA, https://doi.org/10.1520/D7200-06, available at: http://www.astm.org/cgi-bin/resolver.cgi?D7200-06 (last access: 16 January 2021), 2006.

Bailey, K. F., Kelse, J., Wylie, A. G., and Lee, R. J.: The asbestiform and prismatic mineral growth habit and their relationship to cancer study, MSHA, asbestos docket, pictorial presentation, available at: https://www.cdc.gov/niosh/docket/archive/pdfs/ NIOSH-099A/0099A-030104-Pictorialpresentation.pdf (last access: 16 January 2021), 2004.

Bailey, R. M.: Overview of Naturally Occurring Asbestos in California and Southwestern Nevada, Environmental and Engineering Geoscience, 26, 9-14, https://doi.org/10.2113/EEG-2282, 2020a.

Bailey, R. M.: Asbestiform Minerals of the Franciscan Assemblage in California with a Focus on the Calaveras Dam Replacement Project, Environmental and Engineering Geoscience, 26, 21-28, https://doi.org/10.2113/EEG-2264, 2020b.

Belluso, E., Cavallo, A., and Halterman, D.: Crystal habit of mineral fibres, EMU Notes Mineral., 18, 65-109, https://doi.org/10.1180/EMU-notes.18.3, 2017.

Bersani, D., Andò, S., Scrocco, L., Gentile, P., Salvioli-Mariani, E., Fornasini, L., and Lottici, P. P.: Composition of amphiboles in the tremolite - ferro-actinolite series by Raman spectroscopy, Minerals, 9, 491, https://doi.org/10.3390/min9080491, 2019.

Bezacier, L., Reynard, B., Bass, J. D., Wang, J., and Mainprice, D.: Elasticity of glaucophane, seismic velocities and anisotropy of the subducted oceanic crust, Tectonophysics, 494, 201-210, https://doi.org/10.1016/j.tecto.2010.09.011, 2010.

Boscardin, M. and Orlandi, P.: Fengite e glaucofane di Oropa (Biellese), Rivista Mineralogica Italiana, 3, 103, available at: https://www.gmlmilano.it/rmi-dal-1980-al-1989.html (last access: 16 January 2021), 1984.

Cantù, M., Spaggiari, L., Zucali, M., Zanoni, D., and Iole Spalla, M.: Structural analysis of a subduction-related contact in southern Sesia-Lanzo Zone (Austroalpine domain, Italian Western Alps), J. Maps, 12, 22-35, https://doi.org/10.1080/17445647.2016.1155925, 2016.

Carpinteri, A. and Chiaia, B.: Multifractal scaling laws in the breaking behaviour of disordered materials, Chaos Soliton. Fract., 8, 135-150, https://doi.org/10.1016/S0960-0779(96)00088-4, 1997. 
Case, B. W., Abraham, J. L., Meeker, G., Pooley, F. D., and Pinkerton, K. E.: Applying definitions of "asbestos" to environmental and "low dose" exposure levels and health effects, particularly malignant mesothelioma, J. Toxicol. Env. Heal. B, 14, 3-39, https://doi.org/10.1080/10937404.2011.556045, 2011.

CEN Workplace Atmospheres: Size Fraction Definitions for Measurement of Airborne Particles, European Standard EN 481, European Standardization Committee (CEN), Brussels, 1993.

Chisholm, J. E. J.: Planar defects in fibrous amphiboles, Mater. Sci., 8, 475-483, https://doi.org/10.1007/BF00550451, 1973.

Compagnoni, R. and Schmid, S.: Guidebook for the excursion of the Annual Convention of the Swiss Association of Energy Geoscientists (SASEG) Valle d'Aosta (Italy), 22-23 June, available at: https://www.saseg.ch/cms/images/pdf/conventions/2014/ Guide-book_SASEG_Aosta.pdf (last access: 16 January 2021), 2014.

Council of the European Union: European Parliament. Directive 2009/148/EC of the European Parliament and of the Council of 30 November 2009 on the Protection of Workers Against the Risks Associated with Exposure to Asbestos, Publications Office of the European Union: Brussels, Belgium, 2009.

Della Ventura, G.: The analysis of asbestos minerals using vibrational spectroscopies (FTIR, Raman): crystal-chemistry, identification and environmental applications, in: Mineral fibres: crystal chemistry, chemical-physical properties, biological interactions and toxicity, edited by: Gualtieri, A., EMU Notes Mineralog., 18, 135-169, https://doi.org/10.1180/EMU-notes.18.5, 2017.

Della Ventura, G., Redhammer, G. J., Iezzi, G., Hawthorne, F. C., Papin, A., and Robert, J.-L.: A Mössbauer and FTIR study of synthetic amphiboles along the magnesio-riebeckite ferri-clinoholmquistite join, Phys. Chem. Miner., 32, 103-113, https://doi.org/10.1007/s00269-005-0451-1, 2005.

Della Ventura, G., Redhammer, G., Robert, J. L., Sergent, J., Iezzi, G., and Cavallo, A.: Crystal-chemistry of synthetic amphiboles along the richterite - ferro-richterite join: a combined spectroscopic (FTIR, Mössbauer), XRPD and microchemical study, Can. Mineral., 54, 97-114, https://doi.org/10.3749/canmin.1500076, 2016.

Della Ventura, G., Vigliaturo, R., Gierè, R., Pollastri, S., Gualtieri, A., and Iezzi, G.: Infra Red Spectroscopy of the Regulated Asbestos Amphiboles, Minerals, 8, 413, https://doi.org/10.3390/min8090413, 2018.

Della Ventura, G., Hawthorne, F. C., Mihailova, B., and Sodo, A.: Raman and FTIR spectroscopy of synthetic amphiboles: I. The $\mathrm{OH}$ librational bands in synthetic richterites, Can. Mineral., https://doi.org/10.3749/canmin.1900090, in press, 2021a.

Della Ventura, G., Mihailova, B., and Hawthorne, F. C.: Raman and FTIR spectroscopy of synthetic amphiboles: II. Divalent (Mg-Co) substitutions at the octahedral sites, Can. Mineral., https://doi.org/10.3749/canmin.1900091, in press, 2021b.

Donaldson, K., Murphy, F. A., Duffin, R., and Poland, C. A.: Asbestos, carbon nanotubes and the pleural mesothelium: a review and the hypothesis regarding the role of long fibre retention in the parietal pleura, inflammation and mesothelioma, Part. Fibre Toxicol., 7, 5, https://doi.org/10.1186/1743-8977-7-5, 2010.

Erskine, B. G. and Bailey, M.: Characterization of asbestiform glaucophane-winchite in the Franciscan Complex blueschist, northern Diablo Range, California, Toxicol. Appl. Pharmacol., 361, 3-13, https://doi.org/10.1016/j.taap.2018.09.020, 2018.
European Commission: Commission Directive 1999/77/EC Adapting to Technical Progress for the Sixth Time ANNEX I to Council Directive 76/769/EEC on the Approximation of the Laws, Regulations, and Administrative Provisions of the Member States Relating to Restrictions on the Marketing and use of Certain Dangerous Substances and Preparations (Asbestos), Publications Office of the European Union: Brussels, Belgium, 1820, 1999.

Evans, B. and Brown, E.: Blueschists and eclogites, Geological Society of America, Memoir, 164, 169-184, https://doi.org/10.1130/MEM164, 1986.

Fantauzzi, M., Pacella, A., Atzei, D., Gianfagna, A., Andreozzi, G. B., and Rossi, A.: Combined use of X-ray photoelectron and Mössbauer spectroscopic techniques in the analytical characterization of iron oxidation state in amphibole asbestos, Anal. Bioanal. Chem., 396, 2889, https://doi.org/10.1007/s00216-0103576-0, 2010.

Filippakis, S. E., Perdikatsis, B., and Paradellis, T.: An analysis of blue pigments from the greek bronze age, Stud. Conserv., 21, 143-153, https://doi.org/10.1179/sic.1976.024, 1976.

Frost, D. and Langenhorst, F.: The effect of $\mathrm{Al}_{2} \mathrm{O}_{3}$ on Fe$\mathrm{Mg}$ partitioning between magnesiowüstite and magnesium silicate perovskite, Earth Planet. Sc. Lett., 199, 227-241, https://doi.org/10.1016/S0012-821X(02)00558-7, 2002.

Gelzleichter, T. R., Bermudez, E., Mangum, J. B., Wong, B. A., Everitt, J. I., and Moss, O. R.: Pulmonary and Pleural Responses in Fischer 344 Rats Following Short-Term Inhalation of a Synthetic Vitreous Fiber: I. Quantitation of Lung and Pleural Fiber Burdens, Toxicol. Sci., 30, 31-38, https://doi.org/10.1093/toxsci/30.1.31, 1996.

Germine, M. and Puffer, J. H.: Analytical transmission electron microscopy of amosite asbestos from South Africa, Arch. Environ. Occup. H., 75, 36-44, https://doi.org/10.1080/19338244.2018.1556201, 2019.

Gonda, I. and Abd El Khalik, A. F.: On the calculation of the aerodynamic diameters of fibers, Aerosol Sci. Tech., 4, 233-238, https://doi.org/10.1080/02786828508959051, 1985.

Gunter, M. E.: Elongate mineral particles in the natural environment, Toxicol. Appl. Pharm., 361, 157-164, https://doi.org/10.1016/j.taap.2018.09.024, 2018.

Hawthorne, F. C., Oberti, R., Harlow, G. E., Maresch, W. V., Martin, R. F., Schumacher, J. C., and Welch, M.: IMA Report: Nomenclature of the amphibole supergroup, Am. Mineral., 9, 20312048, https://doi.org/10.2138/am.2012.4276, 2012.

ICRP: Human respiratory tract model for radiological protection, International Commission on Radiological Protection Publication 66, Annals of the ICRP 24(1-3), Elsevier Science Ltd., Oxford, UK, available at: https://www.icrp.org/publication.asp?id= _icrppublication66 (last access: 16 January 2021), 1994.

Iezzi, G., Della Ventura, G., Hawthorne, F. C., Pedrazzi, G., Robert, J.-L., and Novembre, D.: The $(\mathrm{Mg}, \mathrm{Fe} 2+)$ substitution in ferriclinoholmquistite, · $\mathrm{Li}_{2} \quad\left(\mathrm{Mg}, \mathrm{Fe}^{2+}\right)_{3} \quad \mathrm{Fe}_{2}^{3+} \mathrm{Si}_{8} \mathrm{O}_{22}(\mathrm{OH})_{2}$, Eur. J. Mineral., 17, 733-740, https://doi.org/10.1127/09351221/2005/0017-0733, 2005.

Ishida, K.: Infrared spectra of alkali amphiboles of the glaucophane-riebeckite series and their relation to chemical composition, Mineralogical Journal, 15, 147-161, https://doi.org/10.2465/minerj.15.147, 1990. 
Ishida, K., Jenkins, D. M., and Hawthorne, F. C.: Mid-IR bands of synthetic calcic amphiboles of the tremolite-pargasite series and of natural calcic amphiboles, Am. Mineral., 93, 1112-1118, https://doi.org/10.2138/am.2008.2756, 2008.

ISO Air Quality: Particle Size Fraction Definitions for Healthrelated Sampling, ISO Standard 7708, International Organization for Standardization (ISO), Geneva, available at: https://www.iso. org/standard/14534.html (last access: 16 January 2021), 1995.

Jenkins, D. M., Della Ventura, G., Oberti, R., and Bozhilov, K.: Synthesis and characterization of amphiboles along the tremolite-glaucophane join, Am. Mineral., 98, 588-600, https://doi.org/10.2138/am.2013.4281, 2013.

Kane, A. B., Boffetta, P., Saracci, R., and Wilbourn, J. D.: Mechanisms of fibre carcinogenesis, IARC Scientific Publication 140, Lyon, International Agency for Research on Cancer, WHO, ISBN: 978-92-832-2140-1, 1996.

Langenhorst, F., Harries, D., and Pollok, K.: Non-stoichiometry, defects and superstructures in sulfide and oxide minerals, EMU Notes Mineralog., 14, 261-295, https://doi.org/10.1180/EMUnotes. 14.8, 2013.

Le Bouffant, L., Daniel, H., Henn, J. P., Martin, J. C., Normand, M. C., Tichoux, G., and Trolard, F.: Experimental study on longterm effects of inhaled MMMF on the lungs of rats, Ann. Occup. Hyg., 31, 765-790, https://doi.org/10.1093/annhyg/31.4b.765, 1987.

Leissner, L., Schlüter, J., Horn, I., and Mihailova, B.: Exploring the potential of Raman spectroscopy for crystallochemical analyses of complex hydrous silicates: I. Amphiboles, Am. Mineral., 100, 2682-2694, https://doi.org/10.2138/am-2015-5323, 2015.

Lister, G. S. and Raouzaious, A.: The Tectonic Significance of a Porphyroblastic Blueschist Facies Overprint During Alpine Orogenesis: Sifnos, Aegean Sea, Greece, J. Struct. Geol., 18, 14171435, https://doi.org/10.1016/S0191-8141(96)00072-7, 1996.

Locock, A. J.: An EXCEL spreadsheet to classify chemical analyses of amphiboles following the IMA 2012 recommendations, Comput. Geosci., 62, 1-11, https://doi.org/10.1016/j.cageo.2013.09.011, 2014.

Militello, G. M., Sanguineti, E., Yus González, A., Mantovani, F., and Gaggero, L.: The Concentration of Asbestos Fibers in Bulk Samples and Its Variation with Grain Size, Minerals, 9, 539, https://doi.org/10.3390/min9090539, 2019.

Ministerial Decree No. 06/09/1994: (All.1-B), Determinazione Quantitativa Dell'amianto in Campioni in Massa, available at: https://www.gazzettaufficiale.it/atto/serie_ generale/caricaArticolo? art.progressivo $=0 \&$ art.idArticolo $=$ $1 \&$ art.versione $=1 \&$ art .codiceRedazionale $=094$ A5917 \&art. dataPubblicazioneGazzetta=1994-09-20\&art.idGruppo= 0\&art.idSottoArticolo1=10\&art.idSottoArticolo=1\&art. flagTipoArticolo=2 (last access: 16 January 2021), 1994.

Morrow, P. E.: Possible mechanisms to explain dust overloading of the lungs, Fundam. Appl. Toxicol., 10, 369-384, https://doi.org/10.1016/0272-0590(88)90284-9, 1988.

Mottana, A., Crespi, R., and Liborio, G.: "Minerali e rocce", Arnoldo Mondadori Editore, ISBN 13: 9788804142898, 1981.

Nagai, H. and Toyokuni, S.: Differences and similarities between carbon nanotubes and asbestos fibers during mesothelial carcinogenesis: Shedding light on fiber entry mechanism, Cancer Sci., 103, 1378-1390, https://doi.org/10.1111/j.13497006.2012.02326.x, 2012.
National Institute for Occupational Safety and Health (NIOSH): Method 7400, Asbestos and other fibers by PCM, Issue 2, 15 August 1994, in: NIOSH Manual of Analytical Methods, 4th Edn., DHSS (NIOSH), Cincinnati, OH, USA, available at: https: //www.cdc.gov/niosh/nmam/pdf/7400.pdf (last asccess: 16 January 2021), 1994a.

National Institute for Occupational Safety and Health (NIOSH): Method 7402: Asbestos by TEM, Issue 2, 15 August 1994, in: NIOSH Manual of Analytical Methods (NMAM), 4th Edn.; DHSS (NIOSH): Cincinnati, OH, USA, available at: https:// www.cdc.gov/niosh/docs/2003-154/pdfs/7402.pdf (last asccess: 16 January 2021), 1994b.

National Institute for Occupational Safety and Health (NIOSH): Asbestos fibers and other elongate mineral particles: State of the science and roadmap for research, Revised Edn., Department of Health and Human Services, DHHS (NIOSH) Publication No. 2011-159, Current Intelligence Bulletin, 62, 1-159, available at: https://www.cdc.gov/niosh/docs/2011-159/default.html (last asccess: 16 January 2021), 2011.

Oberdörster, G. and Graham, U.: Predicting EMP hazard: Lessons from studies with inhaled fibrous and non-fibrous nano- and micro-particles, Toxicol. Appl. Pharm., 361, 50-61, https://doi.org/10.1016/j.taap.2018.05.004, 2018.

Petriglieri, J. R., Laporte-Magoni, C., Gunkel-Grillon, P., Tribaudino, M., Bersani, D., Sala, O., Le Mestre, M., Vigliaturo, R., Bursi Gandolfi, N., and Salvioli-Mariani, E.: Mineral fibres and environmental monitoring: A comparison of different analytical strategies in New Caledonia, Geosci. Front., 11, 189-202, https://doi.org/10.1016/j.gsf.2018.11.006, 2020.

Piana, F., Fioraso, G., Irace, A., Mosca, P., d'Atri, A., Barale, L., Falletti, P., Monegato, G., Morelli, M., Tallone, S., and Vigna, G. B.: Geology of Piemonte region (NW Italy, Alps-Apennines interference zone), J. Maps, 13, 395-405, https://doi.org/10.1080/17445647.2017.1316218, 2017.

Profi, S., Weier, L., and Filippakis, S. E.: X-Ray Analysis of Greek Bronze Age Pigments from Knossos, Stud. Conserv., 21, 34-39, https://doi.org/10.2307/1505608, 1976.

Quick, J. E., Sinigoi, S., Negrini, L., Demarchi, G., and Mayer, A.: Synmagmatic deformation in the underplated igneous complex of the Ivrea-Verbano zone, Geology, 20, 613-616, https://doi.org/10.1130/00917613(1992)020<0613:SDITUI>2.3.CO;2, 1992.

Redhammer, G. J. and Roth, G.: Crystal structure and Mössbauer spectroscopy of the synthetic amphibole potassic-ferriferrorichterite at $298 \mathrm{~K}$ and low temperatures (80-110 K), Eur. J. Mineral., 14, 105-114, https://doi.org/10.1127/09351221/2002/0014-0105, 2002.

Reinsch, D.: Glaucophanites and eclogites from Val Chiusella, Sesia-Lanzo Zone (Italian Alps), Contrib. Mineral. Petr., 70, 257-266, https://doi.org/10.1007/BF00375355, 1979.

Ridley, J.: Arcuate Lineation Trends in a Deep Level, Ductile Thrust Belt, Syros, Greece, Tectonophysics, 88, 347-360, https://doi.org/10.1016/0040-1951(82)90246-3, 1981.

Rodríguez-Carvajal, J.: Recent Developments of the Program FULLPROF, Newsletter in Commission on Powder Diffraction (IUCr), 26, 12-19, available at: https://www.ill.eu/sites/fullprof/ php/reference.html (last access: 16 January 2021), 2001.

Rojac, T., Bencan, A., Drazic, G., Sakamoto, N., Ursic, H., Jancar, B., Tavcar, G., Makarovic, M., Walker, J., Malic, B., and Dam- 
janovic, D.: Domain-wall conduction in ferroelectric $\mathrm{BiFeO} 3$ controlled by accumulation of charged defects, Nat. Mater., 16, 322-327, https://doi.org/10.1038/nmat4799, 2017.

Susta, U., Della Ventura, G., Hawthorne, F. C., Milahova, B., and Oberti, R.: The crystal-chemistry of riebeckite, ideally $\mathrm{Na}_{2} \mathrm{Fe}_{3}^{2+} \mathrm{Fe}^{3+} 2 \mathrm{Si}_{8} \mathrm{O}_{22}(\mathrm{OH})_{2}$ : a multi-technique study, Mineral. Mag., 84, 837-852, https://doi.org/10.1180/minmag.2017.081.064, 2018.

Spalla, M. I., Lardeaux, J. M., Vittorio Dal Piaz, G., Gosso, G., and Messiga, B.: Tectonic significance of Alpine eclogites, J. Geodyn., 21, 257-285, https://doi.org/10.1016/02643707(95)00033-X, 1996.

Tan, H., Verbeeck, J., Abakumov, A., and VanTendeloo, G.: Oxidation state and chemical shift investigation in transition metal oxides by EELS, Ultramicroscopy, 116, 24-33, https://doi.org/10.1016/j.ultramic.2012.03.002, 2012.

Veblen, D. R. and Wylie, A. G.: Mineralogy of amphiboles and 1:1 layer silicates, in: Reviews in Mineralogy and Geochemistry, edited by: Guthrie Jr., G. D. and Mossman, B. T., Mineralogical Society of America: Chantilly, VA, USA, 28, 61-137, https://doi.org/10.1515/9781501509711-006, 1993.

Vigliaturo, R., Capella, S., Rinaudo, C., and Belluso, E.: "Rinse and trickle": a protocol for TEM preparation and investigation of inorganic fibers from biological material, Inhal. Toxicol., 28, 357363, https://doi.org/10.1080/08958378.2016.1175527, 2016.

Vigliaturo, R., Della Ventura, G., Choi, J. K., Marengo, A., Lucci, F., O'Shea, M. J., Pérez-Rodriguez, I., and Gieré, R.: Mineralogical Characterization and Dissolution Experiments in Gamble's Solution of Tremolitic Amphibole from Passo di Caldenno (Sondrio, Italy), Minerals, 8, 557, https://doi.org/10.3390/min8120557, 2018.

Vigliaturo, R., Pollastri, S., Gieré, R., Gualtieri, A. F., and Dražić, G.: Experimental quantification of the Fe-valence state at amosite-asbestos boundaries using acSTEM dualelectron energy-loss spectroscopy, Am. Mineral., 104, 18201828, https://doi.org/10.2138/am-2019-7218, 2019.
Vigliaturo, R., Choi, J. K., Pérez-Rodriguez, I., and Gieré, R.: Dimensional distribution control of elongate mineral particles for their use in biological assays, MethodsX, 7, 100937, https://doi.org/10.1016/j.mex.2020.100937, 2020.

Waeselmann, N., Schlüter, J., Malcherek, T., Della Ventura, G., Oberti, R., and Mihailova, B.: Non-destructive determination of the amphibole crystal chemistry by Raman spectroscopy; one step closer, J. Raman Spectrosc., 51, 1-19, https://doi.org/10.1002/jrs.5626, 2019.

Williams, C., Dell, L., Adams, R., Rose, T., and Van Orden, D.: State-of-the-science assessment of non-asbestos amphibole exposure. Is there a cancer risk?, Environ. Geochem. Hlth., 35, 357-377, https://doi.org/10.1007/s10653-012-9500-0, 2013.

World Health Organisation: WHO Air Quality Guidelines, 2nd Edn., Asbestos, Regional Office for Europe, Copenhagen, Denmark, available at: https://www.euro.who.int/_data/assets/pdf_ file/0005/74732/E71922.pdf (last access: 16 January 2021), 2000.

Wylie, A. G.: Modeling asbestos population: a fractal approach, Can. Mineral., 31, 437-446, https://doi.org/10.3749/1499-127631.2.437, 1993.

Zingg, A.: The Ivrea Crustal Cross-Section (Northern Italy and Southern Switzerland), in: Exposed Cross-Sections of the Continental Crust, edited by: Salisbury, M. H. and Fountain, D. M., NATO ASI Series (Series C: Mathematical and Physical Sciences), 317, Springer, Dordrecht, https://doi.org/10.1007/97894-009-0675-4_1, 1990.

Zoltai, T.: Amphibole asbestos mineralogy, in: Amphiboles and other hydrous pyriboles, Mineralogy, edited by: Veblen, D. R., Rev. Mineral., 9A, 237-278, https://doi.org/10.1515/9781501508219-009, 1981. 